\title{
Dieter Guicking
}

\section{Erwin Meyer}

Ein bedeutender deutscher Akustiker

Biographische Notizen
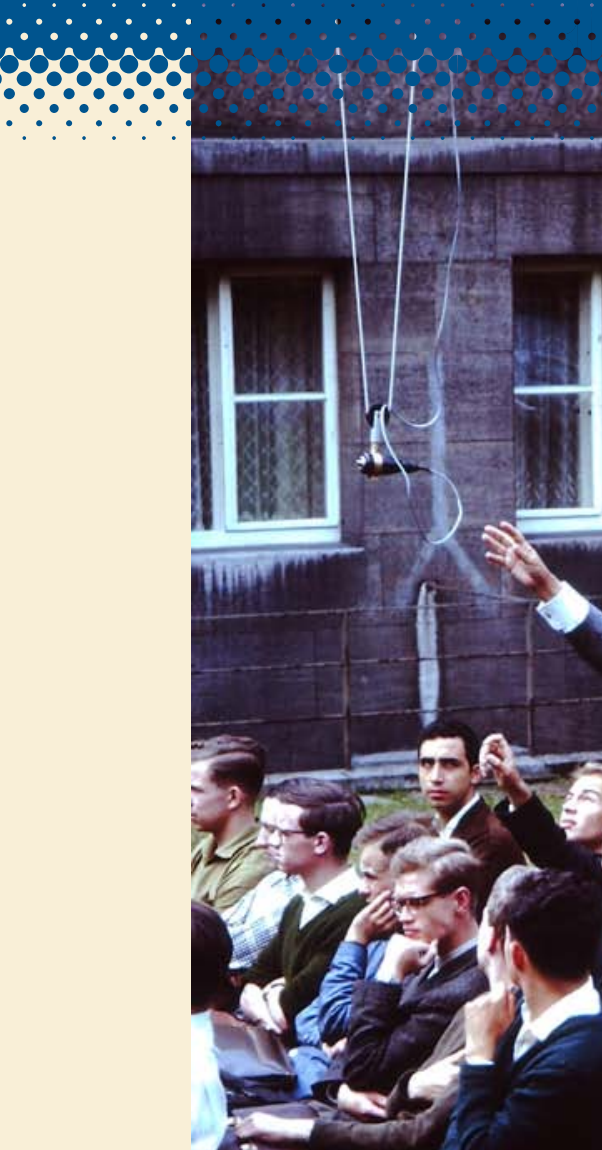

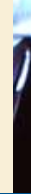

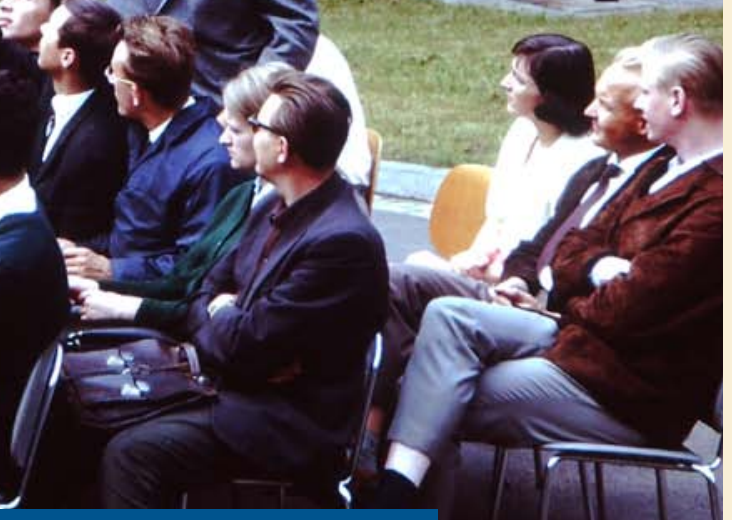

Universitätsdrucke Göttingen 

Dieter Guicking Erwin Meyer

This work is licensed under the Creative Commons License 3.0 "by-nd", allowing you to download, distribute and print the document in a few copies for private or educational use, given that the document stays unchanged and the creator is mentioned. You are not allowed to sell copies of the free version. 
erschienen in der Reihe der Universitätsdrucke im Universitätsverlag Göttingen 2012 
Dieter Guicking

\section{Erwin Meyer}

Ein bedeutender deutscher Akustiker

Biographische Notizen

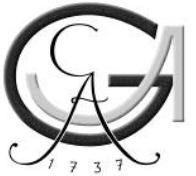

Universitätsverlag Göttingen

2012 
Bibliographische Information der Deutschen Nationalbibliothek

Die Deutsche Nationalbibliothek verzeichnet diese Publikation in der

Deutschen Nationalbibliographie; detaillierte bibliographische Daten sind im Internet über <http://dnb.ddb.de $>$ abrufbar.

Autorenkontakt

Dieter Guicking

E-Mail: guicking@physik3.gwdg.de

Dieses Buch ist auch als freie Onlineversion über die Homepage des Verlags sowie über den OPAC der Niedersächsischen Staats- und

Universitätsbibliothek (http:/ / www.sub.uni-goettingen.de) erreichbar und darf gelesen, heruntergeladen sowie als Privatkopie ausgedruckt werden. Es gelten die Lizenzbestimmungen der Onlineversion. Es ist nicht gestattet, Kopien oder gedruckte Fassungen der freien Onlineversion zu veräußern.

Satz und Layout: Dieter Guicking Umschlaggestaltung: Franziska Lorenz

Titelbild: Erwin Meyer beim Versuchsaufbau zur Messung der

Schallausbreitung über Publikum im Freien (s. S. 34).

(C) 2012 Universitätsverlag Göttingen

http:/ / univerlag.uni-goettingen.de

ISBN: 978-3-86395-059-0 


\section{Inhalt}

Vorwort................................ VII

Einleitung................................

Breslau................................... 3

Berlin................................. 7

Göttingen ............................... 15

Institutserweiterungen ................. 20

Forschungsschwerpunkte................29

Vorlesungen ......................... 43

Schlussbemerkungen ........................ 49

Literaturverzeichnis . ........................ 57

Publikationen von Erwin Meyer...........57

Publikationen über Erwin Meyer...........79

Publikationen aus dem DPI..............85

Sonstige Publikationen ................. 107

Personen- und Sachregister...................... 109

Bildnachweis ........................... 116 



\section{Vorwort}

Ein Kurzvortrag auf der Jahrestagung der Deutschen Gesellschaft für Akustik (DAGA) 2007 in Stuttgart gab den Anstoß für eine ausführliche Dokumentation zum Leben und Werk von Erwin Meyer, der auch 40 Jahre nach seinem Tod noch vielen seiner Schüler und Kollegen in lebhafter Einnerung ist und dessen Lebenswerk von bleibender Bedeutung ist. Eine über längere Zeit ergänzte Online-Version dieser Biographie, die auch ein Stück Geschichte des Dritten Physikalischen Instituts der Universität Göttingen ist, weckte bei den Lesern den Wunsch nach einer gedruckten Fassung. Ich danke dem Universitätsverlag Göttingen, dass er diese Anregung aufgenommen hat.

Göttingen, April 2012

Dieter Guicking 



\section{Einleitung}

Erwin Walter Meyer (1899-1972) gilt als der führende deutsche Akustiker seiner Zeit. Er war ungewöhnlich vielseitig interessiert. $\mathrm{Zu}$ vielen Teilgebieten der Akustik haben er und seine Schüler Wesentliches beigetragen, in frühen Jahren besonders zur Elektroakustik und zur akustischen Messtechnik. Geboren ist er am 21. Juli 1899 in Königshütte (Oberschlesien), seine Eltern waren der Postinspektor Paul Meyer und dessen Ehefrau Margarethe, geb. Schleiffer. Gestorben ist Erwin Meyer am 6. März 1972 in Pontresina (Schweiz). Das Foto in Abbildung 1 zeigt ihn im Alter von 65 Jahren. Für sein Berufsleben waren drei Stationen wichtig: Breslau, Berlin und Göttingen.

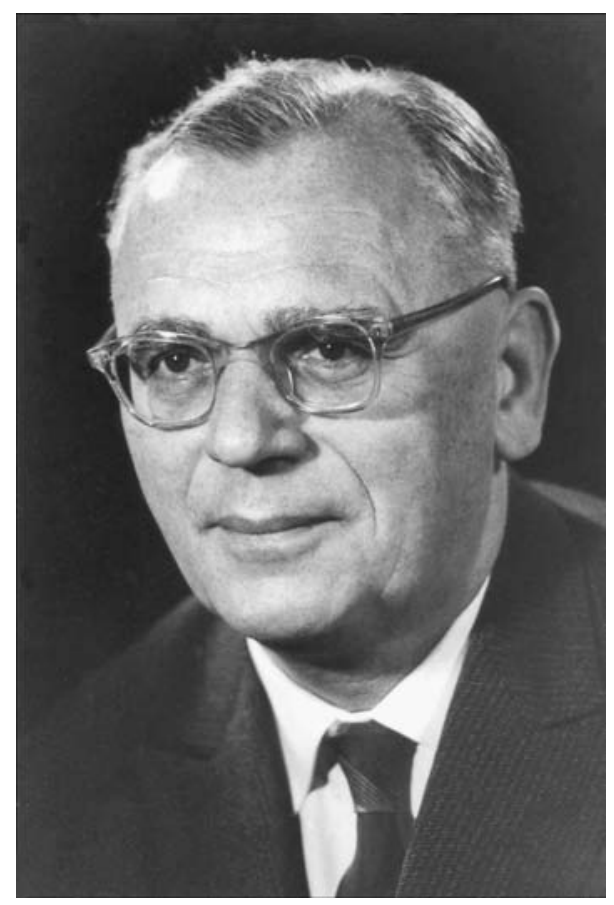

Abbildung 1: Erwin Meyer im Jahre 1964. 



\section{Breslau}

Erwin Meyer (den zweiten Vornamen Walter hat er nur selten angegeben) wuchs in Breslau auf. Er besuchte das humanistische König-Wilhelm-Gymnasium, das er am 1.12.1917 mit einem Notabitur beendete, weil der ganze Jahrgang zum Kriegsdienst eingezogen wurde. Vermutlich seinen Eltern zuliebe ließ er sich in Uniform fotografieren (Abbildung 2, übrigens das einzige Jugendfoto von Erwin Meyer). Das Soldatsein war ihm eine ungeliebte Pflicht - er sagte später, er sei stolz darauf, es nur bis zum Gefreiten gebracht zu haben. Die schlimmen Erlebnisse bis zum Kriegsende im November 1918 waren für sein weiteres Leben aber insofern prägend, als er seine ursprüngliche Absicht, alte Sprachen zu studieren, aufgab und etwas „Lebensnäheres“ suchte. Sein Wunsch Medizin zu studieren entfiel, weil seine Eltern nicht die finanziellen Mittel hatten, ihm eine Praxis einzurichten [1]. Stattdessen wählte er Mathematik und Naturwissenschaften, für die er sich an der Universität Breslau ab Dezember 1918 einschrieb.

Die Akustik galt damals nach den Arbeiten von Hermann von Helmholtz als praktisch abgeschlossenes Fach, das kaum noch jemand bearbeitete. In Breslau befasste sich allerdings Erich Waetzmann mit Akustik; bei ihm wurde Erwin Meyer mit einer Arbeit über Kräfte, die Schallwellen auf schwingende Membranen ausüben (Bjerkneskräfte) am 18.4.1923 zum Dr. phil. promoviert [4] (die Naturwissenschaften waren damals noch an den Philosophischen Fakultäten beheimatet). Meyers Eltern konnten sich nicht vorstellen, dass man als promovierter Physiker seinen Lebensunterhalt verdienen könnte; ihnen zuliebe legte er deshalb noch das Staatsexamen für das Lehramt an höheren Schulen ab der Wunschtraum seiner Mutter war, dass ihr Sohn einmal „Oberlehrer in Patschkau" würde, einer Kleinstadt in der Nähe [1]. Die Staatsexamensarbeit, zu der er sich am 19.7.1923 meldete, hatte ein mathematisches Problem zum Inhalt [7], die mündliche Prüfung war am 22./23.2.1924. Nach der souverän abgelegten Prüfung fragte ihn der Vorsitzende skeptisch, ob man ihn denn nun wohl für den Schuldienst gewinnen könne, worauf Meyer ehrlich antwortete „Ich glaube kaum“. Vom 1.1.1923 bis 15.11.1924 


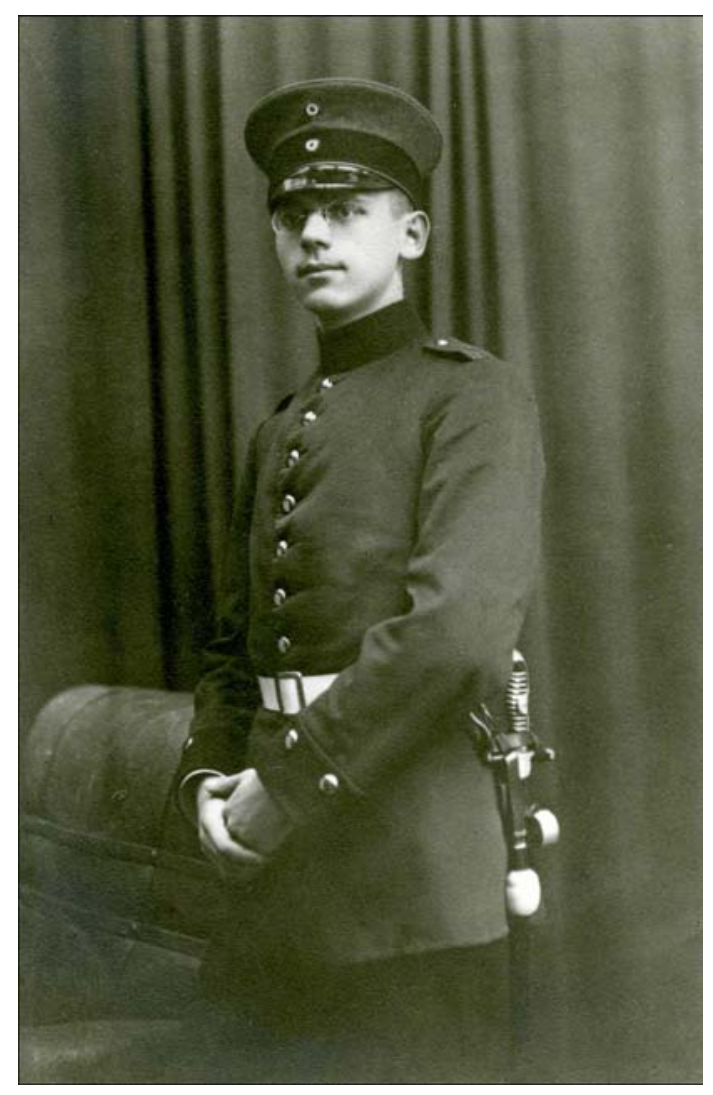

Abbildung 2: Erwin Meyer als Soldat im Jahre 1917.

war Meyer Vorlesungsassistent bei Otto Lummer, was ihn für die Konzeption guter Demonstrationsexperimente sensibilisierte.

Meyers Vater brachte ihm von der Post interne Publikationen über neue technische Entwicklungen mit, so dass er sich unter anderem über die noch ganz junge Rundfunktechnik informieren konnte. Ein Vortrag in Breslau von Postrat Hans Salinger aus Berlin über diese Technik wurde bestimmend für Meyers Zukunft. Salinger wollte sein Rundfunkgerät vorführen, das aber einen Transportschaden erlitten hatte und nicht so schnell zu reparieren war. 
Lummer wusste, dass Meyer ebenfalls einen Eigenbau hatte, den sich Salinger für seinen Vortrag auslieh. Er erkannte nicht nur, dass Meyers Gerät besser als sein eigenes war, sondern ihn beeindruckten auch die Gespräche mit Meyer so sehr, dass er Karl Willy Wagner, dem Leiter des Telegraphentechnischen Reichsamts (TRA; ab 1.4.1928 Reichspostzentralamt, RPZ) in Berlin empfahl, Meyer eine Stelle anzubieten [1]. Am 16.11.1924 trat dieser die Position als "Wissenschaftlicher Hilfsarbeiter" dort an, sein Aufgabengebiet war Fernmelde- und Rundfunktechnik, speziell die möglichst naturgetreue Wiedergabe von Musik. 



\section{Berlin}

Meyer erkannte rasch, dass es für gute Rundfunkübertragungen wichtig war, die Akustik von Räumen, die Eigenschaften von Mikrofonen, Lautsprechern, Musikinstrumenten, Schallfeldern und Tonabnehmern besser zu verstehen. Dazu war es nötig, Messverfahren zu entwickeln, die es bis dahin nicht gab und die erst mit den gerade erfundenen Elektronenröhren (vor allem für Verstärker und Gleichrichter) möglich wurden. Neben zwei Publikationen zum Hörvorgang aus der Zusammenarbeit mit Waetzmann (1925) [5, 6] und einem ausführlichen Handbuchartikel über das Gehör [14] (1927) erschienen in rascher Folge Arbeiten zur Prüfung von Lautsprechern [8] und zur Messung von Schallfeldern [9] (beide 1926), zur Messung der Schnelle- und Druckamplituden in Schallfeldern [10], zur Nachhallmessung [11], zur Messung der Frequenzkurven von Telefonen und Lautsprechern [12] und zu nichtlinearen Verzerrungen von Lautsprechern [13] (alle 1927). 1928 beschrieb Meyer eine Apparatur zur automatischen Aufzeichnung von Nachhallvorgängen mit Frequenzgemischen [16], sowie eine weitere Apparatur zur automatischen Klanganalyse nach dem Suchtonverfahren [17]. „Moderne Verfahren der Klanganalyse“ war auch das Thema seines Habilitationsvortrags an der Technischen Hochschule Berlin (Dezember 1928). Als Privatdozent hielt er seitdem Vorlesungen über Technische Akustik [201]. Einen kritischen Artikel schrieb er auch über die damals gebräuchlichen Methoden zur Hörprüfung, wofür er einige Experimente gemacht hatte [15]. Ebenfalls 1928 bekam Meyer den mit RM 1000,-- dotierten Preis einer Stiftung zugesprochen für eine Arbeit „Über die Anwendung der neuen akustischen Meßverfahren auf elektroakustische Probleme, insbesondere zur Prüfung von Lautsprechern" [200].

Aus seiner Arbeit am RPZ publizierte Meyer 1929 Untersuchungen am Kathodophon, einem zeitweilig benutzten Mikrofon für Tonfilm- und Rundfunkaufnahmen, das mit einer Plasmastrecke arbeitet und - wie Meyer nachwies - ein Schallschnelle-Empfänger ist (während die üblichen Mikrofone Druckempfänger sind) [19]. Im gleichen Jahr beschrieb er Verfahren zur Messung der Frequenzkurven von Tonabnehmern und Grammophonen [22]. Auch 
das Hallraum-Messverfahren für die Gesamtleistung von Schallquellen hat Meyer 1929 erstmals angegeben [23], ferner schrieb er einen längeren Lehrbuchartikel zur Messung der Schallintensität [24], und die Herausgeber des „Handwörterbuchs des elektrischen Fernmeldewesens" (auch 1929) übertrugen Meyer die Bearbeitung der Begriffsdefinitionen zur Akustik [18]. Absorptionsgradmessungen nach der Hallraummethode sind in [20] beschrieben. Manfred von Ardenne schreibt in einem Buch über Meyers Besuch bei ihm im August 1929, dass sie angeregte Gespräche über die Funktechnik führten [248]. Auch der Herausgeber eines Buches über Pioniere der Funktechnik erbat einen Beitrag über Erwin Meyer [247].

K. W. Wagner hatte die Bedeutung der Analogien zwischen mechanischen, akustischen und elektrischen Schwingungsvorgängen erkannt und setzte sich engagiert für die Gründung des Heinrich-Hertz-Instituts für Schwingungsforschung (HHI) ein, wo diese Gebiete in vier kooperierenden Abteilungen erforscht werden konnten: Elektrische Schwingungslehre und Hochfrequenztechnik (Leiter: Gustav Leithäuser), Telegraphie- und Fernsprechtechnik (Hans Salinger), Akustik (Erwin Meyer) und Mechanik (Wilhelm Hort). Zum 1.4. 1929 wechselte Meyer also als Abteilungsvorsteher für Akustik an das HHI in der Nähe der TH Berlin, wo er mit einem größeren Mitarbeiterstab seine breit gefächerten Interessen voll entfalten konnte. Im Jahr 1930 publizierte er mit G. Buchmann die als „Meyerbreite“ bekannt gewordene Methode zur Messung der Schnelleamplitude von Schallplattenaufzeichnungen aus der Breite des Lichtreflexes [27]. Buchmann war der Effekt bei seinen Arbeiten aufgefallen, und Meyer hatte ihn physikalisch erklärt. Dieses Verfahren wurde auch nach 30 Jahren noch regelmäßig angewandt und weiter ausgebaut [515].

Ebenfalls 1930 gab Meyer eine verbesserte Methode zur automatischen Messung der Nachhallzeit an [29], die sich damit objektiv und sehr viel genauer bestimmen ließ als mit der zuvor immer noch praktizierten Messung mit Gehör und Stoppuhr, wie sie schon von W. C. Sabine angegeben war [505, S. 10-14]. Schallisolationsund -absorptionsgradmessungen mit seinen neuen elektronischen Geräten sind in $[21,25,26,30]$ beschrieben. Auch für die Audiolo- 
gie hatte Meyer ein neues elektronisches Gerät entwickelt und 1930 vorgestellt, mit dem sich der Hörverlust zuverlässiger bestimmen ließ als mit den herkömmlichen Verfahren [28]. Wie der Diskussion nach einem späteren Vortrag [69] zu entnehmen ist, stieß die neue Methode bei vielen Hals-, Nasen- und Ohrenärzten allerdings noch lange auf Vorbehalte. Ebenfalls 1931 erschienen Veröffentlichungen von E. Meyer zum Schallschutz in Gebäuden [30, 31] und zur Schallplattentechnik [32], daneben setzte er die von seinem Mitarbeiter Martin Grützmacher weiterentwickelte Suchtonanalyse [506, 507] zur Messung der Spektren von Musikinstrumenten ein $[33,35]$.

Dass Erwin Meyer zu dieser Zeit schon hohes internationales Ansehen besaß, zeigt sich auch darin, dass ihn die 1929 gegründete Acoustical Society of America (ASA), der er bald nach der Gründung beitrat, schon in ihrer zweiten Mitgliederliste 1931 als „Fellow" aufführt, gekennzeichnet durch einen Stern vor dem Namen [206].

1932 heiratete Meyer die elf Jahre jüngere Editha Bergan. Ihre Tochter Angelika wurde 1942 geboren. Frau Meyer überlebte ihren Mann um mehr als 26 Jahre. Angelika ist seit 1968 mit dem Autor dieser Schrift verheiratet, der dadurch auch zu Erwin Meyer in dessen letzten Lebensjahren einen engen persönlichen Kontakt hatte und ihn nicht nur als seinen akademischen Lehrer, sondern auch menschlich sehr schätzen lernte.

An wissenschaftlichen Publikationen erschienen 1932 Arbeiten von Meyer zu den akustischen Eigenschaften von Holz [36] und Flachglas [37], zur Geräuschemission von Kraftfahrzeugen [38], zur Winkel- und Frequenzabhängigkeit der Schallabsorption poröser Stoffe [39, 40] und zur magnetischen Schallaufzeichnung [41]. Weiterhin hielt Meyer Überblicksvorträge zur elektroakustischen Messtechnik [42, 43]. 1933 folgten Publikationen zum Schlagton von Glocken [44] und zur Raumakustik holzausgekleideter Räume [45]. Hierbei hatte Meyer nachgewiesen, dass die günstige Wirkung der Holzverkleidung nicht, wie bis dahin angenommen, auf der Resonanzboden-artigen Abstrahlung von den Holzplatten, sondern auf der Absorption tieffrequenter Schallanteile beruht, was 
den Frequenzgang der Nachhallzeit verbessert. 1934 schrieb er Übersichtsartikel zur akustischen Messtechnik [46], über die damals verfügbaren Schallaufzeichnungsverfahren [47] und über die weltweiten Fortschritte in der Akustik während der letzten vier Jahre [48], ferner über Körperschallmessungen [50] und ein der optischen Gitterspektroskopie ähnelndes Verfahren der Schallspektroskopie, das sich aber nicht praktisch durchgesetzt hat $[51,56]$. Auf einer Tagung zur Lehrerfortbildung hielt er einen Vortrag über akustische Messtechnik und musikalische Akustik [49]. 1934 wurde Meyer zum „nichtbeamteten außerordentlichen Professor" an der TH Berlin ernannt [207].

Für Nachhallmessungen entwickelte Meyer 1935 ein logarithmisches Anzeigegerät mit einem exponentiell geformten Flüssigkeitswiderstand, in den eine Abtastspitze eintauchte [52]. Das Gerät erreichte einen Dynamikbereich von beachtlichen $80 \mathrm{~dB}$. Damit hat Meyer unter anderem den Einfluss von Publikum auf die Nachhallzeiten von Konzertsälen untersucht [53]. Zum Rauschverhalten der in den elektronischen Schaltungen eingesetzten DünnschichtKohlewiderstände haben Meyer und Thiede neue Erkenntnisse geliefert [55]. Ebenfalls 1935 folgten Untersuchungen zum Schalldurchgang durch Mehrfachwände [57, 58] sowie die Beschreibung eines neu entwickelten Erschütterungsmessers zur Messung der Schwinggeschwindigkeit (Schnelle) und seine Anwendung auf Gebäudeerschütterungen [59, 60]. Die tieffrequenten Absorptionseigenschaften von nicht-porösen Platten mit gedämpften Luftpolstern vor Wänden hat Meyer in [61] eingehend beschrieben.

Auf Meyers Initiative geht auch die Gründung der „Akustischen Zeitschrift" zurück, deren Mitherausgeber er während ihres Erscheinungszeitraums war (von 1936 bis 1944).

Über die bedeutende Rolle der Akustik in der Physik haben Meyer und Waetzmann einen interessanten Beitrag zur Physikertagung 1936 geliefert [63, 64]. Darin heben sie Impedanzbetrachtungen in Akustik und Elektrik hervor, die Ähnlichkeiten sinnesphysiologischer Eigenschaften von Auge und Gehör, die Leistungsmessungen in der Ulbricht'schen Kugel (Optik) und im Hallraum, sowie die Rolle der Ultraschallspektroskopie für die Mole- 
kularakustik. Einen Übersichtsvortrag „Raumakustische Probleme" hielt Meyer 1936 vor der Physikalischen Gesellschaft Zürich, in dem er insbesondere auf Nachhall- und Schluckgradmessungen einging [65]. Beim ,16th Meeting of the Acoustical Society of America“ im Oktober 1937 gab man Erwin Meyer zu Ehren ein „Luncheon" [208], und er hielt zwei Vorträge zur Raum- und Bauakustik [66, 67, 68]. Weitere Veröffentlichungen zur Raum- und Bauakustik in den Jahren 1937 und 1938 betrafen das akustische Messwesen [71, 77], Luft- und Körperschallleitung in Bauten [70, 72], Hallraummessungen [73], die Schalldämmung von Federn und Dämmstoffen [74] und die Schallaufnahmetechnik für Kinofilme [76]. Eine weitere Übersicht über die Fortschritte in der Akustik (in den Jahren 1934 bis 1937) schrieb Meyer 1938 [81]. Veröffentlichungen zur Werkstoffprüfung mit Ultraschall finden sich 1938 [75] und 1939 [85]. 1938 wurde Meyer zum persönlichen ordentlichen Professor ernannt [209].

Meyers Ruf als Experte auf dem Gebiet der Elektroakustik trug ihm Einladungen zu Vorträgen in Leningrad und in London ein. Die fünf Vorträge, die er in London im Oktober 1937 hielt, sind von der University of London 1939 als Buch herausgegeben worden [82].

Besonders wichtig ist die von Meyer erfundene Auskleidung „schalltoter Räume“ mit Schluckstoffkeilen aus porösem Material, wie sie seitdem überall zur Schaffung von Freifeldbedingungen in den Messlabors angewandt werden [78] (1938). Am HHI wurde ein „Schalltoter Raum“ mit den neuen Absorberkeilen eingerichtet [86, 87] und 1940 eingehend beschrieben [88]. Auch die „Randdämpfung“ in Zwischenräumen mehrschaliger Wände, Doppelfenster usw. haben Meyer und seine Mitarbeiter entwickelt [1].

Am 3. März 1939 wurde Erwin Meyer unter Berufung zum Beamten auf Lebenszeit zum ordentlichen Professor ernannt. Die Ernennungsurkunde ist noch im Familienbesitz, wie auch andere Urkunden aus Meyers Werdegang.

Um Erfahrungen mit der Hallraummethode zur Schluckgradmessung von Schallabsorptionsmaterialien zu gewinnen und möglicherweise eine Normvorschrift vorzubereiten, wurden unter Meyers 
Federführung umfangreiche Vergleichsmessungen an acht Prüfinstituten mit gleichen Messproben vorgenommen [83]. Eine Norm wurde aber erst wesentlich später verfasst [521]. Mit Konrad Tamm hat Meyer Untersuchungen zu Eigenschwingungen und Dämpfung von Gasblasen in Flüssigkeiten durchgeführt [84], sowie zur Messung von dynamischen Moduln elastischer Stoffe [89].

Der zweite Weltkrieg (1939-1945) weckte durch die Sonar-Ortungsverfahren das Interesse am Wasserschall. Meyers Arbeitsgruppe am HHI untersuchte die Schallausbreitung im Flachwasser und die Schallabsorption im Meerwasser, besonders den Einfluss von Gasblasen. Hierüber hielt Meyer einen ausführlichen Vortrag auf einer militärischen Arbeitstagung im Mai 1943 [90]. (Bei einer ähnlichen Tagung über Schiffsgeräusche im Februar 1944 hielt Meyer zwar keinen Vortrag, übernahm aber die fachliche Leitung und führte in die Problematik ein [91]).

Neben diesen Untersuchungen zur Schallausbreitung in Wasser arbeitete Meyers Gruppe intensiv an der Entwicklung von Wasserschallabsorbern. Zum einen wurden Rippenabsorber zur Auskleidung von Messbecken entwickelt (in der Wirkung ähnlich den Keilabsorbern für Luftschall), die seitdem in vielen Labors eingesetzt werden, zum anderen eine geschickt strukturierte Gummihaut mit Lufteinschlüssen (ein Dünnschicht-Zweikreis-Resonanzabsorber) zum Aufbringen auf Unterwasserkörper, vor allem auf die Außenhaut von U-Booten zur Erschwerung der Sonar-Ortung, nachdem mit dieser Technik der größte Teil der deutschen U-Boote aufgespürt und vernichtet wurde.

Meyer verstand es stets, sehr gute Mitarbeiter um sich zu scharen, und er war froh, sie durch die Wasserschall-Arbeiten davor zu bewahren, zum Fronteinsatz eingezogen zu werden. Über alle diese Arbeiten durften die Forscher nicht publizieren, die Arbeiten waren als „kriegswichtig“ und daher geheim deklariert. Das Projekt zur Entwicklung der Rippenabsorber trug den Decknamen „Fafnir", das der Dünnschichtabsorber lief unter dem Namen "Alberich“ - benannt nach germanischen Sagenfiguren, die sich durch Tarnkappen unsichtbar machen konnten. Meyer war überzeugt, dass der Krieg und das nationalsozialistische Regime 
nicht allzu lange dauern würden und behielt von allen Berichten Durchschläge, die er mit dem durchaus lebensgefährdenden Risiko entdeckt zu werden nach Thüringen brachte und dort unter den Dachboden-Dielen im Haus seiner Schwiegereltern versteckte [1].

Meyer und seine Mitarbeiter waren sich sicher, dass die UBoot-Umkleidung während des Krieges nicht mehr zum Einsatz kam. So steht es auch im Vorwort des "Navy-Reports“ [92, Seite V]. Erst 2008 wurde publik [524], dass die deutsche Marine mindestens ein U-Boot (U-480) mit der schallabsorbierenden Gummihaut überzogen hatte und es im August 1944 im Ärmelkanal operieren ließ, wo es vier Schiffe der Alliierten torpedierte, ohne selbst geortet werden zu können. Vor einer neuen Einsatzfahrt Anfang 1945 hatte der britische Geheimdienst die mit der deutschen Codierungsmaschine „Enigma“ gesendeten Funksprüche aufgefangen und entschlüsselt, wonach sie über den Namen „Alberich“ erschlossen, was es mit dem geheimnisvollen U-Boot auf sich hatte. Die Engländer verlegten heimlich die Schifffahrtsroute und verminten die bisherige, in der U-480 dann vergeblich nach Zielen suchte, bis es am 24. Februar 1945 von einer Mine zerstört wurde. Das Wrack wurde erst 1998 durch Zufall entdeckt, weil sich ein Fischerei-Schleppnetz darin verfangen hatte. Taucher haben dann festgestellt, dass es das weltweit erste „Stealth“-U-Boot war ${ }^{1}$.

Das Kriegsende erlebten Meyer und seine Arbeitsgruppe in Pelzerhaken in der Lübecker Bucht, wohin sie noch zwei Monate vor Kriegsende ausgelagert wurden, nachdem durch die ständigen Luftangriffe in Berlin kein vernünftiges Arbeiten mehr möglich war und das HHI (wie Ende 1943 auch schon Meyers Wohnung) durch Bombardement zerstört war. Schleswig-Holstein lag nach dem Krieg in der britischen Besatzungszone, Thüringen zunächst in der amerikanischen. Als sich abzeichnete, dass Thüringen im Austausch gegen Teile von Berlin der sowjetischen Zone zugeschlagen werden sollte, wandte sich Meyer an die britische Miltärverwaltung und fragte nach jemandem mit technischem Sachverstand. Der Offizier, der ihn daraufhin empfing, erklärte ihm, „Professor

${ }^{1}$ Der Autor dankt Herrn Prof. Dr. W. Eisenmenger für den Hinweis auf den Film über U-480 [524]. 
Meyer, ich kenne Sie; ich habe in Berlin studiert und Ihre Vorlesungen gehört. Was kann ich für Sie tun?". Das war natürlich ein sehr glücklicher Zufall. Meyer erklärte dem Offizier, dass in Thüringen interessante Unterlagen deponiert seien, die er gern international zugänglich machen würde, wozu er sie holen müsste, bevor die Russen im Juli 1945 das Gebiet besetzten. Weil es Bahnverbindungen praktisch noch nicht gab, erbat er ein Auto mit Fahrer, am besten einen Lastwagen, damit er auch einigen Hausrat und Frau und Tochter nach Pelzerhaken holen könne. So kam es, dass Meyer auf der Pritsche des Lastwagens (in das Fahrerhaus ließ der Fahrer den bisherigen „Feind“ nicht, dessen Weg-Anweisungen er aber folgen musste) schon Mitte 1945 durch das zerstörte Deutschland fuhr und schließlich die Unterlagen, seine Familie und einiges Eigentum in „den Westen“ holen konnte [1].

Es gelang Meyer, mit der englischen Besatzungsmacht einen Unterstützungsvertrag auszuhandeln, der es seiner Gruppe erlaubte, aus den Arbeitsberichten ein zusammenhängendes Buch zu machen. Dieser von der US Navy veröffentlichte englischsprachige Bericht „Sound Absorption and Sound Absorbers in Water" [92] (1946/1950) wird wegen der Fülle des Materials und der Sorgfalt der Untersuchungen bis heute von den Hydroakustikern in aller Welt sehr geschätzt. 


\section{Göttingen}

Nach dem Krieg erhielt Meyer zwei Berufungen in die USA und einen Ruf nach Göttingen. In den USA hätte er sofort seine Forschungen weiter betreiben können, fürchtete aber, aufgrund seiner nicht perfekten Sprachkenntnisse in Verhandlungen über die Einwerbung von Geldmitteln usw. wichtige Nuancen nicht zu erkennen und zweitklassig zu bleiben. Ob es in Deutschland zu einer Wiederbelebung der Wissenschaft kommen würde, wusste damals niemand - Meyer erwartete es aber und war sich sicher, in diesem Fall rasch wieder eine Spitzenposition einzunehmen. Aus diesen Gründen nahm er den Ruf an die Universität Göttingen an [1].

Am 1. April 1947 übernahm Meyer die Leitung des neu geschaffenen „III. Physikalischen Instituts“ der Universität Göttingen (später DPI genannt). Dieses Institut entstand durch Zusammenlegung des vorherigen „Instituts für Angewandte Mechanik“ mit dem „Institut für Angewandte Elektrizität“. Beide Lehrstühle waren zu dieser Zeit vakant. Die Gründung der Vorinstitute ging auf Felix Klein zurück, der sich erfolgreich dafür eingesetzt hatte, in Göttingen neben der Experimentalphysik und der Theoretischen Physik auch die Angewandte Physik zu etablieren [504]. Die Zusammenlegung kam Meyers Interessen entgegen, ein breit angelegtes Institut für Schwingungsphysik aufzubauen, mit ähnlicher Zielsetzung wie er sie am Heinrich-Hertz-Institut kennengelernt hatte.

Die früheren Institute waren in verschiedenen Gebäuden untergebracht: die „Angewandte Elektrizität“ in einem Klinkerbau mit roten Ziegelsteinen an der Bunsenstraße, daher im Institutsjargon das „Rote Haus“ genannt (Abbildung 3), im Unterschied zum „Weißen Haus“, einer ehemaligen Villa mit weit nach Süden reichenden Anbauten in der Bürgerstraße (Abbildung 4). Beide Gebäude waren durch einen etwa $200 \mathrm{~m}$ langen Fußweg getrennt - das war nicht optimal, aber zunächst akzeptabel. Zwischen den Gebäuden lag noch ein „Gartenhaus“ mit einem großen Abstellraum und einer Wohnung für den Hausmeister. Im Roten Haus gab es neben einigen Labors auch einen kleinen Hörsaal und das zunächst halbtägige, später ganztägige „Elektrophysikalische Prak- 
tikum“, später „Praktikum für Fortgeschrittene“ mit Versuchen aus der Schwingungsphysik. 1952 wurde zusätzlich ein halbtägiges „Röhrenpraktikum“, später „Elektronik-Praktikum“ eingerichtet. Außerdem gab es dort eine Werkstatt für Elektronik mit dem ungemein tüchtigen Leiter Heinrich Henze, der nach den Ideen von E. Meyer Vorlesungs- und Praktikumsexperimente ausarbeitete und bis zu seinem altersbedingten Ausscheiden 1987 Vorlesungsassistent war, auch noch unter Manfred R. Schroeder, Meyers Nachfolger (siehe auch Abbildung 12, S. 44).

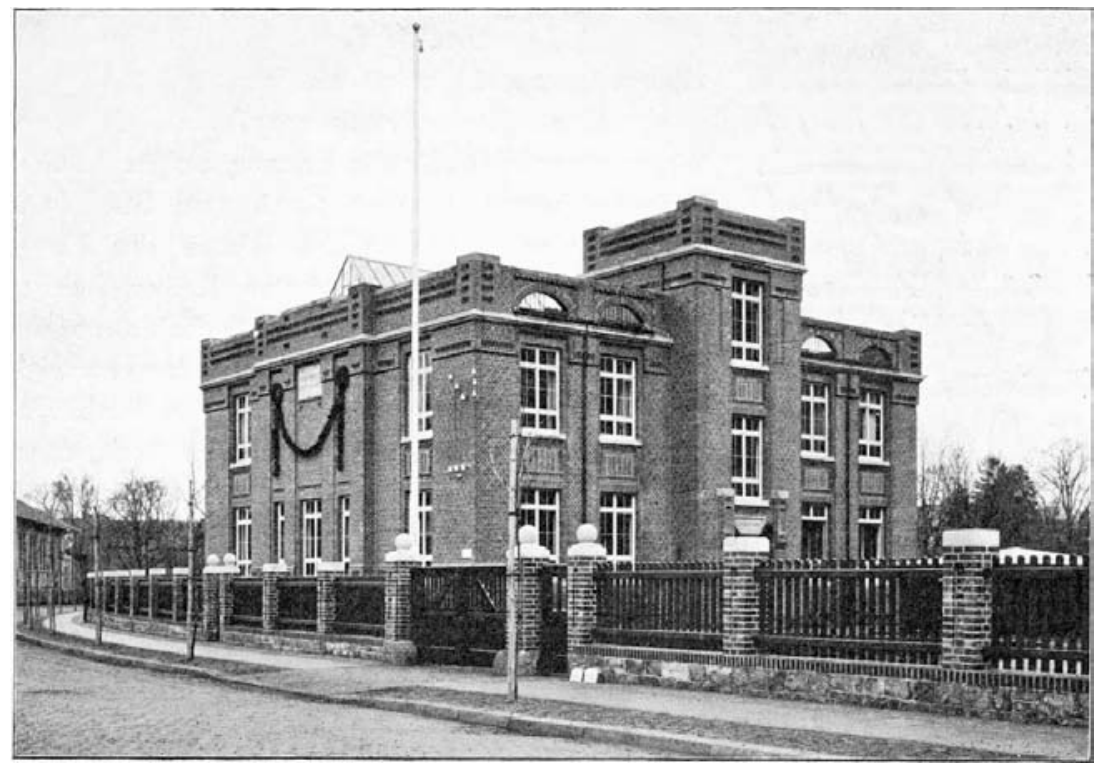

Abbildung 3: Das „Rote Haus“, Bunsenstr. 7 (aus [504, S. 73]).

Das Praktikum und die Vorlesungsexperimente waren weitgehend komplementär aufgebaut: einem akustischen Experiment entsprach ein analoges elektrisches Experiment, typischerweise mit Mikrowellen. Einige dieser Experimente sind in [97] beschrieben. Der Koautor Hans Severin hatte während der Lehrstuhlvakanz das „Rote Haus" weiter geleitet und setzte dort seine Forschungen über Mikrowellen bis zu seinem Ausscheiden im Jahr 1957 fort, 


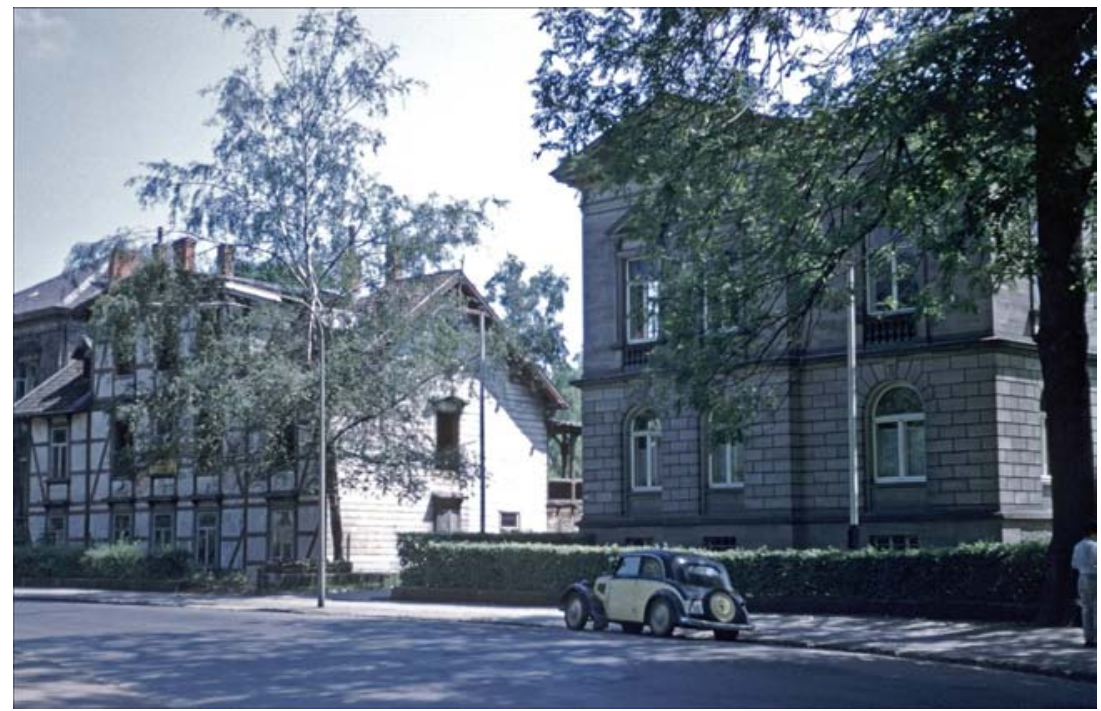

Abbildung 4: Rechts: das „Weiße Haus“, Bürgerstr. 42.

zunächst als Wissenschaftlicher Assistent, nach der Habilitation 1953 als Privatdozent und Oberassistent.

Im „Weißen Haus“ fand Meyer die Bibliothek und eine gut ausgestattete Werkstatt für Feinmechanik, sowie im südlichen Gebäudeteil eine große Versuchshalle vor. Im Erdgeschoss richtete er sich sein Arbeitszimmer ein, daneben das Sekretariat. Im Keller gab es einen Raum mit einer großen Akkumulatoren-Batterie aus in Serie geschalteten Blei-Säure-Zellen, die vom Hausmeister sorgfältig gepflegt wurde und es erlaubte, bei Stromabschaltungen, die es in der Anfangszeit noch gab, die Werkstattmaschinen weiter zu betreiben, und die natürlich auch Gleichstrom für die Laborexperimente lieferte.

Meyer verstand es, seinem neuen Institut in wenigen Jahren Weltgeltung zu verschaffen. Seine Antrittsvorlesung hielt er am 31. Januar 1948 über die Hörtheorie [93]. Geschickt war er in der Einwerbung von Geldmitteln für seine Forschungen. Zur Fortsetzung der Wasserschall-Arbeiten schloss er mit dem Britischen De- 
partment of Scientific and Industrial Research (DSIR), später Department of Naval Physical Research (DNPR) einen Forschungsvertrag ab, der ihm im Juni 1948 die erste Zahlung in der neuen Währung Deutsche Mark (DM) bescherte. Dieser Vertrag wurde Jahr für Jahr sogar über seinen Tod hinaus bis zum Frühjahr 1978 verlängert. Wenige Tage nach der Währungsreform, bei der jeder Deutsche zunächst nur ein „Kopfgeld“ von DM 40,-- bekam, konnte Meyer aus dem „Englandvertrag“ über einen größeren Geldbetrag verfügen. Er gab in der Lokalzeitung ein Inserat auf, in dem er den Kauf elektronischer Geräte jeder Art gegen Barzahlung anbot [1]. Auf diese Weise bekam das Institut viele Geräte aus abgestürzten Flugzeugen und anderen ehemaligen Wehrmachtsbeständen, die Meyers Mitarbeiter für den Bau dringend benötigter Messgeräte verwerten konnten, die zu der Zeit noch nicht wieder zu kaufen waren.

Die erste Doktorarbeit, die Meyer in Göttingen anregte und betreute, bezog sich auf den Einfluss von Echos auf die Hörsamkeit ${ }^{2}$ von Sprache. Es war seit etwa 1927 bekannt, dass frühe Reflexionen eines Schallsignals nicht als Echos wahrgenommen, sondern subjektiv mit dem Primärschall verschmolzen werden. Ernst Petzold nannte die dabei maximal zulässige Laufzeitdifferenz $\Delta t \approx 0,05 \mathrm{~s}$ Verwischungsschwelle [508, S. 8]. Meyer ließ von Helmut Haas in dessen Doktorarbeit (1.7.1947 - 6.10.1949) den Einfluss von Einfachechos auf die Verständlichkeit von Sprache in Abhängigkeit von vielen Parametern wie Echolaufzeit, Intensität, Klangfarbe, Einfallsrichtung, Sprechgeschwindigkeit und Raumnachhall eingehend untersuchen. Während dieser Zeit führte Meyers früherer Mitarbeiter Lothar Cremer den Begriff Gesetz der ersten Wellenfront ein, der besagt, dass der Primärschall den Richtungseindruck festlegt, während frühe Wandechos oder auch zeitverzögert angesteuerte Lautsprecher zwar die Lautstärke erhöhen und den Klangeindruck verbessern können, aber nicht als separate Quellen wahrnehmbar sind [510, S. 126].

\footnotetext{
${ }^{2}$ Unter Hörsamkeit versteht man zusammenfassend die akustischen Bedingungen eines Raumes für Sprach- oder Musikdarbietungen [18].
} 
Das wichtigste und neue Ergebnis der Haas'schen Untersuchungen war, dass das frühe Echo sogar um bis zu $10 \mathrm{~dB}$ lauter sein kann als der Primärschall, ohne störend zu wirken. Meyer erkannte die Bedeutung dieser Erkenntnis für Beschallungsanlagen sofort und veranlasste eine rasche englische Übersetzung der Haas'schen Dissertation, die schon im Dezember 1949 erschien [254] und bald weltweite Beachtung fand. Nach einem Vorschlag von R. H. Bolt [2] nennt man den Befund bis heute Haas-Effekt. Um die gleiche Zeit wurde in den USA eine ähnliche Untersuchung an der Harvard University gemacht und der Begriff precedence effect eingeführt [511]. Haas, der sein früheres Studium als Dipl.-Ing. abgeschlossen hatte, legte übrigens die Doktorprüfung nicht in Göttingen, sondern an der Technischen Hochschule in Braunschweig ab, um den Titel Dr.-Ing. zu bekommen [255]. Die deutschsprachige Veröffentlichung erschien erst 1951 [256]. Frühere ähnliche Beobachtungen zum Echo-Einfluss hatten keine große Beachtung gefunden [518]. Ein erster Praxistest zum Haaseffekt (1951) ist in [257] und [258] beschrieben: Bei den Ruhrfestspielen in Recklinghausen wurde eine „schallverzögernde Leisesprecheranlage“ (so bezeichnet, weil man die Lautsprecher nicht wahrnimmt) mit großem Erfolg installiert - selbst die sonst jegliche Elektroakustik ablehnenden Künstler konnten keine Einwände finden. Wie perfekt solche verzögert angesteuerten Lautsprecher wirken, kann man besonders im großen Saal des Kreml in Moskau erleben. Selbst in den hintersten Reihen der ca. 6000 Plätze hat man die Illusion, die optisch eher winzigen Akteure auf der Bühne direkt singen oder sprechen zu hören, obwohl der gehörte Schall aus Lautsprechern kommt, die in die Rücklehnen der jeweiligen Vordersitze eingebaut sind. Einen ausführlichen Überblick über weitere Arbeiten zum precedence effect haben Litovsky et al. 1999 verfasst [522].

1949 haben Meyer und Tamm einen Ortskurvenschreiber vorgestellt, der die Impedanzen von elektroakustischen Geräten oder rein elektrischen Schaltungen im Tonfrequenzbereich sehr rasch erstellt und sich damit auch für Vorlesungsversuche gut eignet [96].

Auf dem ersten internationalen Ultraschall-Kongress in Rom (14.-17. Juni 1950) regte Meyer an, als Nachfolgerin der „Akus- 
tischen Zeitschrift" eine neue internationale, vor allem aber europäische Zeitschrift, die „Acustica“ zu gründen, in der Beiträge auf deutsch, englisch oder französisch publiziert werden können und die Zusammenfassungen in allen drei Sprachen erscheinen. Als deutscher Herausgeber (neben einem Franzosen und einem Briten, anfänglich auch einem Niederländer und einem Italiener) fungierte Meyer bis zu seinem Tode.

Weil sich in der Zeit um das Kriegsende unveröffentlichte Arbeitsergebnisse aufgestaut hatten, erschienen zu den frühen Jahrgängen der Acustica „Akustische Beihefte“ (mit AB...-Seitenzahlen), in denen diese Manuskripte publiziert wurden, unter anderem auch wichtige Resultate der Wasserschallarbeiten aus dem HHI [104, 107, 114, 259, 260, 261].

Das „Professorenfoto“ (Abbildung 5) aus einer Serie, die in einer Göttinger Buchhandlung angeboten wurde, zeigt Erwin Meyer in dieser Zeit.

\section{Institutserweiterungen}

Sobald es die Verhältnisse erlaubten, bemühte sich Meyer um den Bau akustischer Spezialräume, wie er sie am Heinrich-HertzInstitut in Berlin hatte, zunächst um einen großen „Reflexionsfreien Raum“. Bezüglich der Finanzierung erwies er sich wieder als geschickter Organisator: er warb Geldmittel für den Bau ein vom Bundes-Wohnungsbauministerium, dem Bundespostministerium und dem Niedersächsischen Kultusministerium; die Kosten für die Auskleidung mit Schluckstoffkeilen trug die Notgemeinschaft der Deutschen Wissenschaft, die Vorgängerin der Deutschen Forschungsgemeinschaft [215]. Den Bauantrag stellte Meyer am 19. Januar 1952, fertiggestellt wurde der Raum in einem eigenen Anbau südlich der Versuchshalle im Januar 1953. Am 8. Juni 1953 war die feierliche Einweihung des mit einem Volumen von $1600 \mathrm{~m}^{3}$ damals weltweit größten Raumes dieser Art. Zur Einweihung kamen neben Universitätsrepräsentanten (Rektor, Kurator, Dekan und andere) auch der Niedersächsische Kultusminister Vogt [213].

Zwei Neuerungen wurden hier nach Meyers Ideen erstmals realisiert: zum einen schlossen sich an die Schluckstoffkeile an ihrem 


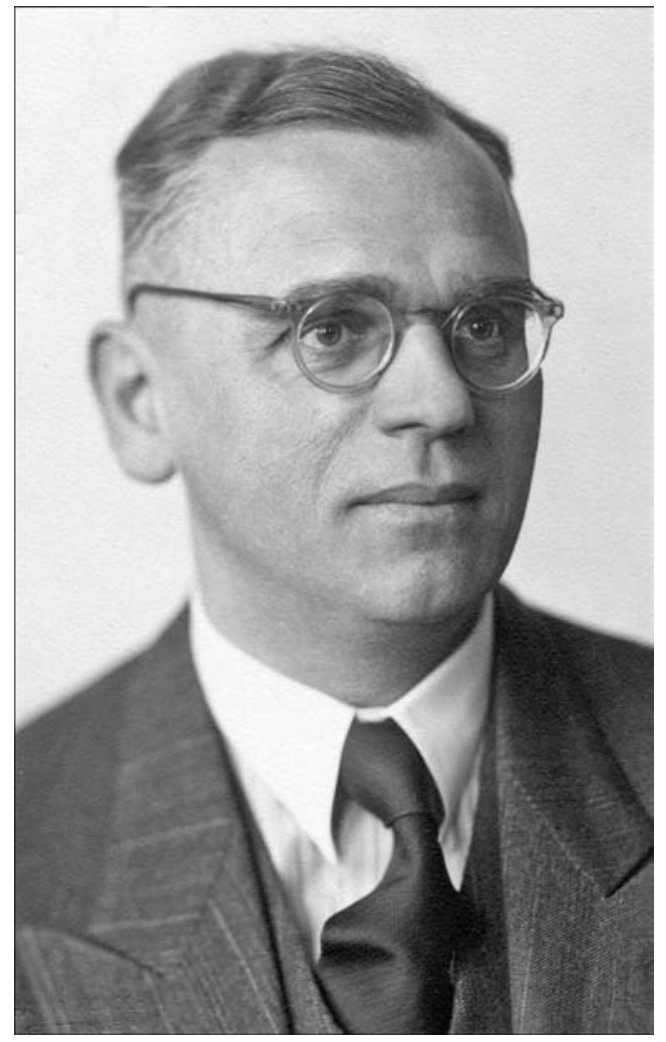

Abbildung 5: Erwin Meyer im Jahre 1950.

breiten Ende Resonanzabsorber (Helmholtzresonatoren) an, die auf die untere Grenzfrequenz der Keilabsorber abgestimmt waren und so mit geringem zusätzlichen Platzbedarf den Frequenzbereich nach unten erweiterten [262, 79], und zum anderen war in den Schluckstoff Graphitpulver eingesaugt, sodass die Keile auch elektromagnetische Wellen absorbierten [110]. Ausführlich beschrieben ist der Raum in [113]. Das beachtliche internationale Interesse an dieser Neuentwicklung zeigte sich auch darin, dass das US-Magazin LIFE International [214] in einem Sonderheft über das wiedererstarkende Deutschland diesen Raum abbildete (Abbildung 6). Was 
man trotz der raffinierten Ausleuchtung nur schwach erkennt, ist ein Netz aus straff gespannten Stahlseilen oberhalb der Bodenkeile, das den Raum begehbar machte. Weitere Verbesserungen ließen sich in einem bald danach eingerichteten reflexionsarmen Raum bei der PTT in Bern in der Schweiz realisieren: statt des Graphits wurden kurze Stahlwollefäden in das Absorptionsmaterial eingebettet, sodass die Keile hell aussahen und nicht so schmutzig-grau wie in Göttingen. Außerdem wurde statt des Drahtnetzes ein Netz aus Kunststoffseilen angebracht, damit der Raum auch nach unten elektrisch absorbiert [263].

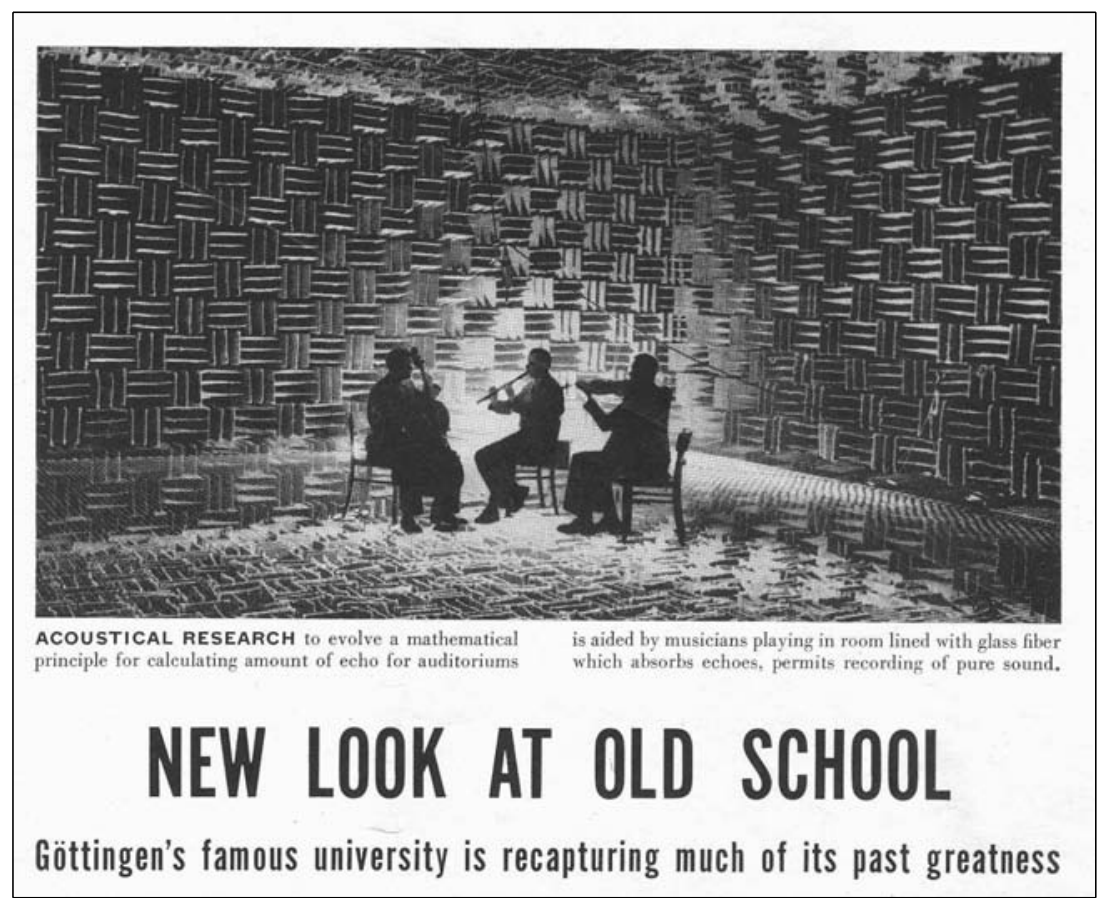

Abbildung 6: Im neuen „Reflexionsfreien Raum": drei damalige Diplomanden, Heinrich Kuttruff (Violine), Wolfgang Westphal (Querflöte) und Frieder Eggers (Cello), bei der Aufnahme nachhallfreier („trockener") Musik. Aus LIFE International [214]. 
Als nächstes plante Meyer den Bau eines großen Hallraums. Weil es dafür kaum Vorbilder gab, ließ er in Vorarbeiten an kleineren Modellen die optimale Form und Ausstattung ermitteln [140]. Im Juni 1956 stellte er den Bauantrag, im April 1957 kam die Genehmigung für den Bau des mit einem Volumen von $342 \mathrm{~m}^{3}$ ebenfalls sehr großen Hallraums, wieder in einem eigenen Anbau und wesentlich finanziert durch die Deutsche Forschungsgemeinschaft. Zur Luftschallisolierung gegen Umgebungslärm wurde der Raum zweischalig aufgebaut, und außerdem der eigentliche innere Hallraum zur Erschütterungsisolierung auf Stahlfedern gestellt. Weil Hallraummessungen ein diffuses Schallfeld voraussetzen, wurden parallele Wände vermieden (schiefwinkliger Grundriss und geneigte Decke), und außerdem 24 gebogene Plexiglasscheiben von je $2 \mathrm{~m}^{2}$ Fläche als Streukörper unregelmäßig im Raum aufgehängt. Die Voruntersuchungen, der Bau, der Raum selbst und erste Testmessungen sind in [152] beschrieben.

Als Neuheit sorgte eine Beschichtung der Innenwände mit Kupferfolien dafür, dass der Raum auch für elektromagnetische Wellen ein Hallraum wurde. Abbildung 7 zeigt einen Blick in den neuartigen Hallraum mit den Streukörpern und mit Absorberkeilen als Messobjekt auf dem Boden, rechts unten ein Richtmikrofon mit Parabolreflektor. Die Stoßfugen der Kupferblechbahnen sind mit weißen Leitlackstreifen überbrückt. Weil auch der Boden mit der empfindlichen Folie beklebt war, durfte man den Hallraum nur mit Filzpantoffeln betreten, die im Vorraum bereit lagen.

Die Übertragung der akustischen Hallraum-Messtechnik auf elektromagnetische Wellen ist in [156] und [162] beschrieben.

Die beiden Spezialräume sind hohen Besuchern in Göttingen oft als besondere Attraktionen geboten worden, z. B. im Dezember 1960 einer Delegation aus der Vereinigten Arabischen Republik (VAR), angeführt vom ägyptischen Ministerpräsidenten Kamaleddin Hussein (einem engen Vertrauten des Staatspräsidenten Nasser), was in der Lokalpresse eingehend gewürdigt wurde [225, 226]; im Juli 1965 kam der Botschafter der USA in Deutschland, George McGhee nach Göttingen und besuchte auch das III. Physikalische Institut [235]. 


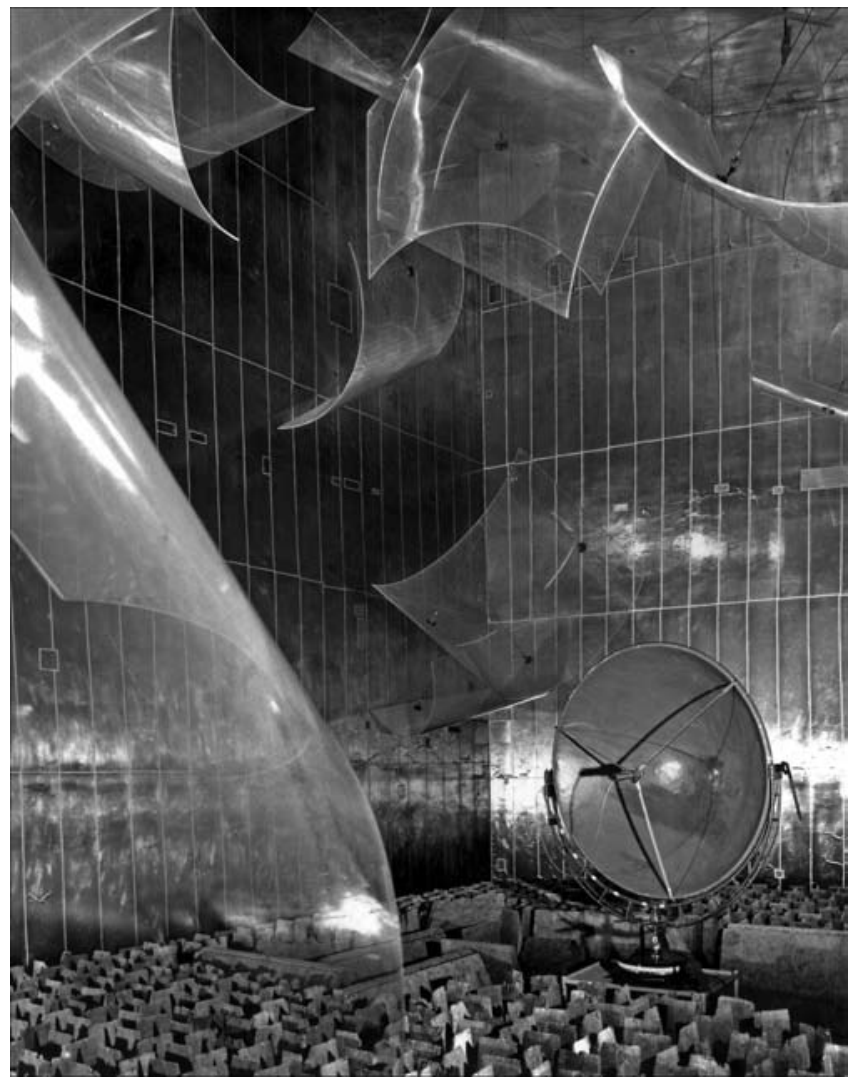

Abbildung 7: Der neue „Hallraum“.

Im Jahr 1956 bekam Meyer einen Ruf an die Universität Heidelberg. Im Göttinger Universitätsarchiv [215] findet sich unter dem Datum 2.10.1956 ein Brief des Kurators Dr. Müller an das Kultusministerium in Hannover, in dem er schreibt, es sei dringend zu wünschen, dass Meyer diesen Ruf ablehnt. Die Bleibeverhandlungen zeigten, dass sich bereits früher aufgestellte Pläne für eine großzügige Institutserweiterung nun realisieren ließen. Schon 1953 hatte der Regierungspräsident das Grundstück Bürgerstr. 44 mit dem kleinen Fachwerkhaus links in Abbildung 4 (S. 17) aufge- 
kauft, „um Erweiterungsmöglichkeiten für das Dritte Physikalische Institut zu schaffen" [216]. Ende 1957 wurden der Abriss dieses Nachbargebäudes und der dreigeschossige große Anbau an den Altbau Bürgerstr. 42 genehmigt. Ende Mai 1959 war das Richtfest [219, 220], Anfang 1960 wurde der Bau fertig, und am 30. Mai 1960 war die offzielle Einweihung mit etwa 150 Ehrengästen, einem eindrucksvollen Experimentalvortrag von Meyer und Laborbesichtigungen [223, 224]. Abbildung 8 zeigt in einer Fotografie vom gegenüberliegenden Stadtwall einen Blick auf das neue Institutsgebäude. Gleichzeitig mit dem Anbau wurde auch der Altbau gründlich saniert.

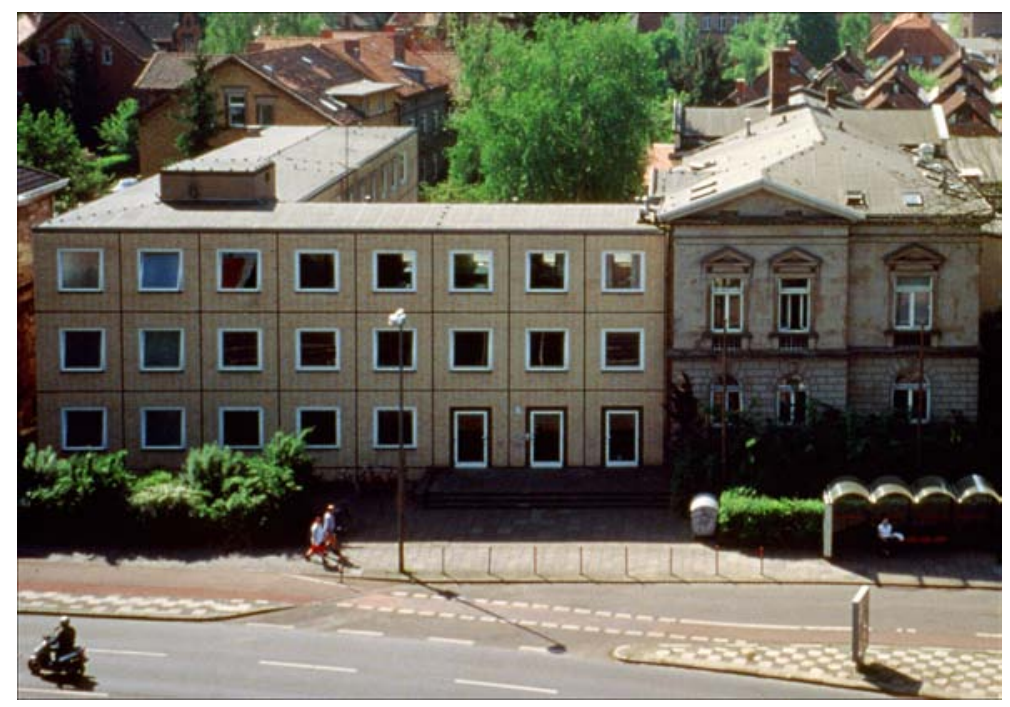

Abbildung 8: Das Dritte Physikalische Institut (DPI), Bürgerstr. 4244, rechts der Altbau, links der 1960 fertig gestellte Erweiterungsbau.

Das „Rote Haus“ wurde nun geräumt und von der Universität anderweitig genutzt. Im Neubau gab es Platz für viele Labors, die Praktika, die Elektronik-Werkstatt, die Bibliothek, den größeren Hörsaal (natürlich mit hervorragender Akustik), die sehr umfangreiche Sammlung von Vorlesungsgeräten, und außerdem im Keller als Neuheit einen reflexionsarm ausgekleideten großen Tieftank für 
Wasserschallexperimente, $4 \mathrm{~m}$ tief in den Boden eingelassen und finanziert durch das Bundesministerium für Verteidigung $[153,154]$. Abbildung 9 zeigt den $100 \mathrm{~m}^{3}$ fassenden Tieftank mit Rippenabsorbern entlang den Wänden und auf dem Boden (hier mit einer Installation für Streumessungen an schallweichen Kugeln [383]).

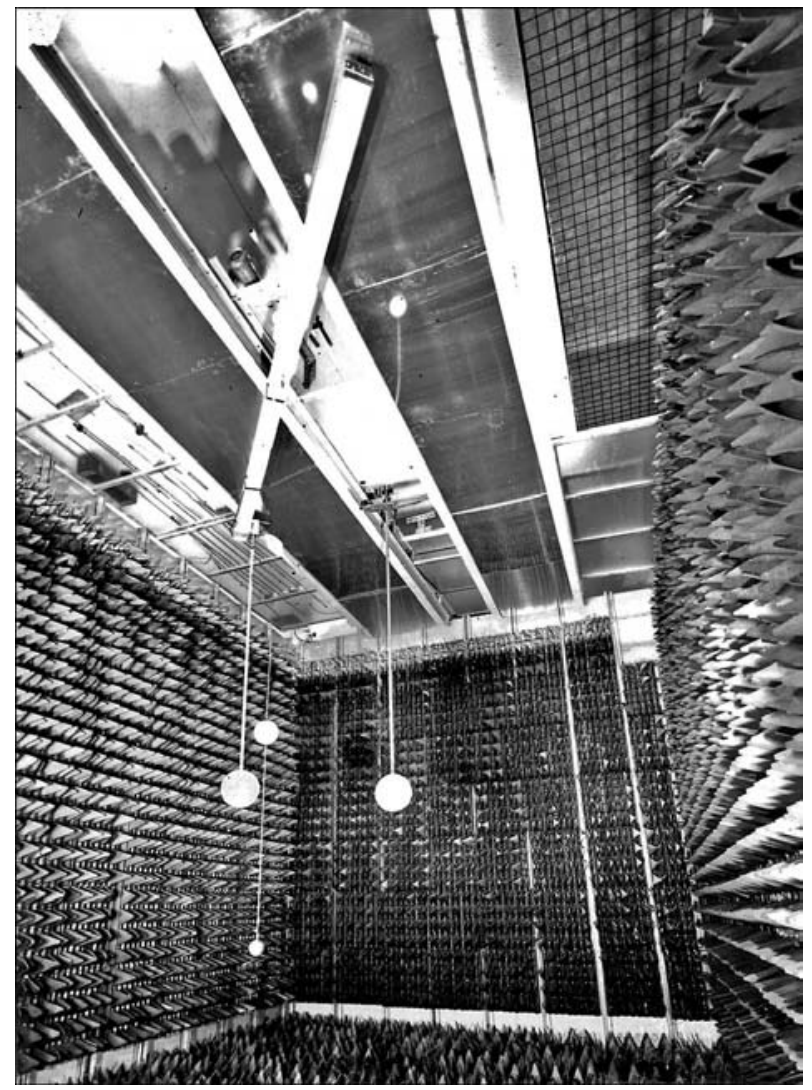

Abbildung 9: Der reflexionsarm ausgekleidete Tieftank (ohne Wasser).

In diesem Bauzustand blieb das Institut im Wesentlichen bis zu Meyers Emeritierung.

Die Liste der Veröffentlichungen aus dem DPI zeigt von Anfang an eine große Themenvielfalt. Meyer fühlte sich stets verpflichtet, 
die Forschungsergebnisse seines Instituts rasch zu veröffentlichen - schließlich werden die meisten Arbeiten an Universitäten durch die „öffentliche Hand“ finanziert. Dabei legte er aber, im Unterschied zu vielen anderen Institutsleitern, keinen Wert darauf, oft als Koautor genannt zu werden, obwohl er als Initiator und engagierter Begleiter der Arbeiten natürlich wesentlichen Anteil an den Ergebnissen hatte.

Einige von Meyers bewährten, langjährigen Mitarbeitern aus der Berliner Zeit waren ihm nach Göttingen gefolgt und halfen, einen Stab von jüngeren Assistenten heranzubilden. 1960 sah der Stellenplan des Instituts außer der Direktorenstelle (E. Meyer) einen Oberassistenten (habilitiert) und 3 Wissenschaftliche Assistenten (promoviert) vor, außerdem natürlich Stellen im technischadministrativen Bereich. Der Oberassistent leitete seine Arbeitsgruppe weitgehend selbstständig, außerdem organisierte er das Praktikum. Die Assistenten halfen bei der Betreuung von Diplomund Doktorarbeiten, daneben mussten sie einige Verwaltungsaufgaben übernehmen und Praktikumsversuche betreuen. Einer der Berliner Mitarbeiter war Konrad Tamm, der sich Ende 1951 mit einer Arbeit über die Schallabsorption in Wasser und Elektrolytlösungen habilitierte [392] und bis März 1961 eine eigene Arbeitsgruppe leitete, bevor er einen Ruf an die Universität Heidelberg annahm.

Die erfolgreiche Teilnahme an einem der FortgeschrittenenPraktika in den experimentellen Physik-Instituten war Voraussetzung dafür, eine Diplomarbeit beginnen zu können. Meyer unterhielt sich eingehend mit den Studenten im Praktikum und hatte genügend Erfahrung und Menschenkenntnis um zu beurteilen, wer sich gut in das leistungsfähige Team des Instituts einfügen würde. Die Themenvergabe und die Einstellung neuer Mitarbeiter besprach er natürlich mit seinen Mitarbeitern, behielt sich aber die letzte Entscheidung für die Auswahl neuer Diplomanden, gelegentlich auch Staatsexamenskandidaten und Doktoranden vor. Die meisten Doktorarbeiten ergaben sich allerdings aus den vorangegangenen Diplomarbeiten. Den Danksagungen in den Examensarbeiten und Veröffentlichungen ist zu entnehmen, dass Meyer fast 
alle Arbeitsthemen selbst vorschlug. Sein Ideenreichtum war schier unerschöpflich, und die Forschungsergebnisse waren fast immer bedeutungsvoll.

Bei regelmäßigen Rundgängen durch die Labors informierte Meyer sich detailliert über die Fortschritte und gab bei auftretenden Problemen gute Tipps und oft auch Anregungen für den Austausch mit anderen Diplomanden und Doktoranden, die - in meist anderem Zusammenhang - mit verwandten Problemen kämpften. Meyer hatte dadurch stets den Überblick über die laufenden Arbeiten der typischerweise 30 Diplomanden und 15 Doktoranden. Bei seinen Rundgängen pflegte er auf den Fluren laut mit den Fingern zu schnippen - dadurch war man vorgewarnt: gleich kommt der Chef.

In Meyers Institut herrschte ein gutes „Betriebsklima“ - sicherlich eine Folge davon, dass Meyer es durchaus mit Autorität, aber immer geradlinig und fair führte, und weil es wegen der vielen Forschungsbereiche niemals Überlappungen der Arbeitsthemen oder Unklarheiten über Kompetenzen gab. Konkurrenzkampf oder Missgunst kannten seine Mitarbeiter daher nicht, sondern nur ein konstruktives Miteinander. Und wenn gelegentlich ein Diplomand Meyers recht hohen Ansprüchen nicht gewachsen war, halfen ihm die tüchtigeren Kollegen kameradschaftlich, damit er "dem Chef “ nicht zu negativ auffiel.

Der angenehmen - wenn auch anspruchsvollen - Arbeitsatmosphäre war es auch zu verdanken, dass viele gute Mitarbeiter ihr ganzes Arbeitsleben am Institut blieben, vor allem im nicht-wissenschaftlichen Bereich. Heinrich Henze wurde schon genannt (S. 16), auch etliche Feinmechaniker und Elektroniker begannen als Lehrlinge, bekamen eine sehr gute Ausbildung und wurden, wenn es der Stellenplan erlaubte, als Gesellen (später natürlich Auszubildende und Techniker genannt) oder auch Meister auf Dauerstellen übernommen. Am 1. Mai 1948 stellte Meyer die junge Edith Kuhfuß als Sekretärin ein, die sich als absolut zuverlässig und einsatzfreudig erwies und von allen Mitarbeitern sehr geschätzt wurde. Durch ihr einnehmendes Wesen wurde „Fräulein Kuhfuß“ bald die „Seele“ des Instituts. Nachdem ihr Verlobter im 
Krieg gefallen war, blieb sie unverheiratet und fand ihre Aufgabe im Wirken für das Institut. Mit vielen Mitarbeitern führte sie bis ins hohe Alter regen Briefwechsel, auch noch als Rentnerin (ab April 1980).

\section{Forschungsschwerpunkte}

Meyer unterstützte nachdrücklich die Arbeiten von H. Severin und dessen Mitarbeitern über elektromagnetische Mikrowellen, insbesondere Beugung und Streuung, Strahler, Empfänger und Messleitungen. Meyer regte die Entwicklung von Mikrowellenabsorbern [115, 117, 264, 265, 266] und die Messung von Materialeigenschaften natürlicher und künstlicher Dielektrika an [267, 268, 121], und er lenkte die Aufmerksamkeit auf die Analogien zur Akustik [110, 120, 139]. Über Demonstrationsexperimente mit Zentimeterwellen berichteten Meyer und Severin in [97].

Nach Severins Ausscheiden (1957) leitete R. Pottel die Mikrowellen-Arbeitsgruppe in zunächst enger Absprache mit Meyer, nach seiner Habilitation 1965 zunehmend selbstständiger. Ein Forschungsschwerpunkt war weiterhin die Entwicklung von Absorbern nach verschiedenen Prinzipien [269] bis [279], [172]. Einen ausführlichen Überblick über Mikrowellenabsorber schrieben Meyer und Pottel im Jahr 1960 [157]. Neben Untersuchungen zur Ausbreitung [282, 283, 165], Beugung [284] und Streuung [285] bildeten Messungen an Dielektrika einen weiteren Schwerpunkt [286] bis [290], später vor allem an Flüssigkeiten [291] bis [298]. Finanziert wurden diese Arbeiten zum Teil durch einen Forschungsvertrag mit dem U.S. Air Research and Development Command (European Office, Brüssel), und die hervorragende Ausstattung mit Spezialgeräten für einen immer größeren Frequenzbereich war der Deutschen Forschungsgemeinschaft zu verdanken.

Mit der Führung von Mikrowellen entlang dielektrischer Leitungen befasste sich E.-G. Neumann intensiv [299] bis [306], der sich 1967 mit diesem Thema habilitierte und unter anderem auch ein akustisches Analogon zur Yagi-Antenne für Mikrowellen entwickelte, ein Mikrofon mit vorgesetzter Scheibenleitung, das dadurch zu einem schlanken Richtmikrofon wird [307]. 
In der Mikrowellen-Abteilung arbeiteten etwa ein Drittel der Institutsmitglieder. Die Mehrheit verteilte sich aber auf die verschiedenen Arbeitsrichtungen der Akustik.

Ein wichtiges Gebiet war die Raumakustik. Den Einfluss von „Schallspiegeln" (Reflektoren) seitlich und oberhalb der Bühne großer Säle haben Meyer und seine Mitarbeiter mit Hilfe der geometrischen Raumakustik analysiert und die Ergebnisse oft praktisch angewandt [105].

Ein international damals viel diskutiertes Problem war die Charakterisierung der akustischen Qualität von Räumen durch Kenngrößen. Nach W. C. Sabines grundlegenden Untersuchungen zum Nachhall [505] war es klar, dass die Nachhallzeit die wichtigste Größe ist, aber sie allein reicht nicht aus (beispielsweise kann ein gekacheltes Badezimmer die gleiche Nachhallzeit haben wie ein Konzertsaal). Nach früheren Vorarbeiten (z. B. [509]) hatten R. H. Bolt und R. W. Roop [512] die ,frequency irregularity“ (Frequenzkurvenschwankung) als weiteren Parameter in der Erwartung eingeführt, damit ein Maß für die räumliche Ungleichförmigkeit des Schallfeldes zu bekommen. Aber Meyers Student M. R. Schröder (später schrieb er sich Schroeder) zeigte in seiner Dissertation und einer Folgearbeit durch statistische Analysen, dass diese Größe (außer bei sehr tiefen Frequenzen) durch die Nachhallzeit festgelegt ist, also keine zusätzliche Information über den Raum liefert $[308,309]^{3}$. Dies wurde durch Messungen von H. Kuttruff in seiner Diplomarbeit und von R. Thiele in seiner Doktorarbeit in vielen Räumen bestätigt [310, 311].

Es war klar, dass die Hörsamkeit in einem Raum durch die dem Direktschall folgenden Reflexionen von den Begrenzungsflächen bestimmt sein musste. Meyer ließ deshalb von seinen Studenten G. R. Schodder, R. Thiele und später W. Burgtorf umfangreiche Messungen zur zeitlichen Abfolge [312] und zur Richtungsverteilung $[313,134]$ der Schallrückwürfe nach Impulsanregung in vie-

\footnotetext{
${ }^{3}$ Diese beiden grundlegenden, deutschsprachigen Arbeiten wurden bei den Bell Laboratories in den USA für den internen Gebrauch 1963 [308] bzw. 1972 [309] ins Englische übersetzt, aber trotz ihrer immer noch großen Bedeutung erst 1987 publiziert.
} 
len Räumen und an jeweils vielen Sitzplätzen vornehmen. Aus dem Vergleich mit den subjektiven Eindrücken der Hörsamkeit ergab sich, dass die frühen Rückwürfe maßgeblich die Klarheit oder „Deutlichkeit“ (engl. „,definition“ oder „,clearness“) bestimmen, von Meyer und Thiele quantitativ definiert als das Verhältnis der Schallenergie in den ersten $50 \mathrm{~ms}$ der Impulsantwort zur Gesamtenergie. Damit sich Konzertbesucher in das Schallgeschehen gleichsam eingebettet fühlen, erschien es damals wichtig, dass die Rückwürfe möglichst gleichmäßig aus allen Richtungen und möglichst gleich stark einfallen, also die „Richtungsdiffusität“ („directional diffusivity“) hoch ist [122]. Sie wurde so definiert, dass sie im reflexionsfreien Schallfeld gleich 0 und im ideal diffusen Feld gleich 1 ist. Gemessen wurde die Diffusität mit einem schwenkbaren Richtmikrofon (Parabolspiegel mit Mikrofon im Brennpunkt, siehe Abbildung 7) [313] und veranschaulicht durch einen „Schalligel", eine Kugel oder Halbkugel, in die in radialer Richtung Metallstäbe eingesetzt sind, deren Länge der aus der jeweiligen Richtung einfallenden Schallenergie proportional ist (Abbildung 10). Meyers erster Vortrag in den USA über diese neuen Erkenntnisse [116] fand sehr großes Interesse, ebenso wie weitere Vorträge 1956 [123] und 1958 [137]. M. R. Schroeder beschrieb nach theoretischen Analysen eine Messmethode für die Diffusität in Hallräumen, die ohne den sperrigen Parabolreflektor auskommt [516]. Später zeigten M. Barron durch Schallfeldsimulationen im Reflexionsfreien Raum [519] und Schroeder mit seinen Mitarbeitern durch Kunstkopfaufnahmen in vielen Konzertsälen [314], dass für einen guten Raumeindruck vor allem frühe seitliche Rückwürfe wichtig sind.

In der Praxis benutzt haben Meyer und seine Mitarbeiter, vor allem H. Kuttruff, ihre Erkenntnisse bei der akustischen Beratung ungezählter Festsäle, Studios, Konferenz- und Sitzungsräume usw., z. B. der Liederhalle Stuttgart (1955/56) [315], der Beethovenhalle in Bonn (1959) [148], des Plenarsaals im Baden-Württembergischen Landtag in Stuttgart 1962 [159] und der „Jahrhunderthalle“ in Höchst bei Frankfurt (1963) [170] mit einer der größten je gebauten elektroakustischen Verzögerungsanlagen zur Erzeugung künstlichen Nachhalls. 


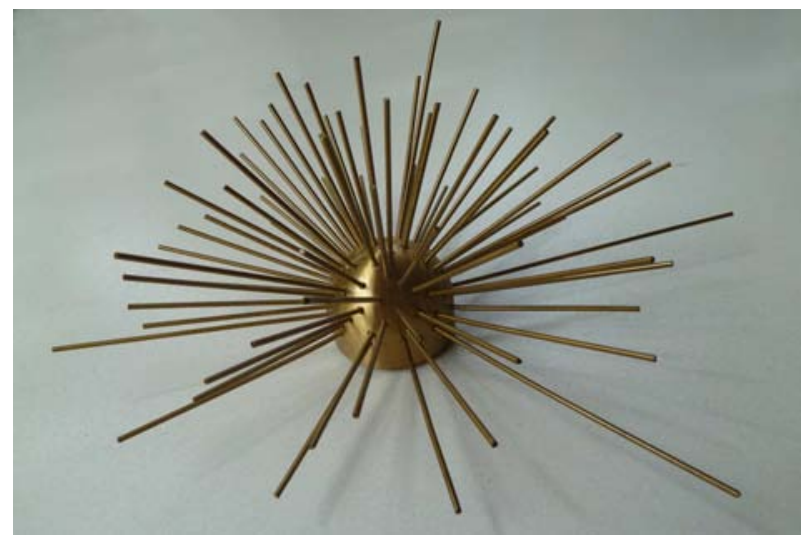

Abbildung 10: „Schalligel“ nach Meyer und Thiele, im Laborjargon auch „Thiele-Igel" genannt. Kugeldurchmesser: $4 \mathrm{~cm}$. Hier für ein Schallfeld mit recht guter Diffusität.

Im September 1962 wurde der niedersächsische Landtag im wieder aufgebauten Leineschloss in Hannover eingeweiht. Allerdings war die Akustik im neu gebauten Plenarsaal so schlecht, dass viele Abgeordnete und Gäste die Festrede des Bundespräsidenten nicht verstehen konnten. Nach heftigen Diskussionen der Politiker mit dem Architekten Professor Oesterlen und dem von ihm hinzugezogenen Akustiker Thienhaus wurde E. Meyer um ein Gutachten gebeten. Er stellte fest, dass die doppelte Krümmung der Holzverkleidung für fokussierte Echos und die geringe Schallabsorption für eine zu lange Nachhallzeit verantwortlich waren. Nach Meyers Vorschlägen wurden die Wände begradigt und eine neue Täfelung mit stärkerer Schallschluckung angebracht (gelochte Holzplatten, mit Absorptionsmaterial hinterlegt), und außerdem eine bessere Elektroakustik-Anlage installiert, unter anderem mit verzögerter Speisung der Tribünen-Lautsprecher. Damit waren die Probleme behoben, und der Landtag konnte ab Oktober 1963 wieder regulär arbeiten. Die ganze Angelegenheit wurde natürlich in der Presse eingehend behandelt [227] bis [230]. Auch die 1964 eröffnete Stadthalle in Göttingen haben Meyer und Kuttruff akustisch 
beraten. Als Mehrzweckhalle geplant, sollte die Nachhallzeit im Bereich um $1000 \mathrm{~Hz}$ etwa 1,6 s betragen - ein Kompromiss für Musik- und Sprachdarbietungen. Entgegen den Erwartungen erwies sich die gemessene Nachhallzeit des fertigen Saales im mittleren Frequenzbereich um etwa 0,5 s länger als nach der statistischen Nachhalltheorie vorausberechnet [177]. Als Ursache für diese Diskrepanz stellte sich nach spontanen Vermutungen und späteren Modellversuchen mangelnde Diffusität heraus [187].

Auch in den USA war Meyers Kompetenz gefragt. Um die Ursache akustischer Unzulänglichkeiten in der im Herbst 1962 eröffneten Philharmonic Hall im Lincoln Center in New York zu klären, veranlasste Meyer Messungen an einem verkleinerten Modell der abgehängten Deckenreflektoren, womit sich die Probleme teilweise erklären ließen (neben einer ungünstigen Grundrissform) [166]. ${ }^{4}$

Der britische Akustiker E. G. Richardson hatte ein Handbuch über technische Aspekte der Akustik herausgegeben. Der erste Band [513] erschien 1953 und behandelte den Hörfrequenzbereich unter verschiedenen Aspekten; zum zweiten Band [514] über Ultra- und Wasserschall sowie Fluglärm hatte Meyer zwei Kapitel geschrieben [130, 131]. Richardson starb während der Vorbereitung des dritten Bandes über neuere Fortschritte der Akustik, und der Verlag bat Meyer, das Werk zu vollenden. So wurde er Mitherausgeber des dritten Bandes, zu dem er zusammen mit H. Kuttruff ein Kapitel über Raumakustik beisteuerte [164].

Einen ausführlichen, allgemeinverständlichen Überblick über die Akustik von großen Sälen gab Meyer in einem beeindruckenden Abendvortrag mit vielen Experimenten in der Jahrhunderthalle Hoechst bei der Physikertagung 1965 [179, 236]. Häufig wurde er zu Vorträgen über moderne elektroakustische Anlagen eingeladen [103, 111, 126, 174, 182]. Über Modellversuche zur Diffusität in Räumen mit optischen, elektromagnetischen und Ultraschallverfahren hielt er einen Vortrag in Venedig [129].

Die Schallabsorption von und die Schallausbreitung über Publikum ließ Meyer messen und versammelte dazu seine Instituts-

\footnotetext{
${ }^{4}$ Der Autor dankt Herrn Professor Kuttruff für Hinweise auf Ungenauigkeiten in einer früheren Online-Version dieser Biographie.
} 
angehörigen und die Hörer seiner Vorlesung auf Stuhlreihen im Hallraum [169] und im Freien [173]. Über das „Publikum“ wurde ein Aufnahmemikrofon mit einem Seilzug entlang gezogen. Als sich das Mikrofon verklemmte, versuchte Meyer, es zu lösen, wie auf dem Titelfoto zu sehen. Zur Klärung einiger Befunde regte er auch Modellmessungen an [316].

Ebenfalls mit Modellmessungen ließ Meyer untersuchen, welchen Einfluss die durch das Einbringen von Absorberproben in einen Hallraum zwangsläufig verletzte Diffusität auf die Messwerte des Schallabsorptionsgrades hat [167, 184]. In der letzteren Veröffentlichung, die aus der Diplomarbeit von W. Lauterborn hervorging, ist auch ein neues Verfahren zur direkten Anzeige der Nachhallzeit beschrieben, das erheblich schnellere Messungen erlaubt. Über Korrelationsmessungen in der Raumakustik, u. a. zur Diffusitätsmessung, ist in [317] bis [319] berichtet worden.

Um den Einfluss von Wand- und Deckenreflexionen auf den Raumeindruck von Zuhörern experimentell untersuchen zu können, wurden später im Reflexionsfreien Raum nach Vorarbeiten mit 10 Kanälen [320] 80 Lautsprecher so aufgehängt, dass sie einen Testplatz halbkugelförmig umgaben (Abbildung 11). Über eine Verstärkerbank und einen Kreuzschienenverteiler im Vorraum (das war die Versuchshalle) ließen sich die Lautsprecher einzeln ansteuern. Eine Tonbandschleife mit verschiebbaren Leseköpfen erlaubte es, ein Primärsignal zeitlich versetzt abzugreifen, sodass sich verzögerte, abgeschwächte (oder verstärkte) und in der Klangfarbe veränderte Reflexionen aus fast beliebigen Richtungen in bis zu 20 Kanälen gleichzeitig simulieren ließen. Über einen kleinen Hallraum konnten die Signale auch mit Nachhall versehen werden [178, 193].

Weil es bei diesen Untersuchungen um die subjektive Wahrnehmung der verschiedenen Schallsignale geht, kann man sie auch als Beiträge zur Hör- oder Psychoakustik ansehen [109, 178], [321] bis [327]. Auch Neuentwicklungen zur akustischen Messtechnik sind hier zu nennen [328] bis [331].

In mehreren Diplom- und Doktorarbeiten ließ Meyer den subjektiven Eindruck von mit der Lautsprecher-Halbkugel erzeugten 


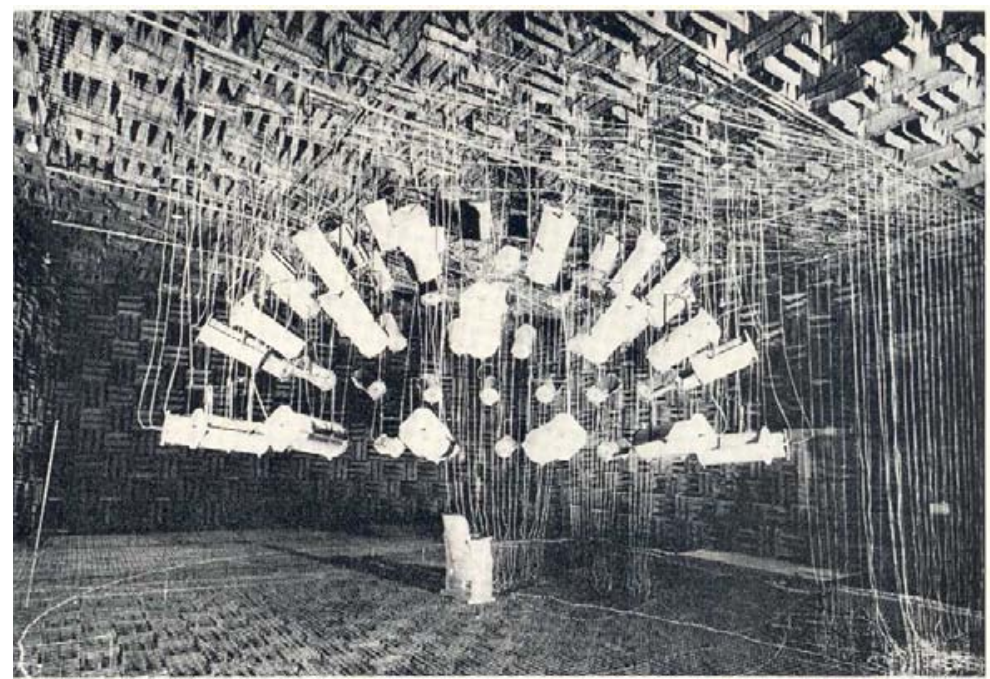

Abbildung 11: Lautsprecher-Halbkugel im Reflexionsfreien Raum.

synthetischen Schallfeldern untersuchen. In [332] ist beschrieben, wie sich der Räumlichkeitseindruck mit abnehmender Kohärenz einiger weniger Lautsprechersignale verbreitert. Zum Richtungshören war seit langem bekannt, dass in der Horizontalebene (links - vorn - rechts) insbesondere die Intensitäts- und Laufzeitunterschiede der beiden Ohrsignale relevant sind. Warum eine recht zuverlässige Schallquellenortung auch in der Median- oder Scheitelebene (vorn - oben - hinten) möglich ist, lässt sich dadurch nicht erklären. Eingehende Messungen dazu mit Kunstkopf- und Testpersonen-Aufnahmen ergaben, dass das Gehirn offenbar leichte Spektralveränderungen bekannter Signale wie Sprache verwertet $[333,334]$. In Schallfeld-Nachbildungen mit Direktschall und wenigen Rückwürfen ist der zugefügte Nachhall für den Richtungseindruck wichtig [335]. Auch die „kopfbezogene Stereophonie“ ließ Meyer eingehend untersuchen; mit ihr lassen sich durch Übersprechkompensation alle Einfallsrichtungen der Schallsignale mit zwei Stereolautsprechern wiedergeben, nicht nur die zwischen den Lautsprechern liegenden [336, 337, 338]. 
Zur Bauakustik ließ Meyer in seinem Institut mehrere Aspekte untersuchen: die Dämmung [339] bis [342] und Dämpfung von Körperschall, vor allem durch körnige Materialien wie Sand und Kies [98], [343] bis [346], die Körperschallausbreitung [101, 127, 128], [347] bis [349], den Schalldurchgang durch und die Abstrahlung von Platten [350] bis [352], auch für den Ultraschallbereich [353, 354], und es wurden auch hier neue Messverfahren entwickelt [355] bis [359].

Über Ultraschall (Frequenzbereich von $20 \mathrm{kHz}$ bis $1 \mathrm{GHz}$ ) hatte Meyer schon in Berlin gearbeitet [75, 85]. In Göttingen entwickelte er neuartige Versuche für sein „Praktikum für Fortgeschrittene" [100], und er nutzte Ultraschall gern für Modellversuche $[108,118,150]$. Ein Handbuchartikel von Meyer über Ultraschall erschien 1957 [130]. Auch über Hyperschall (Frequenzen über $1 \mathrm{GHz}$ ) wurde im III. Physikalischen Institut geforscht, und zwar in der Arbeitsgruppe von W. Eisenmenger [360]. Über Dämpfungsmessungen an Quarz wird in [180, 361] berichtet. Später nutzte Eisenmenger einen Forschungsaufenthalt bei den Bell Laboratories in den USA zu neuartigen Experimenten an Phononen in Supraleitern [362].

Ein wichtiges Forschungsgebiet war auch der Wasserschall (Hydroakustik) - in Fortführung der Arbeiten am HHI während des Krieges. Neben der Entwicklung neuer Messverfahren [363] bis [370] ließ Meyer neue Typen von Wasserschallabsorbern untersuchen, zunächst durch Energiedissipation in Polymeren [119, 171, 189, 371]. Die Hoffnung, mit den modernen Kunststoffen die früher entwickelten Absorber (mit speziellen Gummimischungen) zu verbessern, zerschlug sich, weil hohe Verlustfaktoren zwar leicht erreichbar sind, aber durch die Kramers-Kronig-Relationen (z. B. [199]) zwangsläufig mit starken Temperatur- und Frequenzabhängigkeiten des entsprechenden elastischen Moduls verknüpft sind, sodass sich besonders gute Absorber nur für einen engen Temperatur- und Frequenzbereich eignen. Als Alternative boten sich Strömungsverluste in engen Schlitzen an [168, 185, 188, 190, 372, 373, 374, 197]. Weil die dynamischen Eigenschaften viskoelastischer Stoffe, also ihre elastischen Moduln und deren Verlustfak- 
toren, auch für die Körperschalldämmung und -dämpfung in der Bauakustik und im Maschinenbau wichtig sind, machten Meyer und seine Mitarbeiter unabhängig von der Absorberentwicklung entsprechende Messungen mit meist neuen Verfahren [95, 375]. Außerdem liefern diese Daten Informationen über die Materialstruktur, insbesondere Relaxationen [143], [376] bis [381].

Die Schallausbreitung in (engen) wassergefüllten Rohren [261, 382] wurde ebenso untersucht wie die Streuung von Wasserschall an verschiedenen Objekten im dreidimensionalen Schallfeld des Tieftanks [383, 384, 385] bzw. im zweidimensionalen Feld in einem Flachtank [386, 387].

Recht intensiv wurden - großenteils finanziert durch den oben erwähnten „Englandvertrag“ - mit verschiedenen Verfahren in einem großen Frequenzbereich die Schallgeschwindigkeit und -dämpfung in Flüssigkeiten gemessen, vor allem in Wasser [388, 389, 390] und Elektrolytlösungen [391] bis [397], sowie einigen anderen Flüssigkeiten [398] bis [401]. In Zusammenarbeit mit Manfred Eigen aus dem Göttinger Universitätsinstitut für Physikalische Chemie erhärtete sich die Deutung dieser Vorgänge als verschiedene Formen von Relaxationen, die teilweise extrem schnell verlaufen (bis zu $10^{-9} \mathrm{~s}$ ) [402]; Eigen erhielt für die Erforschung der schnellen Reaktionen später den Nobelpreis für Chemie.

Schon in der Berliner Zeit untersuchten Meyer und sein Team den Einfluss von Gasblasen auf die akustischen Eigenschaften von Wasser [92, 114]. Diese Arbeiten wurden in Göttingen in großem Maßstab fortgesetzt - nicht nur im Hinblick auf den Blaseneinfluss auf Schallausbreitung und Dämpfung in Wasser [403] bis [406], sondern auch auf die Blasenentstehung [407] bis [410], ihre nichtlinearen Schwingungen [411] bis [416], Kavitation [125, 132, 141], [417] bis [428] und Sonolumineszenz [146, 147], [429] bis [434]. Diese Gebiete bearbeitete vor allem W. Lauterborn mit einer größeren Arbeitsgruppe. Die Bedeutung der Kavitation für die Oberflächenreinigung mit Ultraschall ließ Meyer in einem weiten Frequenzbereich eingehend untersuchen [435]. Einen Handbuchartikel über Gasblasen in Wasser schrieb Meyer 1957 [131], und 1962 hielt er einen Vortrag über „High-Intensity Sound in Liquids“ [163]. 
Auf Meyers Anregung hin befasste sich G. Sessler eingehend mit der Schallausbreitung in Gasen bei niedrigem Druck $p$ und hohen Frequenzen $f\left(f / p\right.$-Werte von $10^{6}$ bis $10^{11} \mathrm{~Hz} /$ atm, Frequenzen von 100 bis $600 \mathrm{kHz}$ ), wie sie von anderen Arbeitsgruppen noch nicht erreicht wurden. Dies ermöglichte der Einsatz von elektrostatischen Wandlern als Sender und Empfänger („Sell-Wandler“) [100, 436, 437]. Während bei 1-atomigen Gasen nur die „klassische“ Dämpfung durch innere Reibung und Wärmeleitung auftritt, kommen bei 2-atomigen Gasen Rotationsanregungen der Moleküle hinzu. Das wurde durch Messungen an Argon, Luft, Sauerstoff, Stickstoff und Wasserstoff bestätigt [133, 438, 439]. Bei den höchsten Frequenzen muss wegen der starken Dämpfung der Schallweg zwischen Sender und Empfänger kleiner als die freie Weglänge der Gasmoleküle sein (die Wandlermembranen ,spielen Ping-Pong mit den Gasmolekülen“). Die Theorie dafür haben Meyer und Sessler entwickelt [133]. Diese Publikation ist übrigens Meyers meistzitierte Veröffentlichung [3]. Bei mehratomigen Gasen kommen weitere Effekte hinzu, z. B. eine Relaxation bei $\mathrm{CO}_{2}$ [100] und eine seit frühen Untersuchungen (u. a. von Albert Einstein) unverstandene Dissoziation bei $\mathrm{NO}_{2} \rightleftharpoons \mathrm{N}_{2} \mathrm{O}_{4}$ [440], die Sessler nach seinen Messungen deuten konnte [441]. Weitere experimentelle Untersuchungen und theoretische Deutungen zur Ultraschallabsorption und -dispersion in mehratomigen Gasen und Dämpfen mit SellWandlern bei hohen Frequenz/Druck-Werten wurden in [442] bis [447] veröffentlicht. Sellwandler benötigen zur Linearisierung eine hohe Gleich-Vorspannung (z. B. [199]); später hat G. Sessler bei den Bell Laboratories in den USA zusammen mit seinem Mitarbeiter J.E. West die Elektretmikrofone erfunden, bei denen diese Vorspannung durch eine „eingefrorene“ Ladung auf speziellen Kunststofffolien als Dielektrikum erzeugt wird [517].

Als neues Gebiet startete Meyer in seinem Göttinger Institut die Strömungsakustik, die gegenseitige Beeinflussung von Schallausbreitung und Luft- oder Wasserströmungen. Zur Finanzierung der Arbeiten mit Luftströmungen schloss er einen weiteren Forschungsvertrag mit der US Air Force ab, die Wasserschallarbeiten liefen im Rahmen des „Englandvertrages“. Als An- 
fang 1960 der Instituts-Neubau nutzbar wurde, ließ Meyer im Keller einen Windkanal installieren, finanziert durch den „AmerikaVertrag“. Schon vorher veranlasste er Messungen der Schalldämpfung in einem kleinen Rechteckkanal mit turbulenter Luftströmung und verschiedenen Absorberbeschichtungen auf den breiteren Kanalwänden [138, 448]; die Resultate helfen bei der Dimensionierung von Schalldämpfern in Rohrleitungen. Eingehende spätere Untersuchungen hierzu sind in [449] bis [453] beschrieben. Einige Projekte befassten sich mit der Beeinflussung der Strömungsgrenzschicht in Luft durch Schall $[454,455]$ und durch Wandschwingungen [456]. Der Einfluss der Luftströmung auf die Schallabstrahlung, insbesondere auf die Impedanz einer Rohrmündung, ist in $[457,458]$ theoretisch und experimentell behandelt worden. Mit einer Schlierenoptik wurde die Luftschallausbreitung im Strömungskanal untersucht [459].

Mit relativ einfachen Laborexperimenten ließen sich die Strömungsgeräusche von Wasser in dünnwandigen glatten Rohren, Intermittenzen zwischen laminarer und turbulenter Strömung und der Einfluss von Querschnittsverengungen messen [155, 460]. Verbesserte Methoden zur Messung von Störungen der Grenzschicht in Wasser mit einer Hitzdrahtsonde sind in [461] beschrieben.

Meyers Assistent F. P. Mechel betreute die Arbeitsgruppe Strömungsakustik. Er wählte aber für seine Habilitation (1965) die theoretische Behandlung der Streuung von ebenen Wellen an Zylindern und Kugeln mit komplexer Impedanz. Teilergebnisse sind in $[462,463,464]$ veröffentlicht, die komplette Habilitationsschrift mit Hunderten gerechneter Streudiagramme war jedoch viel zu umfangreich für eine Zeitschriftenpublikation. Meyer lagen solche mathematisch-theoretischen Arbeiten nicht sehr; er hat sich aber mit eingestandener Mühe [1] in diese Materie eingearbeitet, um vor der Akademie der Wissenschaften in Göttingen darüber einen Vortrag zu halten, sodass die Akademie den Druck finanzierte [465]. Nach Mechels Weggang (1965) leitete D. Ronneberger die Gruppe Strömungsakustik sehr erfolgreich weiter [466] bis [469], in enger Zusammenarbeit mit dem Max-Planck-Institut für Strömungsforschung und den DLR-Instituten in Göttingen. 
Um die Vielseitigkeit der Arbeiten in Meyers Institut zu illustrieren, seien noch einige kleinere Projekte genannt. In zwei Examensarbeiten ließ Meyer die Schwingungen der Luftteilchen in der Nähe von Grenzflächen messen, und zwar vor absorbierenden Wänden [102] und in der Grenzschicht vor einer starren Wand [112], beide Male mit kleinen Schwebeteilchen und optischem Nachweis. Mit dem gleichen Verfahren ließ er die Schnelletransformation in der Druckkammer eines Trichterlautsprechers modellmäßig untersuchen [158]. - Mit Unterstützung aus der Industrie ist die Absorption von Ultraschall in tierischem Gewebe und in Kunststoffen gemessen worden [470]. - In einem Flachraum für Luftschall ermittelte ein Diplomand den Absorptionsgrad gebräuchlicher Schluckstoffe und Resonatoren für schrägen Schalleinfall im unteren kHz-Bereich [471]. - Seiner sehr tüchtigen Mitarbeiterin Marie-Luise Exner (später Beyer) [403, 339, 341, 344, 404] bot Meyer die Habilitation an, was sie aber ablehnte, um genügend Zeit für die Familie zu haben [1]. Frau Exner hat auch eine viel beachtete Arbeit zur Anwendung der Autokorrelations- und Fourieranalyse veröffentlicht [472]. - Die Deutsche Bundesbahn finanzierte Schwingungsmessungen an Eisenbahnschienen [473, 474]. K. Tamm und G. Kurtze erfanden 1954 ein Richtmikrofon mit einem dem Mikrofon vorgesetzten geschlitzten Rohr, wie es seitdem z. B. für Fernsehaufnahmen routinemäßig eingesetzt wird [475]. - An einem etwa 55-fach vergrößerten mechanischen Ohrmodell hat H.-G. Diestel akustische Messungen vorgenommen, die zu einem besseren Verständnis der Hydrodynamik der Cochlea beigetragen haben [476]. - W. Güth hat die Leitung von Schallimpulsen in Metallstäben theoretisch und schlierenoptisch untersucht und Verbindungen zur Riffelbildung auf Schienen und in Lagerschalen aufgezeigt [477]. - Die Firma Telefunken finanzierte Messungen zu den nichtlinearen Verzerrungen piezoelektrischer Tonabnehmer bei niedrigen Frequenzen, die sich als Folge der hohen mechanischen Eingangsimpedanz erwiesen [478]. - Mit Unterstützung verschiedener Institutionen wurden objektive und subjektive Lautstärkemessungen an vielen Geräuschen vorgenommen, um Diskrepanzen zu erklären [479]. - Finanziert vom Bundesministerium für Woh- 
nungsbau, wurde die Schalldämmung von verschiedenen Wandkonstruktionen anhand von Nachbildungen durch elektrische Filter untersucht, was den experimentellen Aufwand drastisch reduziert [480]. - M. R. Schroeder entwickelte ein neuartiges Verfahren zur Messung von Dielektrizitätskonstanten durch Aufspaltung entarteter Hohlraumresonanzen [481]. - Zwischen zwei Kugeln in einer stehenden Schallwelle gibt es anziehende oder abstoßende Kräfte (Bjerkneskräfte), die im Rahmen einer Diplomarbeit gemessen wurden [482]. - Dielektrische Eigenschaften verschiedener Baumaterialien sind vor allem hinsichtlich des Wassergehalts gemessen worden [483]. - Relaxationen erstrecken sich über einen breiten Frequenzbereich, sodass ihre Messung mit Sinussignalen über etwa vier Oktaven recht aufwändig ist. In [484] ist erprobt worden, wie sich die Relaxationsparameter aus der Verformung eines Rechteckimpulses direkt ermitteln lassen. - Mit einer kapazitiven Abtastmethode hat F. Eggers, ein engagierter Cellist, in seiner Diplomarbeit die Schwingungen einer Lautsprechermembran genauer gemessen als es vorher möglich war [485]. Für seine Dissertation hat er das Verfahren so ausgebaut, dass er die Korpusschwingungen eines Violoncellos exakt vermessen konnte und u.a. eine einfache Methode gefunden, den "Wolfston“ (eine unangenehme Resonanz) zu unterdrücken [486]. - K. Tamm und O. Weis haben Biegewellen (einschließlich der Nahfelder) mit spannungsoptischen Methoden untersucht [487, 488] und außerdem die verschiedenen Wellentypen in verlustbehafteten Festkörpern berechnet [489, 490]. - Im (auch für elektromagnetische Wellen) reflexionsfreien Raum ließ Meyer den Radar-Rückstreuquerschnitt von Metallzylindern messen [144].

Der Verbesserung der Diffusität in Räumen dienten Messungen zur Schallstreuung an Phasengittern, womit sich die spiegelnde Reflexion der Schallwellen an Wänden auffächern lässt [161]. M. R. Schroeder hat dieses Verfahren später optimiert [520]. - Die Lichtblitze eines Rubinlasers ließen sich durch Anregen der Longitudinalschwingungen des Rubinstabes in Resonanz synchronisieren [175]. - Bei der akustischen Planung von Räumen muss man oft versuchen, akustisch wirksame Bauelemente optisch zu „,verste- 
cken". Wie dies mit gitterartig durchbrochenen Paneelen möglich ist, wurde in einer Diplomarbeit theoretisch und experimentell untersucht [176]. - An einfachen Modellen poröser Schallabsorber aus parallelen Röhrchen („Rayleigh-Absorber“) ließ Meyer das Reflexions- und Durchlassverhalten messen [181].

Zwei Dozenten blieben Meyers Institut besonders lange treu: Heinrich Kuttruff und Wolfgang Eisenmenger (die übrigens eine lebenslange Freundschaft verbindet). Beide kamen als Diplomanden im September 1953 ins Institut. Kuttruff machte die schon auf S. 30 erwähnten Messungen zur Frequenzkurvenschwankung in Räumen [310], Eisenmenger befasste sich mit dem elektrokinetischen Effekt, aus dem sich ein neuartiges Ultraschall-Sondenmikrofon für Wasserschall ergab [496]. In seiner Doktorarbeit untersuchte Kuttruff mit optischen und akustischen Modellexperimenten die Erzeugung diffuser Schallfelder im Hallraum [497], außerdem behandelte er theoretisch und experimentell nicht-exponentiell abfallende Nachhallkurven [498]. Eisenmenger entwickelte eine Methode zur Messung der Oberflächenspannung von Flüssigkeiten durch parametrische Anregung stehender Kapillarwellen und konnte Literaturangaben für Wasser und wässrige Lösungen korrigieren und erweitern [499]. Kuttruff habilitierte sich 1962 mit Untersuchungen zum Zusammenhang zwischen Schwingungskavitation und Sonolumineszenz [432]. Eisenmenger entwickelte im Rahmen des „Englandvertrages“ eine neuartige Impulsschallquelle mit einer Spiralflachspule und eng anliegender Metallmembran, die durch Wirbelstromabstoßung nach Kondensatorentladung durch die Flachspule einen Druckimpuls in Flüssigkeiten bis zu $200 \mathrm{~atm}$ erzeugt [500]. Er habilitierte sich 1963 mit der Bestimmung von Stoßfrontdicken in Flüssigkeiten [501]. Beide, Kuttruff und Eisenmenger, verließen das Institut im September 1969, um Berufungen nach Stuttgart (Eisenmenger) bzw. Darmstadt - später Aachen - (Kuttruff) anzunehmen. Eisenmenger griff die Stoßwellenerzeugung mit dem Flachspulprinzip später wieder auf, um Nierensteine zu zertrümmern [523].

Länger noch als Kuttruff und Eisenmenger, seit September 1952, war Meyers wissenschaftlicher Mitarbeiter H.-W. Helberg 
am Institut tätig. Er hatte zunächst über Akustik gearbeitet [156, 382, 407, 408, 495], dann über Mikrowellenabsorber [172, 273, 275, 276, 278] und wandte sich später mehr der Festkörperphysik zu [279, 280, 281]. Meyer hatte schon früh erkannt, dass Helberg sehr gewissenhaft, zuverlässig und verantwortungsvoll arbeitete; er berief ihn zunächst auf eine Assistentenstelle und ab April 1964 auf die unbefristete Stelle als Kustos, später Akademischer Rat/Oberrat/Direktor. In dieser Funktion war Helberg bis zu seiner Pensionierung 1993 für die Instituts-Geschäftsführung verantwortlich, d. h. für die Mittelbewirtschaftung und das Personalwesen. Er führte aber während der ganzen Zeit seine Forschungsarbeiten vor allem über organische Leiter und Supraleiter fort.

\section{Vorlesungen}

Wenn auch die physikalische (vor allem akustische) Forschung den Hauptteil von Erwin Meyers (Berufs-)Leben ausmachte, so widmete er doch viel Zeit seinem "Kolleg“, einem viersemestrigen Zyklus zweistündiger Experimentalvorlesungen, die er immer aktualisierte. Die Grundlagen der Schwingungsphysik vermittelte er in der „Schwingungs- und Wellenlehre“, es folgten „Physikalische und Technische Akustik", „Elektronische Messtechnik" und schließlich "Physikalische Grundlagen der Hochfrequenztechnik". Meyer sprach immer sehr lebhaft und anschaulich, und vor allem legte er Wert auf die vielen Demonstrationsexperimente, die seine Vorlesungen zu unvergesslichen Erlebnissen machten. Meyers Vorlesungen waren deshalb sehr beliebt und immer gut besucht. Kennzeichnend für das Göttinger Institut war, wie schon mehrfach betont, die Vielseitigkeit der behandelten Probleme. Beeinflusst von der Gründungsidee des HHI hatte Meyer schon immer die Analogien zwischen elektrischen und mechanischen bzw. akustischen Schwingungen bei seinen Forschungen benutzt. Diese schon auf S. 16 erwähnte Zweigleisigkeit - Akustik und Hochfrequenztechnik - führte zu vielen wechselseitigen Anregungen, z. B. bei der Absorberentwicklung und bei Relaxationsuntersuchungen. Auch seine Vorlesungen und Vorträge profitierten hiervon. Einem mechanischakustischen Versuch folgte meist ein analoger elektrischer oder um- 
gekehrt. Im Bestreben, aktuelle Entwicklungen durch Vorlesungsexperimente zu veranschaulichen, ließ Meyer viele neue Demonstrationsversuche entwickeln. Einige wurden publiziert: zur parametrischen (oder rheolinearen) Verstärkung und Anregung [151], beides Verfahren, die erst kurz zuvor praktische Bedeutung erlangt hatten und deshalb ins Vorlesungsprogramm aufgenommen wurden [199], zur Wanderwellenverstärkung [491], zur Impulskompression [492], zum Schallstrahlungsdruck [493] und zu Stoßwellen [494]. Meyers Vorlesungstermin war immer der Freitag, von $9^{15}$ bis $10^{45}$ Uhr. Die Versuche wurden von H. Henze (siehe Seite 16) und wenn nötig seinen Werkstatt-Mitarbeitern vorher aufgebaut. Am Donnerstag vormittag besprach Meyer mit Herrn Henze alle Versuche für den nächsten Tag eingehend, eine Art Generalprobe. Ein Foto zeigt Abb. 12.

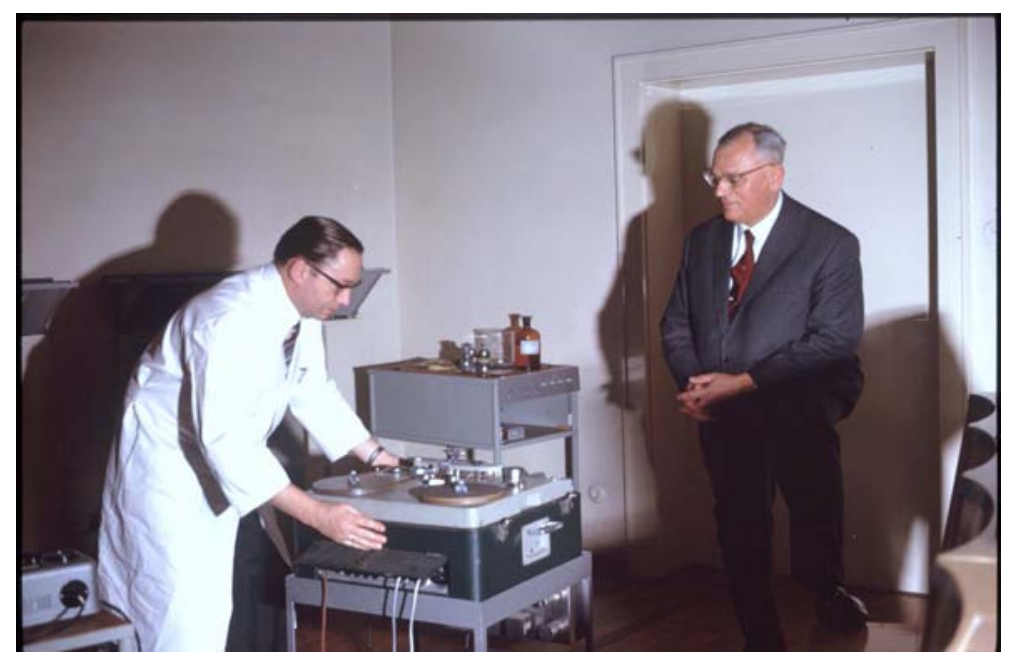

Abbildung 12: Erwin Meyer und Heinrich Henze (links) im Hörsaal bei der Vorlesungsvorbereitung für die „Elektronische Messtechnik“ am 25. Juni 1966.

Meyer, der manuell nicht sehr geschickt war, ließ Herrn Henze alle Versuche selbst vorführen. Dass ein Versuch nicht gelang, kam äußerst selten vor. Abb. 13 zeigt Meyer während seiner Vorle- 
sung und Abb. 14 nach der Vorlesung beim "Testieren“. Einmal im Semester mussten damals die Studenten das Studienbuch ihren Professoren vorlegen, die durch ihre Unterschrift bestätigten, dass die belegte Vorlesung auch besucht wurde. Später wurde die Testatpflicht abgeschafft, sie war schließlich nur noch eine Formalität. Man sieht, dass Meyer das Testat eigenhändig gab. Viele Professoren ließen sich Faksilime-Stempel ihrer Unterschrift anfertigen und die Stempel oft auch nur von ihren Assistenten abdrucken.

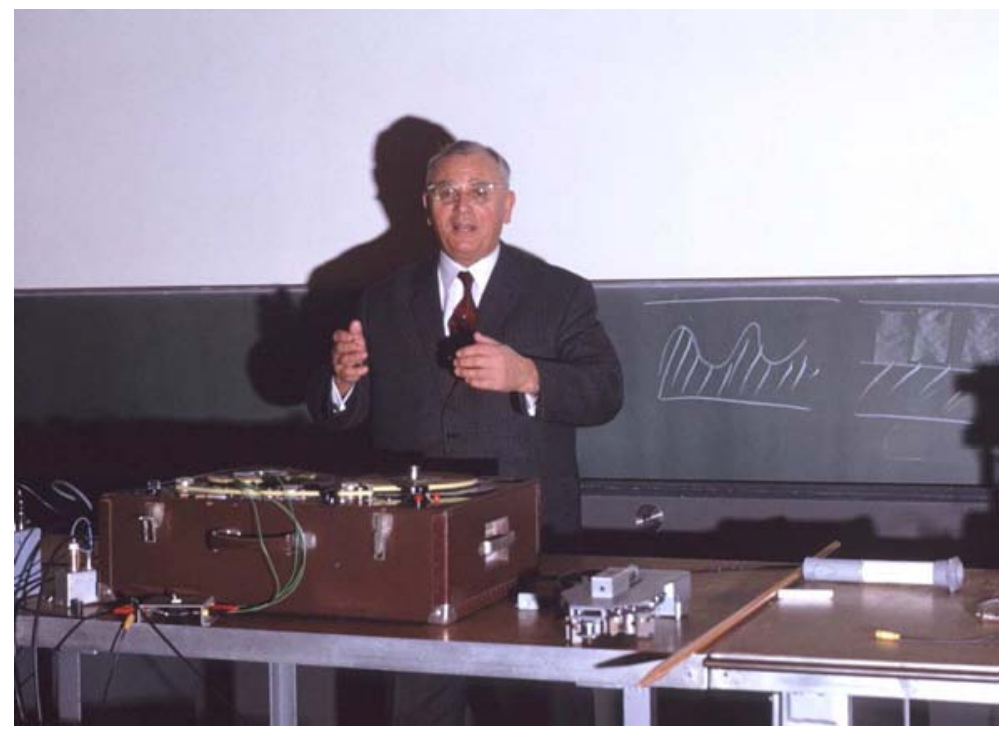

Abbildung 13: Erwin Meyer während seiner Vorlesung am 25. Februar 1966.

Mehrfach waren Verlage an Meyer herangetreten und hatten angeregt, seine Vorlesungen als Bücher herauszugeben. Dem Drängen gab Meyer erst nach, als er seinen letzten Vorlesungszyklus begann. Ihm war klar, dass er die Bücher nicht allein schreiben konnte-zum einen war er mit der Institutsleitung voll ausgelastet, zum anderen lag ihm die „Pingeligkeit“ nicht, die das Schreiben der Manuskripte forderte. Die Routinearbeiten bei der Herausgabe der Acustica erledigte damals E.-G. Neumann, der dadurch 


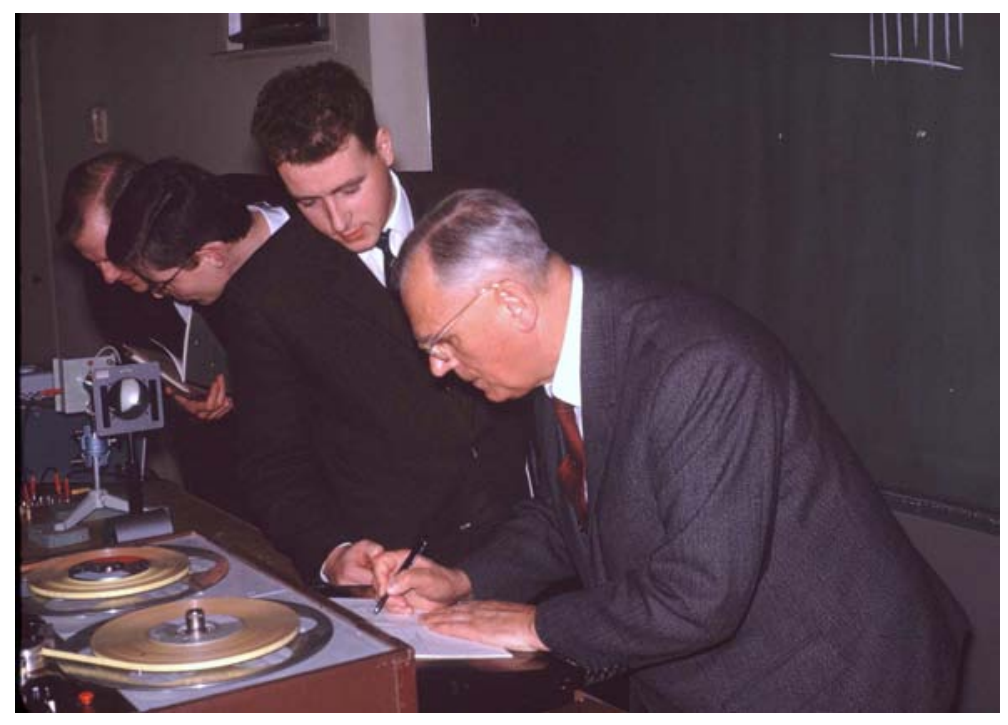

Abbildung 14: Erwin Meyer beim Testieren nach der AkustikVorlesung am 25. 2. 1966. Der Student neben ihm ist B. Wagener, der später Leiter des Rechenzentrums der Universität Oldenburg wurde.

recht versiert im Formulieren war. Meyer trug Neumann deshalb an, die Manuskripte für die vier Bücher zu schreiben, beginnend mit dem Band „Physikalische und Technische Akustik". Neumann erkannte aber bald, dass die vorlesungsfreie Zeit nicht ausreichte, ein druckreifes Manuskript mit der nötigen Sorgfalt zu erstellen. Deshalb versicherte sich Meyer für die weiteren Bände anderer Mitarbeiter. So entstanden drei Bücher, die "Akustik“ in mehreren Auflagen, auch in englischer Übersetzung [183, 194, 198, 199]. Ein Buch über „Elektronische Messstechnik“ war in Arbeit, wurde aber nicht vollendet. Das Buch „Schwingungslehre“ hat der Autor dieser Schrift - die Zeit-Vorgabe des Verlags weit überschreitend nach Meyers Tod abgeschlossen, sodass es Meyers letzte Publikation wurde. Diese Bücher werden von vielen Dozenten auch wegen der Versuchsbeschreibungen sehr geschätzt.

Neben Meyers Vorlesungszyklus hielten die am Institut tätigen Dozenten regelmäßig (meist einstündige) Vorlesungen über Spezi- 
althemen, stets durch Experimente aufgelockert. Der Hörsaal war auch Treffpunkt für das wöchentliche Hauskolloquium, in dem jeder Diplomand und Doktorand mindestens einmal während seiner Examensarbeit einen Vortrag über ein vorzugsweise (etwas) fachfremdes Thema halten musste, das anschließend meist lebhaft diskutiert wurde. Ein das Kolloquium organisierender Assistent führte eine Liste mit Themenvorschlägen, vor allem über neuere Entwicklungen in der Physik; die Vortragenden konnten aber durchaus auch eigene Gebiete auswählen, etwa aus ihren Hobbys (Segelfliegen, Bumerangs etc.) und die zugehörige Physik erläutern. Die Vorträge sollten einerseits die Nervosität abbauen, vor einem kritischen (aber loyalen) Publikum zu sprechen, andererseits trainieren, sich in vernünftiger Zeit in ein neues Thema so weit einzuarbeiten, dass man darüber mehr als nur Oberflächliches berichten konnte. Das Programm war nicht starr, sodass auch strittige Aspekte des eigenen Gebietes diskutiert werden oder Besucher ihr eigenes Arbeitsgebiet vorstellen konnten. Für die Vortragenden waren die Kolloquiumsvorträge ein gutes Übungsfeld für spätere Vorträge auf Fachkongressen, und für die Zuhörer fast immer interessante Erweiterungen ihres physikalischen Wissens. Sie gaben auch Anregungen für eigene Arbeiten, so hat P. Wille, der damals die Wasserschallgruppe (und später eine Ozeanographische Forschungsanstalt in Kiel) leitete, in Analogie zu Mikrowellengeräten aspektunabhängige Sonarreflektoren [502] und ein strömungsgünstiges Richthydrofon [503] entwickelt. 



\section{Schlussbemerkungen}

Erwin Meyer arbeitete immer sehr intensiv, nicht nur im Institut, sondern auch noch im Wohnzimmer zu Haus, wo er seinen Schreibtisch stehen hatte (ein häusliches Arbeitszimmer hatte er sich nicht eingerichtet). So saß er abends und am Wochenende oft stundenlang mit dem Rücken zum eigentlichen Wohnbereich, bis seine Frau den Schreibtisch umdrehte, damit sie ihren Mann auch mal von vorn sehen konnte.

Meyer wurde zum Ende des Sommersemesters 1967 emeritiert, nachdem er das 68. Lebensjahr vollendet hatte. Da noch kein Nachfolger am Institut war, konnte er sich noch für ein volles Jahr „selbst vertreten“, d. h. die Institutsleitung bis Oktober 1968 fortsetzen. Er hatte ein sicheres Gespür für „gute Leute“, sodass viele wichtige Positionen weltweit von seinen Schülern besetzt wurden. Einen seiner profiliertesten Schüler, Manfred R. Schroeder, gewann man dann auch für seine Nachfolge (ab Herbst 1969; in der Zwischenzeit leitete H. Kuttruff das Institut). Schroeder war nach seiner Promotion zu den Bell Laboratories in die USA gegangen und hat vor allem zur Raumakustik und zur Physikalischen Sprachforschung in den USA und weiterhin auch in Göttingen bahnbrechende Beiträge geleistet, die den guten Ruf des Instituts weiter festigten. Der Autor dieser Schrift wurde 1994 zu einem Vortrag auf einer der halbjährlichen Tagungen der Acoustical Society of America von dem Sitzungsleiter mit den Worten angekündigt „Dieter comes from the legendary Third Physical Institute in Göttingen“. Hätte Schroeder den Ruf nach Göttingen abgelehnt, hätten Kuttruff und Eisenmenger auch hier bleiben können; sie standen gemeinsam als „Doppelspitze“ an zweiter Stelle auf der Berufungsliste.

Manche von Meyers frühesten Göttinger Studenten, die noch von den Kriegserlebnissen geprägt und vorwiegend an praktischen Dingen interessiert waren, schnitten in den Theorieprüfungen nicht sonderlich gut ab. Der Theoretiker Richard Becker, bekannt durch gute deutschsprachige Lehrbücher, aber international weniger profiliert, gewann dadurch den Eindruck, dass in Meyers Institut keine ernst zu nehmende Physik betrieben wurde und ließ Meyer dies auch spüren. Das änderte sich, als Becker auf einer Infor- 
mationsreise durch die USA mehrfach zu hören bekam, dass er als Göttinger Physikprofessor ja wohl für Erwin Meyer arbeiten müsse [234]. Nach Beckers Rückkehr erzählte er dies seinem Kollegen Meyer freimütig und revidierte seine Meinung über dieses Institut nach einem ausführlicheren Gespräch, zumal bald auch die Prüfungsleistungen der Studenten besser wurden.

H. Kuttruff schrieb 1969 zu Meyers 70. Geburtstag „E. Meyers zahlreiche Schüler kennen ihn als einen temperamentvollen und humorvollen Institutsdirektor, von dem zwar stets die entscheidenden Impulse ausgingen, dem aber autoritäres Auftreten und Kleinlichkeiten jeder Art gleichermaßen fremd sind" [241].

Meyers heitere Grundstimmung zeigte sich nicht zuletzt in vielen lockeren Redewendungen. Wenn seine Studenten ihm gute Arbeitsergebnisse präsentierten, sagte er meistens „fein, fein“, oft auch ,à la bonne heure“. Als jemand die herausragende Bedeutung seines Forschungsresultats selbst nicht erkannte, meinte Meyer darüber spöttisch zu einem Assistenten „die dümmsten Bauern ernten die dicksten Kartoffeln“. Wenn ihn etwas überrascht hatte, sagte er gern „da brat mir einer 'nen Storch“ oder „es sind schon Nachtwächter bei Tage gestorben“. Die Lösung experimenteller Probleme durch geschicktes Improvisieren kommentierte er gern mit „der Mensch kann dumm sein wie er will, er muss sich nur zu helfen wissen". Wenn ihm ein Name nicht gleich einfiel, schnippte er mit den Fingern und sagte „der Herr Dingsperlingsel“. Bei anstehenden Entscheidungen liebte er kein langes Abwägen, sondern drängte „da wird nicht lange gefackelt“, oder auch ,,jetzt kommt der entscheidende Moment, wo der Affe ins Wasser springt". Das war dann eine Entscheidung „par ordre de Mufti“. Ermahnend sagte er oft „mein lieber Freund und Kupferstecher". Er freute sich „wie ein Ietsch" (schreibt man das so?), und er würde sich „lieber ein Monogramm in den Hintern beißen" als etwas ihm zuwider Laufendes zu tun.

Nach den nicht ganz vollständigen Sekretariatsunterlagen wurden an Meyers Göttinger Institut während seiner Dienstzeit etwa 150 Diplomarbeiten, 90 Dissertationen und 10 Staatsexamensarbeiten sowie 9 Habilitationen erfolgreich abgeschlossen. Mit seinen 
vielen Besuchern führte Meyer intensive Gespräche, bevor er selbst oder einer seiner Assistenten sie zu einem Rundgang durch die Labors einlud. Seit den frühen 1950er Jahren arbeiteten stets auch Gastforscher aus dem Ausland für einige Monate oder Jahre im Institut.

Meyer pflegte rege Kontakte zu den Kollegen im In- und Ausland, um sich über neue Entwicklungen auf dem Laufenden zu halten. Die kollegiale Verbundenheit auch während des Krieges, als direkte Kontakte nicht möglich waren, zeigte sich in gelegentlichem Briefwechsel, den der damalige Präsident der Acoustical Society of America, F.A. Firestone, in der Verbandszeitschrift abdruckte [211, 212]. Auch zu den Kollegen in der DDR pflegte Meyer den Kontakt, vor allem zum „Institut für Technische Akustik" der damaligen TH Dresden. Dessen Leiter, Prof. W. Reichardt, kam mehrmals mit einigen Mitarbeitern nach Göttingen, solange die DDR-Führung solche Reisen noch erlaubte, und Meyer mit seinen Mitarbeitern besuchte wiederholt das Dresdener Institut. Meyer fuhr regelmäßig zu wichtigen Kongressen, vor allem den ICA-Kongressen der International Commission for Acoustics (alle drei Jahre seit 1953) und zu vielen Tagungen der Deutschen Physikalischen Gesellschaft, wovon sich ab 1970 die etwa jährlichen DAGA-Tagungen der Deutschen Arbeitsgemeinschaft (später: Gesellschaft) für Akustik abspalteten. Meyer war an der Gründung der ICA und der DAGA wesentlich beteiligt. Er legte auch Wert darauf, dass seine Mitarbeiter Kongresse besuchten und dort ihre Forschungsergebnisse vortrugen. Der International Commission for Acoustics hatte Meyer angeboten, den Dritten ICAKongress vom 1. bis 8. September 1959 in Deutschland abzuhalten, und zwar in Stuttgart. Meyer war dort der lokale Tagungsleiter. Sein Schlusswort beim zweiten und die Begrüßungsansprache beim dritten ICA-Kongress sind in den Kongressunterlagen abgedruckt [124, 145].

Beliebt waren die oft mehrtägigen wissenschaftlichen Exkursionen im Universitäts-eigenen Omnibus zu anderen Forschungsinstituten und wichtigen Firmen, an denen alle Institutsangehörigen teilnehmen konnten. 
Meyer liebte es durchaus, Feste im Kreis seiner Mitarbeiter zu feiern. Die Veranstaltungen zu den Institutserweiterungen wurden schon erwähnt, aber er lud auch zu den alljährlichen Weihnachtsfeiern im Hörsaal und alle fünf Jahre zu seinen runden Geburtstagen die Institutsangehörigen zu Tanzfesten in angemietete Säle der Göttinger Gastronomie ein, wo es immer ein ansprechendes Festprogramm gab, das (scheinbar ohne Meyers Wissen) von seinen Mitarbeitern vorbereitet war. Davon zeugen unter anderem etliche "Sonderausgaben“ der Zeitschrift „Ac(o)ustica“ mit manchmal bissigem Humor, aber stets pfiffig formuliert und aufgelockert durch gekonnte Karikaturen oder Fotomontagen.

Meyer hatte eigentlich keine Hobbys. Sein Lebenswerk war die wissenschaftliche Leistung. Er litt sichtlich darunter, die Institutsleitung 1968 abgeben zu müssen, behielt aber dort noch ein Arbeitszimmer.

Er liebte ausgedehnte Wanderungen, besonders in den Bergen, in früheren Jahren auch das Skilaufen, und genoss die Natur. Nach dem alljährlichen Winterurlaub am Semesterende, oft im Engadin, kam er extrem braun gebrannt zurück, sodass seine kleine Enkelin sich einmal beim Abholen am Bahnhof vor dem „schwarzen Mann“ ängstigte und schreiend auf Mamas Arm rettete. Meyers Kollege Flammersfeld stellte dann auch treffend fest: „Herr Meyer, Sie sind ja ein Pigmentprotz".

Erwin Meyer war eine beeindruckende Persönlichkeit und besaß eine natürliche Autorität, der sich niemand entziehen konnte, der mit ihm zusammenkam. Er genoss als bedeutender Akustiker weltweites Ansehen, war überaus beliebt und wurde vielfach geehrt. Schon 1933 verlieh ihm die Georg-August-Universität Göttingen „für seine Verdienste um die Weiterentwicklung des elektrischen Nachrichtenwesens" die "Gauss-Weber-Denkmünze“, und 1961 in Würdigung seiner wissenschaftlichen Verdienste um die Nachrichtentechnik die Gauss-Weber-Medaille. 1950 nahm ihn die Göttinger Akademie der Wissenschaften als Ordentliches Mitglied auf [250], 1957 ernannte ihn das Institute of Radio Engineers (IRE) zum „Senior Member“, 1958 verlieh ihm die Technische Universität Berlin „die Akademische Würde Doktor-Ingenieur Ehren 
halber" (Dr.-Ing. E. h.) [217, 218, 142]. Zu seinem 60. Geburtstag gab die Acustica ein Sonderheft mit 16 Beiträgen von Schülern und Kollegen heraus, alle mit dem Vermerk „Herrn Prof. Dr. phil. Dr.-Ing. E. h. E. Meyer zum 60. Geburtstag gewidmet“, bzw. „Dedicated to Professor Dr. Dr. E. Meyer on his 60th Birthday“ [222]. 1964 ehrte ihn die Acoustical Society of America mit dem Wallace Clement Sabine Award „For internationally recognized contributions to all aspects of architectural acoustics" (für die Festschrift ließ er das Atelierfoto in Abbildung 1 anfertigen) [233, 234, 238].

Die British Acoustical Society zeichnete Meyer 1969 mit der erstmals verliehenen Lord Rayleigh-Medaille aus. Mit seiner in [195] abgedruckten „dinner address“ beim Festmahl nach der Verleihung lockerte er die bis dahin etwas trübe Stimmung spürbar auf. Meyer liebte keine steifen Formalitäten. Lange hatte er nach etwas Heiterem für seine Tischrede gesucht, bis er zufällig auf dem Titelblatt der BILD-Zeitung einen Bericht über Messungen des schon recht alten Vern O. Knudsen in seinem Hallraum in Los Angeles fand, der die Schallabsorption von Frauen mit Miniröcken und normal langen Röcken verglichen hatte - natürlich absorbierten die Miniröcke weniger stark. Meyer stellte die Frage an den Anfang, was Miniröcke und Tischreden miteinander verbinde und gab auch gleich die Antwort: beide sollten "short and attractive" sein, bevor er kurz den Inhalt des amüsanten Zeitungsberichts erläuterte und seinen Dank an die British Acoustical Society aussprach. Danach gab es plötzlich wieder lebhafte Gespräche über diese Messungen [1]. Knudsen hatte Meyers Verdienste anlässlich seines 65. Geburtstages eingehend gewürdigt [231], insbesondere seinen Vortrag beim vierten ICA-Kongress in Kopenhagen 1962 mit einem Überblick über neuere akustisch-elektromagnetische Analogien [160].

In Deutschland gab es damals noch die studentische Tradition der Fackelzüge. Mit ihnen ehrten die Studenten besonders geschätzte Professoren, wenn es einen besonderen Anlass gab. Erwin Meyer wurde diese Ehrung zweimal zuteil: zu seinem 65. Geburtstag am 21. Juli 1964 [232] und am 18. Oktober 1968, nachdem er die Institutsleitung abgegeben hatte [239, 240]. 
Meyer erfreute sich einer sehr robusten Gesundheit. Nur selten war er leicht erkältet, was ihn aber wenig beeinträchtigte, Kopfschmerzen kannte er gar nicht. Als Folge eines Medikaments gegen Bluthochdruck bekam er 1964 eine Gelbsucht, die ihn zu seinem einzigen Krankenhausaufenthalt zwang. In dieser Zeit wollte er eigentlich in die USA reisen, um den erwähnten Wallace Clement Sabine Award zu empfangen, den dann stellvertretend M. R. Schroeder für ihn entgegen nahm. Von der Gelbsucht erholte Meyer sich rasch. Bedenklicher war ein Herzanfall während einer Dienstreise nach England, den er und seine ihn begleitende Frau der Familie verschwiegen. Ein leichter Herzinfarkt nach seiner Emeritierung fesselte ihn mehrere Wochen ans Bett, er erholte sich aber auch davon wieder gut. Sein Arzt hatte keine Bedenken, als er im Frühjahr 1972 wieder in die Berge reisen wollte, und zwar allein, weil sich seine Frau für diese Zeit einige Renovierungen im Haus vorgenommen hatte. Sein plötzlicher Tod durch einen Herzinfarkt während dieses Urlaubs im März 1972 in Pontresina (Schweiz) kam für alle völlig überraschend und riss ihn aus immer noch aktivem Schaffen, vor allem für akustische Beratungen, z. B. für das nach Kriegszerstörung wieder aufgebaute Nationaltheater in Bukarest (Rumänien), eine Aufgabe, die er zusammen mit H. Kuttruff übernommen hatte. Nach Meyers Tod hat Kuttruff dieses Projekt allein zu Ende geführt. Die Einweihung des neuen Theaters war im Jahr 1973.

In Nachrufen würdigten Meyers Kollegen sein vielfältiges Wirken [243, 244, 245]. Zu seinem 100. Geburtstag im Jahre 1999 ehrte ihn die Stadt Göttingen durch eine Marmor-Gedenktafel an seinem früheren Haus [249, 251], Abbildung 15 (die Jahreszahlen bezeichnen die Zeit, während der er dort wohnte).

Eine Kurzfassung dieser Biografie wurde bei der DAGA 2007 in Stuttgart vorgetragen [253]. Dort gab auch A. Kohlrausch einen Überblick über Meyers frühe Arbeiten zur Psychoakustik [252]. 


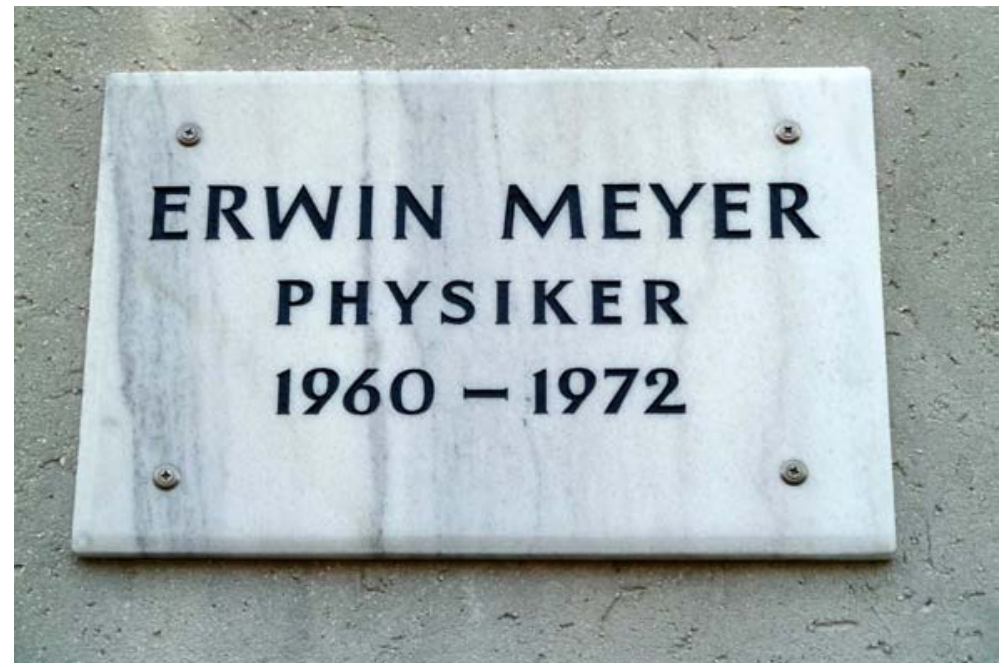

Abbildung 15: Gedenktafel für Erwin Meyer an seinem Wohnhaus in Göttingen, Otfried-Müller-Weg 6 . 



\section{Literaturverzeichnis}

[1] Persönliche Mitteilung von Erwin Meyer.

[2] Persönliche Mitteilung von Manfred R. Schroeder.

[3] Persönliche Mitteilung von Gerhard Sessler.

(Die folgende Liste enthält von [4] bis [199] alle dem Verfasser dieser Biographie bekannt gewordenen Veröffentlichungen von Erwin Meyer in chronologischer Reihenfolge (auf einige weniger wichtige Zitate wird nicht im Text verwiesen). Publikationen über Erwin Meyer sind danach aufgelistet: [200] bis [253], dann folgen ausgewählte Veröffentlichungen aus dem DPI [254] bis [503], sowie einige sonstige Arbeiten ab [504].

[4] Meyer, Erwin: Ponderomotorische Wirkungen von Tonwellen auf resonierende Membranen. Annalen der Physik, Vierte Folge, Band 71 (1923) 567-590 (gekürzte Breslauer Dissertation).

[5] Meyer, E[rwin]; Waetzmann, E[rich]: Über den Grad der Dämpfung der Ohrresonatoren. Die Naturwissenschaften, Bd. 13, Heft 13 (27.3. 1925) 268-271.

[6] Meyer, Erwin: Über das stereoakustische Hören. Elektrotechnische Zeitschrift (ETZ) 46(22) (28. Mai 1925) 805-807.

[7] Meyer, Erwin: Zwei Beispiele zweidimensionaler elektrostatischer Kraftlinienbilder. Mathematische Annalen 93(1) (Dezember 1925) 157-160.

[8] Meyer, Erwin: Die Prüfung von Lautsprechern. Elektrische Nachrichtentechnik (ENT) 3(8) (August 1926) 290-296.

[9] Meyer, Erwin: Über die Messung von Schallfeldern. Zeitschrift für technische Physik 7(12) (Dezember 1926) 609-616. 
[10] Meyer, Erwin: Über die Messung der Geschwindigkeitsamplitude und der Druckamplitude in Schallfeldern. Elektrische Nachrichtentechnik (ENT) 4(2) (Februar 1927) 86-90. Vorgetragen auf der 89. Jahresversammlung Deutscher Naturforscher und Ärzte, Düsseldorf, 19. bis 26. September 1926.

[11] Meyer, Erwin: Beiträge zur Untersuchung des Nachhalles. Elektrische Nachrichtentechnik (ENT) 4(3) (März 1927) 135-139. Vorgetragen auf der 89. Jahresversammlung Deutscher Naturforscher und Ärzte, Düsseldorf, 19. bis 26. September 1926.

[12] Grützmacher, Martin; Meyer, Erwin: Eine Schallregistriervorrichtung zur Aufnahme der Frequenzkurven von Telefonen und Lautsprechern. Elektrische Nachrichtentechnik (ENT) 4(5) (Mai 1927) 203211.

[13] Meyer, Erwin: Über die nichtlineare Verzerrung von Lautsprechern und Fernhörern. Elektrische Nachrichtentechnik (ENT) 4(12) (Dezember 1927) 509-515.

[14] Meyer, Erwin: Das Gehör. In: H. Geiger und Karl Scheel: Handbuch der Physik, Bd. 8, Akustik. Verlag von Julius Springer, Berlin 1927, Kapitel 11, S. 477-543.

[15] Katz, F. G.; Meyer, E[rwin]: Messungen über die Intensitätsverhältnisse bei der zur qualitativen Hörprüfung verwandten kontinuierlichen Tonreihe. Ein Beitrag zur Kritik der qualitativen Hörprüfung nach Bezold-Edelmann. I. Klinischer Teil von Dr. Katz (S. 316-324); II. Physikalischer Teil von Dr. Erwin Meyer (S. 325-328). Zeitschrift für Hals-, Nasen- und Ohrenheilkunde 19 (1928) 316-328.

[16] Meyer, Erwin; Just, Paul: Zur Messung von Nachhalldauer und Schallabsorption. Elektrische Nachrichtentechnik (ENT) 5(8) (August 1928) 293-300. Referat: Die Schalltechnik 2(1) (Januar 1929) 15.

[17] Meyer, Erwin: Über eine einfache Methode der automatischen Klanganalyse und der Messung der Nichtlinearität von Kohlemikrophonen. Elektrische Nachrichtentechnik (ENT) 5(10) (Oktober 1928) 398-403. Referat: Die Schalltechnik 2(1) (1929) 15.

[18] Meyer, Erwin: In: Ernst Feyerabend, Hugo Heidecker, Franz Breisig, August Kruckow (Herausgeber): Handwörterbuch des elektrischen Fernmeldewesens, Verlag von Julius Springer, Berlin 1929. Erster 
Band (A-K), VIII + 830 S., Zweiter Band (L-Z), IV + 903 S., Beiträge zu folgenden Stichworten: Geräusch (Bd. 1, S. 542), Hörfläche (646), Hörsamkeit (646), Hörtheorie (646-647), Klang (770), Nachhall (Band 2, S. 128), Ohr (184), Raumakustik (273), Richtungshören (299-300), Schallfeld (371-372), Schallmessung (372-375), Sekundäre Klangerscheinungen (465-466), Sprache (524-525, mit H[ans] Salinger), Ton (673-674), Unterschiedsempfindlichkeit für Lautstärken (715-716), Unterschiedsempfindlichkeit für Tonhöhen (716), Vokale (783).

[19] Meyer, Erwin: Über die Wirkungsweise des Kathodophons. Elektrische Nachrichtentechnik (ENT) 6(1) (Januar 1929) 17-21. Referat: Die Schalltechnik 2(3) (Mai 1929) 47.

[20] Meyer, Erwin; Just, Paul: Über Messungen an schalldämpfenden Materialien. Telegraphen- und Fernsprechtechnik (TFT) 18(2) (1929) 40-45.

[21] Meyer, Erwin; Just, Paul: Ein neuer Schallisolationsmesser.

Die Schalltechnik 2(3) (Mai 1929) 33-38.

[22] Meyer, Erwin; Just, Paul: Frequenzkurven von elektrischen Tonabnehmern und mechanischen Grammophonen. Elektrische Nachrichtentechnik (ENT) 6(7) (Juli 1929) 264-268.

[23] Meyer, Erwin; Just, Paul: Messung der Gesamtenergie von Schallquellen. Zeitschrift für Technische Physik 10(8) (August 1929) 309316.

[24] Meyer, Erwin: Messung der Intensität des Schalles. In: MüllerPouillet, Lehrbuch der Physik, 11. Aufl., 1. Band, 3. Teil: Akustik. Friedr. Vieweg \& Sohn, Braunschweig 1929, S. 350-379.

[25] Meyer, Erwin: Schallisolation und Schallabsorption. Verfahren zu ihrer Messung. Zeitschrift des Vereins Deutscher Ingenieure (VDI) 74(9) (1. März 1930) 273-279.

[26] Meyer, Erwin: Messung und Begutachtung von Schallisolierstoffen. Die Schalltechnik 3(2) (März 1930) 23-27. Vortrag, gehalten auf der Schwingungstagung des VDI in Berlin am 10.3.1930.

[27] Buchmann, Gerhard; Meyer, Erwin: Eine neue optische Meßmethode für Grammophonplatten. Elektrische Nachrichtentechnik (ENT) 7(4) (April 1930) 147-152. 
[28] Meyer, Erwin: Die Messung von Hörschwellen mit dem Überlagerungssummer. Zeitschrift für Hals-, Nasen- und Ohrenheilkunde 27 (1930) 418-422. Verhandlungen der Gesellschaft deutscher Hals-, Nasen- und Ohrenärzte (e.V.) auf der X. Jahresversammlung in Basel, 5.-7.6. 1930 .

[29] Meyer, Erwin: Ein neues automatisches Verfahren der Nachhallmessung. Zeitschrift für technische Physik 11(7) (Juli 1930) 253-259. Vorgetragen auf der Professorenkonferenz des Reichspostzentralamtes, April 1930.

[30] Meyer, Erwin: Grundlegende Messungen zur Schallisolation von Einfach-Trennwänden. Sitzungsberichte der Preußischen Akademie der Wissenschaften, Physikalisch-Mathematische Klasse IX (12. März 1931) 166-181.

[31] Meyer, Erwin: Schallschutz in Hochbauten. Zeitschrift des Vereins Deutscher Ingenieure (VDI) 75(18) (2. Mai 1931) 563-566.

[32] Buchmann, Gerhard; Meyer, Erwin: Über den Frequenzbereich des Nadelgeräusches bei Schallplatten. Elektrische Nachrichtentechnik (ENT) 8(5) (1931) 218-223.

[33] Meyer, Erwin: Die Klangspektren der Musikinstrumente. Zeitschrift für technische Physik 12(12) (Dez. 1931) 606-611. Vorgetragen auf dem 7. Deutschen Physiker- und Mathematikertag in Bad Elster, 13. bis 18. September 1931.

[34] Meyer, Erwin: Analysis of Noise and Musical Sounds. Proceedings of the Physical Society (1931) 53-61. [So von Meyer in Publikationslisten angegeben. In Proceedings of the Physical Society (London) nicht nachzuweisen].

[35] Meyer, Erwin; Buchmann, Gerhard: Die Klangspektren der Musikinstrumente. Sitzungsberichte der Preußischen Akademie der Wissenschaften 1931, XXXII. Sitzung der Physikalisch-Mathematischen Klasse, 5. 11. 1931, S. 735-778.

[36] Meyer, Erwin: Raumakustische Messungen an Sperrholz. Sperrholz - Organ des Verbandes der deutschen Sperrholzfabrikanten e. V. 4(1/2) (Januar 1932) 135-138.

[37] Meyer, Erwin: Schalltechnische Eigenschaften des Flachglases. Glastechnische Berichte 10(4) (April 1932) 200-204. 
[38] Meyer, Erwin; Willms, Walter: Geräuschmessungen an Kraftfahrzeugen. Zeitschrift des Vereins Deutscher Ingenieure (VDI) 76(41) (8. Oktober 1932) 983-987.

[39] Kühl, Viktor; Meyer, Erwin: Absorption of Sound by Porous Materials. Nature (London) 130, No. 3285 (15.10.1932) 590-591.

[40] Kühl, Viktor; Meyer, Erwin: Untersuchungen über die Winkel- und Frequenzabhängigkeit der Schallschluckung von porösen Stoffen. Sitzungsberichte der Preußischen Akademie der Wissenschaften 1932, XXVI. Sitzung der Physikalisch-Mathematischen Klasse, 27.10. 1932, S. 416-435.

[41] Meyer, Erwin; Schüller, Eduard: Magnetische Schallaufzeichnung auf Stahlbänder. Zeitschrift für technische Physik 13(12) (Dezember 1932) 593-599.

[42] Meyer, Erwin: L'utilisation de l'électricité dans la lutte contre le bruit. Congrés International d'Electricité (Paris 1932). Comptes rendus des travaux de la douzième section, tome 13 (1932) 159-175.

[43] Meyer, Erwin: Grundlagen und Instrumente der Geräuschmessung. In: K. W. Wagner (Herausgeber): Lärmabwehr. VDI-Verlag, Berlin 1933, S. 17-19. Vortrag, gehalten auf der Tagung des Fachausschusses für Lärmminderung, Oktober 1932.

[44] Meyer, Erwin; Klaes, Johannes: Über den Schlagton von Glocken. Die Naturwissenschaften 21, Heft 39 (29. September 1933) 697-701.

[45] Meyer, Erwin; Cremer, Lothar: Über die Hörsamkeit holzausgekleideter Räume. Zeitschrift für technische Physik 14(11) (November 1933) 500-507.

[46] Meyer, Erwin: Akustische Meßtechnik. In: W. Wien und F. Harms: Handbuch der Experimentalphysik, Band 17, 2. Teil: Technische Akustik, erster Teil (1934), 2. Kapitel, S. 73-159.

[47] Meyer, Erwin: Schallplatten- und Magnettontechnik. In: W. Wien und F. Harms: Handbuch der Experimentalphysik, Band 17, 3. Teil: Technische Akustik, zweiter Teil (1934), 11. Kapitel, S. 313-348.

[48] Meyer, Erwin: Akustik. 1. [Bericht über die Fortschritte der Akustik 1930-1933]. Die Physik in regelmäßigen Berichten 2(3) (1934) 97-122. 
[49] Meyer, Erwin: Fortschritte der akustischen Meßtechnik und der musikalischen Akustik. Zeitschrift für mathematischen und naturwissenschaftlichen Unterricht 65 (1934) 231-239. Auszug aus einem Experimentalvortrag auf der 36. Hauptversammlung des Deutschen Vereins zur Förderung des mathematischen und naturwissenscahftlichen Unterrichts.

[50] Meyer, Erwin: Körperschallmessungen in Raum- und Bauakustik. Zeitschrift des Vereins Deutscher Ingenieure (VDI) 78(32) (11. August 1934) 957-963.

[51] Meyer, Erwin; Thienhaus, Erich: Schallspektroskopie, ein neues Verfahren der Klanganalyse. Zeitschrift für technische Physik 15(12) (Dezember 1934) 630-637.

[52] Meyer, Erwin; Keidel, Ludwig: Röhrenvoltmeter mit logarithmischer Anzeige und seine Anwendungen in der Akustik. Elektrische Nachrichtentechnik (ENT) 12(2) (Februar 1935) 37-46.

[53] Meyer, Erwin; Jordan, Vilhelm: Nachhallzeiten von Konzerträumen und Schallschluckung der Zuhörerschaft. Elektrische Nachrichtentechnik (ENT) 12(7) (Juli 1935) 213-220.

[54] Meyer, Erwin: Method for Very Rapid Analysis of Sounds. [Abstract]. Journal of the Acoustical Society of America 7(1) (July 1935) 76; Paper 29, presented at the 13th Meeting of the Acoustical Society of America, New York, NY, USA, April 29-30, 1935 (read by F. A. Firestone).

[55] Meyer, Erwin; Thiede, Heinz: Widerstandsschwankungen dünner Kohleschichten. Elektrische Nachrichtentechnik (ENT) 12(8) (August 1935) 237-242.

[56] Meyer, Erwin: A Method for Very Rapid Analysis of Sounds - Sound Grating Spectroscopy. Journal of the Acoustical Society of America 7(2) (October 1935) 88-93.

[57] Meyer, Erwin: Die Mehrfachwand als akustisch-mechanische Drosselkette (kurzer Auszug). Zeitschrift für technische Physik 16(12) (Dezember 1935) 565-566. Vortrag auf der 11. Deutschen PhysikerTagung in Stuttgart vom 22. bis 28. September 1935.

[58] Meyer, Erwin: Die Mehrfachwand als akustisch-mechanische Drosselkette. Elektrische Nachrichtentechnik (ENT) 12(12) (Dezember 1935) 393-400. 
[59] Meyer, Erwin; Böhm, Walter: Ein elektrodynamischer Erschütterungsmesser und seine Anwendung auf die Untersuchung von Gebäudeerschütterungen (kurzer Auszug). Zeitschrift für technische Physik 16(12) (Dezember 1935) 567-568. Vortrag auf der 11. Deutschen Physiker-Tagung in Stuttgart vom 22. bis 28. September 1935.

[60] Meyer, Erwin; Böhm, Walter: Ein elektrodynamischer Erschütterungsmesser und seine Anwendung auf die Untersuchung von Gebäudeerschütterungen. Elektrische Nachrichtentechnik (ENT) 12(12) (Dezember 1935) 404-414.

[61] Meyer, Erwin: Über das Schallschluckvermögen schwingungsfähiger, nichtporöser Stoffe. Elektrische Nachrichtentechnik (ENT) 13(3) (März 1936) 95-102.

[62] Meyer, E[rwin]; Hort, W[ilhelm]: Arbeiten des Instituts für Schwingungsforschung an der Technischen Hochschule Berlin. Forschung auf dem Gebiet des Ingenieurwesens 7(5) (Sept./Okt. 1936) 248-250.

[63] Meyer, Erwin; Waetzmann, E[rich]: Die Bedeutung der Akustik im Rahmen der gesamten Physik und Technik. Zeitschrift für technische Physik 17(12) (Dezember 1936) 508-512. Vorgetragen von Erwin Meyer auf dem 12. Deutschen Physiker- und Mathematikertag in Bad Salzbrunn, 13. bis 19. September 1936.

[64] Meyer, Erwin; Waetzmann, Erich: Die Bedeutung der Akustik im Rahmen der gesamten Physik und Technik. Akustische Zeitschrift 1(3) (Dezember 1936) 114-118. Vorgetragen von Erwin Meyer auf dem 12. Deutschen Physiker- und Mathematikertag in Bad Salzbrunn, 13. bis 19. September 1936.

[65] Meyer, Erwin: Raumakustische Probleme. Schweizerisches Archiv für angewandte Wissenschaft und Technik (1936) 167-179. Vortrag vor der Physikalischen Gesellschaft Zürich.

[66] Meyer, Erwin: Reverberation and Absorption of Sound. Journal of the Acoustical Society of America 8(3) (January 1937) 155-161. Paper 14 , presented at the 16th Meeting of the Acoustical Society, New York, NY, USA, October 29-31, 1936.

[67] Meyer, Erwin: Transmission of Sound and Vibrations in Buildings. [Abstract]. Journal of the Acoustical Society of America 8(3) (January 1937) 206. Paper 1, presented at the 16th Meeting of the Acoustical Society of America, New York, NY, October 29-31, 1936. 
[68] Meyer, Erwin: Reverberation and Absorption. [Abstract]. Journal of the Acoustical Society of America 8(3) (1937) 209. Paper 14, presented at the 16th Meeting of the Acoustical Society of America, New York, NY, USA, October 29-31, 1936. [Voraus ging ein "Luncheon of the Acoustical Society of America in honor of Professor Erwin Meyer of Berlin"].

[69] Meyer, Erwin: Physikalische Eigenschaften der elektroakustischen Hörschärfemesser und Hörhilfen. Zeitschrift für Hals-, Nasen- und Ohrenheilkunde 40 (1937) 278-287. Diskussionsbeitrag: S. 495-496. Vorgetragen auf dem III. Internationalen Oto-Rhino-LaryngologenKongreß, Berlin, 17.-22. August 1936.

[70] Meyer, Erwin: Versuche über Körperschalleitung (Schallbrücken). Akustische Zeitschrift 2(2) (März 1937) 72-75.

[71] Meyer, Erwin: Eigenschaften und Prüfung von Baustoffen und Baukonstruktionen für schalltechnische Zwecke. International Congress of the International Association for Testing Materials, London, April 1924, 1937. Advance proofs of Papers, Group D, pp. 46-49.

[72] Meyer, Erwin: Transmission of Sound and Vibration in Buildings. Journal of the Society of Motion Picture Engineers 28(3) (March 1937) $271-283$.

[73] Meyer, Erwin: Über die Messung von Schallschluckstoffen in Hallräumen. Akustische Zeitschrift 2(4) (Juli 1937) 179-192.

[74] Meyer, Erwin; Keidel, Ludwig: Zur Schalldämmung von Federn und Dämmstoffen. Zeitschrift für technische Physik 18(10) (Oktober 1937) 299-304.

[75] Meyer, Erwin; Buchmann, Gerhard: Über einfache Werkstoffprüfungen mit magnetostriktiven Ultraschallgeräten. Akustische Zeitschrift 3(3) (Mai 1938) 132-136.

[76] Meyer, Erwin: Allgemeine raumakustische Betrachtungen zur elektroakustischen Schallaufnahme. Kinotechnik: Zeitschrift für die Technik im Film 20 (1938) 183-186. Vortrag in der Deutschen Kinotechnischen Gesellschaft am 13. Juni 1938.

[77] Meyer, Erwin: Schalltechnisches Prüfwesen. Wärme- und KälteTechnik 40(7) (Juli 1938) 97-103. 
[78] Meyer, Erwin; Schoch, Arnold; Buchmann, Gerhard: Schallschluckanordnung hoher Wirksamkeit. Patentschrift DE 809 599. Anmelder: Werner Genest GmbH, Stuttgart-Degerloch. Anmeldung: 9. Juli 1938. Erteilung: 23. Mai 1951. Klasse 37f, Gruppe 1/02. Folgepatent: Dispositif très efficace pour l'amortissement ou l'absorption des sons, FR 855 789, Anmeldung: 5. Juni 1939, Erteilung: 26. Feb. 1940, Veröffentlichung: 20. Mai 1940, Französische Klasse: 12/2.

[79] Meyer, Erwin; Kurtze, Günther: Schallschluckanordnung hoher Wirksamkeit. Patentschrift DE 878 731. Zusatz zum Patent DE 809 599. Anmelder: Werner Genest GmbH, Stuttgart-Degerloch. Anmeldung: 1. Juli 1950. Erteilung: 16. Okt. 1952. Klasse 42g, Gruppe 1/10. Priorität (DE): 10. Juli 1938, DE 809599.

[80] Meyer, Erwin: Erich Waetzmann zum Gedächtnis. Akustische Zeitschrift 3(5) (September 1938) 241-244.

[81] Meyer, Erwin: Akustik. 2. [Bericht über Fortschritte der Akustik 1934-1937]. Die Physik in regelmäßigen Berichten 6 (Oktober 1938) 127-162.

[82] Meyer, Erwin: Electro-Acoustics. [Five Lectures given at the University of London, October 12, 13, 15, 18, and 20, 1937]. G. Bell and Sons, London, 1939. xi $+117 \mathrm{pp}$.

[83] Meyer, Erwin; Schoch, Arnold: Schluckgradvergleichsmessungen. Akustische Zeitschrift 4(1) (Januar 1939) 51-61.

[84] Meyer, Erwin; Tamm, Konrad: Eigenschwingung und Dämpfung von Gasblasen in Flüssigkeiten. Akustische Zeitschrift 4(3) (Mai 1939) 145-152. English translation: Natural Vibration and Damping of Gas Bubbles in Liquids. David Taylor Model Basin, Washington, DC, Report No. 0156266, April 1943 (14 pp.) Abstract: http://www.stormingmedia.us/15/1562/0156266.html.

[85] Meyer, Erwin; Bock, Erwin: Hörschall- und Ultraschalluntersuchungen von Betonbalken mit Rissen. Akustische Zeitschrift 4(4) (Juli 1939) 231-237.

[86] Meyer, E[rwin]; Buchmann, G[erhard]; Schoch, A[rnold]: Eine neue Schallschluckanordnung hoher Wirksamkeit und der Bau eines schallgedämpften Raumes. Zeitschrift für technische Physik 21(12) (1940) 372-375. Vortrag auf der Deutschen Physikertagung in Berlin 1940. 
[87] Meyer, E[rwin]; Buchmann, G[erhard]; Schoch, A[rnold]: Eine neue Schallschluckanordnung hoher Wirksamkeit und der Bau eines schallgedämpften Raumes. Verhandlungen der Deutschen Physikalischen Gesellschaft im Jahre 1940, 3. Reihe, 21. Jahrgang, S. 44-45. Vortrag auf der Deutschen Physikertagung in Berlin 1940.

[88] Meyer, Erwin; Buchmann, Gerhard; Schoch, Arnold: Eine neue Schallschluckanordnung hoher Wirksamkeit und der Bau eines schallgedämpften Raumes. Akustische Zeitschrift 5(6) (Dezember 1940) $352-364$.

[89] Meyer, Erwin; Tamm, Konrad: Ein akustisches Meßverfahren zur Bestimmung der dynamischen Kompressibilität und des Verlustfaktors elastischer Stoffe. Akustische Zeitschrift 7(2) (März 1942) 45-50.

[90] Meyer, Erwin: Akustische Eigenschaften von Gasblasen in Flüssigkeiten und ihr Einfluß auf die Schalldämpfung in Wasser. In: Bericht über die Arbeitstagung „Schallausbreitung im Wasser", Rankenheim, 20.-21. Mai 1943 (79 S.), S. 35-50.

[91] Bericht über die Arbeitstagung „Propeller- und Fahrtgeräusche im Wasser", Gotenhafen, 6. Februar 1944 (120 S.)

[92] Meyer, Erwin (Editor); Kuhl, Walter; Oberst, Hermann; Skudrzyk, Eugen; Tamm, Konrad: Sound Absorption and Sound Absorbers in Water (Dynamic Properties of Rubber and Rubberlike Substances in the Acoustic Frequency Region). Translated by Charles E. Mongan Jr., Department of the Navy, Bureau of Ships, Washington, D.C., USA, Report NavShips 900,164, Vol. 1. Manuscript delivered 1946, published 1950 (XVIII + 519 pp.)

[93] Meyer, Erwin: Über den derzeitigen Stand der Theorie des Hörens. Die Naturwissenschaften 34(12) (1947) 358-362. Antrittsvorlesung an der Universität Göttingen, gehalten am 31. Januar 1948.

[94] Meyer, E[rwin] (Buchbesprechung), Otto Schumann: Elektrische Wellen. Carl Hanser Verlag, München 1948. Die Naturwissenschaften 35(11) (Nov. 1948) 349.

[95] Kuhl, W[alter]; Meyer, E[rwin]: Dynamical Properties of Rubber and Rubber-like Materials in a Large Frequency Range. The Physical Society (GB), Acoustics Group Symposium 1949, pp. 181-188. 
[96] Meyer, Erwin; Tamm, Konrad: Ein Gerät zur Aufzeichnung der Ortskurven von Scheinwiderständen im Tonfrequenzbereich. Technische Mitteilungen PTT (herausgegeben von der Schweizerischen Post-, Telegraphen- und Telephonverwaltung) 4 (1949) 164-168.

[97] Meyer, Erwin; Severin, Hans: Über einige Demonstrationsversuche mit elektromagnetischen Zentimeter-Wellen. Zeitschrift für Physik 126(7-9) (1949) 711-720.

[98] Kaiser, Helmut; Kuhl, Walter; Meyer, Erwin: Schalldämpfende Bauweise. Patentschrift DE 817 649. Anmeldung: 27. Nov. 1949. Erteilung: 30. Aug. 1951. Klasse 37a, Gruppe 7/01.

[99] Meyer, Erwin: Istituto Nazionale Di Ultracustica „O. M. Corbino“ in Rom. Die Naturwissenschaften 37(6) (März 1950) 136-137.

[100] Meyer, E[rwin]: Über Ultraschallversuche im Physikalischen Praktikum. Il Nuovo Cimento, Supplemento al Volume VII, Serie IX, No. 2 (1950) 248-254. (Vortrag, gehalten beim „Convegno Internazionale di Ultracustica" [Internationaler Ultraschallkongress], Rom, 14.-17. Juni 1950).

[101] Meyer, E[rwin]; Parkin, P. H.; Oberst, H[ermann]; Purkis, H. J.: A Tentative Method for the Measurement of Indirect Sound Transmission in Buildings. Acustica 1(1) (1951) 17-28.

[102] Meyer, E[rwin]; Karmann, R[ichard] W.: Die Schwingung der Luftteilchen in der Nähe einer schallabsorbierenden Wand. Acustica 1(3) (1951) 130-136.

[103] Meyer, Erwin: Electro-Acoustic Aids for Music and Speech. Building Research Congress, London 1951. Proceedings: Division 3, Part 1, pp. $43-48$.

[104] Meyer, E[rwin]; Tamm, K[onrad]: Breitbandabsorber für Flüssigkeitsschall. Acustica 1/2(2) (1951/52) AB 91 - AB 104.

[105] Meyer, E[rwin]; Kuhl, W[alter]: Bemerkungen zur geometrischen Raumakustik. Acustica 2(2) (1952) 77-83.

[106] Meyer, Erwin; Diestel, Horst-Gunther: Hallraumversuche mit gerichteten Sende- und Empfangsanlagen. Acustica 2(4) (1952) 161-166.

[107] Meyer, Erwin; Oberst, Hermann: Resonanzabsorber für Wasserschall. Acustica 2(3) (1952) AB 149 - AB 170. 
[108] Meyer, Erwin; Bohn, Lothar: Schallreflexion an Flächen mit periodischer Struktur. Modelluntersuchungen mit Ultraschall im Bereich von 15 bis $60 \mathrm{kHz}$. Acustica 2(4) (1952) AB 195 - AB 207.

[109] Meyer, Erwin; Schodder, Georg R[enatus]: Über den Einfluß von Schallrückwürfen auf Richtungslokalisation und Lautstärke bei Sprache. Nachrichten der Akademie der Wissenschaften in Göttingen, Mathematisch-Physikalische Klasse, IIa: Mathematisch-PhysikalischChemische Abteilung, Jahrgang 1952, Nr. 6, S. 31-42.

[110] Meyer, Erwin; Severin, Hans: Reflexionsarmer Absorber für elektromagnetische und allenfalls akustische Wellen. Patentschrift DE 955 612. Anmelder: Werner Genest GmbH, Stuttgart-Degerloch. Anmeldung: 28. März 1953. Veröffentlichung: 21. Juni 1956. Erteilung: 13. Dez. 1956. Klasse 21a4, Gruppe 71. Int. Cl.: G01R, H04P. Besprechung: Genest GmbH, Fachwissenschaftliche Abhandlungen, Nr. 4a (Feb. 1954), 2 pp. Folgepatent: Revêtement de murs pour l'absorption d'ondes acoustiques et électriques, FR 1.092.750, Anmeldung: 4. Feb. 1954, Erteilung: 10. Nov. 1954, Veröffentlichung: 26. April 1955, Französische Klasse: Gr. 7, Cl. 3.

[111] Meyer, Erwin: Elektroakustische Übertragungsanlagen (Public Address Systems). 1st International Congress on Acoustics (ICA), Delft, NL, June 16-24, 1953. Proceedings: Section II, pp. 53-60.

[112] Meyer, E[rwin]; Güth, W[ernfried]: Zur akustischen Zähigkeitsgrenzschicht. Acustica 3(3) (1953) 185-187.

[113] Meyer, Erwin; Kurtze, Günther; Severin, Hans; Tamm, Konrad: Ein neuer großer reflexionsfreier Raum für Schallwellen und kurze elektromagnetische Wellen. Acustica 3(AB 3) (1953) 409-420.

[114] Meyer, E[rwin]; Skudrzyk, E[ugen]: Über die akustischen Eigenschaften von Gasblasenschleiern in Wasser. Acustica 3(AB 3) (1953) 434-440.

[115] Meyer, Erwin; Severin, Hans; Umlauft, Gerhard: Resonanzabsorber für elektromagnetische Wellen. Zeitschrift für Physik 138(3-4) (1954) 465-477.

[116] Meyer, Erwin: Definition and Diffusion in Rooms. Journal of the Acoustical Society of America 26(5) (1954) 630-636. 
[117] Meyer, Erwin; Schmitt, Hans-Jürgen; Severin, Hans: Resonanzabsorber zur Schluckung elektromagnetischer Zentimeterwellen. Patentschrift DE 1004 248. Anmelder: Werner Genest GmbH, StuttgartDegerloch. Anmeldung: 23. Feb. 1955. Veröffentlichung: 14. März 1957. Erteilung: 22. Aug. 1957. Kl.: 21a4 48/63. Int. Cl.: H03H, H04P.

[118] Meyer, Erwin: Études aux ultra-sons, sur maquettes, de la diffusion directive dans les salles. [Text deutsch, ausführliche französische Zusammenfassung]. Communications du Congrès International sur les Traitements par les Ultra-Sons, Marseille, 23.-28. 5. 1955, p. 141-147.

[119] Meyer, Erwin; Tamm, Konrad; Kurtze, Günther; Blau, Hans: Verfahren zum Herstellen einer reflexionshindernden Schicht an Grenzflächen gegen Flüssigkeiten. Deutsches Patentamt, Auslegeschrift DE 1099 405. Anmelder: Fa. Hermann Wiederhold, Hilden. Anmeldung: 21. Juni 1955. Veröffentlichung: 9. Feb. 1961. Kl. 74d 6/12. Int. Cl.: G08F. Folgeanmeldungen: BE 432 319, 20. Juni 1956, Patent BE 548 822; CA 709,463, 19. Juni 1956; FR 716 776, 20. Juni 1956, Patent FR 1186 829; GB 19315/56, 21. Juni 1956, Patent GB 810.505; IT 27 776, 20. Juni 1956; NL 208 093, 18. Juni 1956, NO 121 106, 18. Juni 1956; US 592,077, 18. Juni 1956.

[120] Meyer, Erwin; Severin, Hans: Absorptionsanordnungen für elektromagnetische Zentimeterwellen und ihre akustischen Analogien. Zeitschrift für angewandte Physik 8(3) (März 1956) 105-114.

[121] Meyer, Erwin; Schmitt, Hans Jürgen; Severin, Hans: Dielektrizitätskonstante und Permeabilität künstlicher Dielektrika bei $3 \mathrm{~cm}$ Wellenlänge. Zeitschrift für angewandte Physik 8(6) (1956) 257-263.

[122] Meyer, E[rwin]; Thiele, R[olf]: Raumakustische Untersuchungen in zahlreichen Konzertsälen und Rundfunkstudios unter Anwendung neuerer Meßverfahren. Acustica 6(AB 2) (1956) 425-444.

[123] Meyer, Erwin: Physical Measurements in Rooms and Their Meaning in Terms of Hearing Conditions. 2nd International Congress on Acoustics (ICA), Cambridge, MA, USA, June 17-23, 1956. Proceedings: pp. 59-68.

[124] Meyer, Erwin: This Congress and the Next (Closing Address). 2nd International Congress on Acoustics (ICA), Cambridge, MA, USA, June 17-23, 1956. Proceedings: pp. 111-113. 
[125] Meyer, Erwin: Some Measurements of Cavitation. [Abstract]. Journal of the Acoustical Society of America 28(4) (July 1956) 801. Paper KB2, presented at the 51st Meeting of the Acoustical Society of America, Joint Meeting with the 2nd ICA Congress, Cambridge, MA, USA, June 17-23, 1956.

[126] Meyer, Erwin: Neuere Erkenntnisse auf dem Gebiet der Elektroakustik. Elektrotechnische Zeitschrift (ETZ) A 77(21) (November 1956) 782-789.

[127] Meyer, E[rwin]: Messungen zur Körperschallübertragung an Hand von Modellen. Acustica 6(AB 1) (1956) 51-58. Zusammenfassender Vortrag auf der Tagung „Schall und Schwingungen in Festkörpern“, Göttingen, 19. - 22. April 1955.

[128] Meyer, E[rwin]: Messungen zur Körperschallübertragung an Hand von Modellen. VDI-Berichte 8(1) (1956) 7-14.

[129] Meyer, Erwin: Über Modellversuche zur Schalldiffusität in Räumen. Atti del Convegno di Venezia (1.-4.10. 1955) su „I Modelli Nella Tecnica“, Rom (1956), Vol. 1, pp. 202-213.

[130] Meyer, E[rwin]: [Ultrasound:] Technique of Measurements and Apparatus. In: E. G. Richardson (ed.): Technical Aspects of Sound. Vol. II: Ultrasonic Range, Underwater Acoustics (1957), Chapter 4, pp. 201-221.

[131] Meyer, E[rwin]: [Underwater Acoustics:] Air Bubbles in Water. In: E. G. Richardson (ed.): Technical Aspects of Sound. Vol. II: Ultrasonic Range, Underwater Acoustics (1957), Chapter 5, pp. 222-239.

[132] Meyer, Erwin: Some New Measurements on Sonically Induced Cavitation. Journal of the Acoustical Society of America 29(1) (January 1957) 4-8.

[133] Meyer, Erwin; Sessler, Gerhard: Schallausbreitung in Gasen bei hohen Frequenzen und sehr niedrigen Drucken. Zeitschrift für Physik 149(1) (1957) 15-39.

[134] Meyer, E[rwin]; Burgtorf, W[olfgang]: Über die Zeitabhängigkeit der Schallrichtungsverteilung in Räumen bei impulsartiger Anregung. Acustica 7(AB 1) (1957) 313-324. 
[135] Meyer, Erwin: Microwave - Acoustic Analog Experiments at Göttingen. [Title only]. Journal of the Acoustical Society of America 29(11) (November 1957) 1248. Invited Paper A1, presented at the 54th Meeting of the Acoustical Society of America, Ann Arbor, MI, USA, October 24-26, 1957.

[136] Meyer, Erwin; Mechel, F[ridolin]; Kurtze, G[ünther]: Some Experiments on Sound Propagation in Damped Air Ducts with Flow Velocities up to $80 \mathrm{~m} / \mathrm{sec}$. [Abstract]. Journal of the Acoustical Society of America 29(11) (November 1957) 1259. Paper I8, presented at the 54th Meeting of the Acoustical Society of America, Ann Arbor, MI, USA, October 24-26, 1957.

[137] Meyer, Erwin: Neuere Meßverfahren zur Raumakustik und ihre Bedeutung für die akustische Beurteilung von Räumen. De Ingenieur, No. 14 (1958), , Technisch Wetenschappelijk Onderzoek 5“, 11 S. [Vortrag mit Diskussion].

[138] Meyer, Erwin; Mechel, Fridolin; Kurtze, Günther: Experiments on the Influence of Flow on Sound Attenuation in Absorbing Ducts. Journal of the Acoustical Society of America 30(3) (March 1958) 165-174.

[139] Meyer, Erwin: Experiments on cm Waves in Analogy with Acoustic Techniques Made in Göttingen. Journal of the Acoustical Society of America 30(7) (July 1958) 624-632.

[140] Meyer, Erwin; Kuttruff, Heinrich: Akustische Modellversuche zum Aufbau eines Hallraumes. Nachrichten der Akademie der Wissenschaften in Göttingen, Mathematisch-Physikalische Klasse, IIa: Mathematisch-Physikalisch-Chemische Abteilung, Jg. 1958, Nr. 6, S. $97-114$.

[141] Meyer, Erwin: Recent Investigations on Sonic and Ultrasonic Cavitation in Göttingen. Second Symposium on Naval Hydrodynamics: Hydrodynamic Noise [and] Cavity Flow, Washington, D.C., USA, August 25-29, 1958. Proceedings: Report ACR-38, Office of Naval Research - Department of the Navy, Washington, D.C., pp. 179-200.

[142] Meyer, Erwin: (Ansprache anlässlich der Verleihung der Ehrendoktorwürde der Technischen Universität Berlin am 18. November 1958). Druckschrift der Technischen Universität Berlin, 1958, S. 13-16. 
[143] Meyer, Erwin; Brendel, Klaus; Tamm, Konrad: Pulsation Oscillations of Cavities in Rubber. Journal of the Acoustical Society of America 30(12) (December 1958) 1116-1124.

[144] Meyer, E[rwin]; Kuttruff, H[einrich]; Severin, H[ans]: Experimentelle Bestimmung des Radar-Streuquerschnittes zylindrischer Metallkörper. Zeitschrift für angewandte Physik 11(1) (Januar 1959) 1-6.

[145] Meyer, Erwin: Begrüßungsansprache des Kongress-Präsidenten. 3rd International Congress on Acoustics (ICA), Stuttgart, September 1-8, 1959. Proceedings: pp. 1-4.

[146] Meyer, E[rwin]; Kuttruff, H[einrich]: Zur Phasenbeziehung zwischen Lumineszenz und Kavitationsvorgang bei periodischer Schallanregung. 3rd International Congress on Acoustics (ICA), Stuttgart, September 1-8, 1959. Proceedings: pp. 340-343.

[147] Meyer, Erwin; Kuttruff, Heinrich: Zur Phasenbeziehung zwischen Sonolumineszenz und Kavitationsvorgang bei periodischer Anregung. Zeitschrift für angewandte Physik 11(9) (September 1959) 325-333.

[148] Meyer, E[rwin]; Kuttruff, H[einrich]: Zur akustischen Gestaltung der neuerbauten Beethovenhalle in Bonn. Acustica 9(6) (1959) 465468.

[149] Meyer, E[rwin]: Ludwig Bergmann †. Acustica 9(6) (1959) 468.

[150] Meyer, E[rwin]; Schnupp, P[eter]: Modellversuche zur elektromagnetischen Rückstrahlortung (Radar) mit Ultraschallwellen (Sonar). Acustica 10(1) (1960) 1-13.

[151] Meyer, E[rwin]; Eisenmenger, W[olfgang]: Demonstrationsversuche zur Parameterverstärkung. Zeitschrift für Physik 158(4) (1960) 379-385.

[152] Meyer, E[rwin]; Kurtze, G[ünther]; Kuttruff, H[einrich]; Tamm, K[onrad]: Ein neuer Hallraum für Schallwellen und elektromagnetische Wellen. Acustica 10(AB 1) (1960) 253-264.

[153] Meyer, E[rwin]; Schilz, W[olfram]; Tamm, K[onrad]: Über den Bau eines reflexionsfreien Wasserschall-Meßbeckens. Acustica 10(AB 1) (1960) 281-287. 
[154] Meyer, E[rwin]; Schilz, W[olfram]; Tamm, K[onrad]: The Construction of an Anechoic Tank for Underwater Sound Measurements. USRL Translation No. 18, translated by John M. Taylor Jr. from Acustica 10(AB 1) (1960) 281-287 (9 pp.).

[155] Meyer, E[rwin]; Dinkelacker, A[lbrecht]; Tamm, K[onrad]: Flow Noise in Water-Filled Tubes. Acustica 10(5/6) (1960) 322-325.

[156] Meyer, Erwin; Helberg, Hans-Wilhelm; Vogel, Siegfried: Hallraummeßtechnik und Bau eines großen Hallraums für elektromagnetische Wellen. Zeitschrift für angewandte Physik 12(8) (Aug. 1960) 337-346.

[157] Meyer, E[rwin]; Pottel, R[einhard]: Reflexionsarme Absorber für elektromagnetische Wellen. Fortschritte der Hochfrequenztechnik 5 (1960) 1-72.

[158] Meyer, E[rwin]; Schunk, E[rich]: Modelluntersuchungen zur Schnelle-Transformation in Druckkammern für Trichterlautsprecher. Acustica 11(AB 1) (1961) 248-253.

[159] Meyer, E[rwin]; Kuttruff, H[einrich]: Die raumakustischen Maßnahmen beim Neubau des Plenarsaals des Baden-Württembergischen Landtages in Stuttgart. Acustica 12(1) (1962) 55-57.

[160] Meyer, Erwin: Neuere Analogien zwischen akustischen und elektromagnetischen Schwingungen und Wellenfeldern. 4th International Congress on Acoustics (ICA), Kopenhagen, DK, August 21-28, 1962. Congress Report II (Invited Papers), pp. 139-156.

[161] Meyer, E[rwin]; Kuttruff, H[einrich]; Rischbieter, F[ritz]: Messungen der Schallstreuung an Flächen mit periodisch wechselnder Impedanz (Phasengittern). Acustica 12(5) (1962) 334-341.

[162] Meyer, Erwin; Helberg, Hans-Wilhelm; Roy, Norbert: Messung der abgestrahlten Leistung von Antennen in einem Hallraum für elektromagnetische Wellen. Zeitschrift für angewandte Physik 14(10) (Oktober 1962) 608-612.

[163] Meyer, E[rwin]: High-Intensity Sound in Liquids. Underwater Acoustics (1962), Lecture 9: pp. 139-157. Published by Plenum Press, Inc., New York, NY, USA.

[164] Meyer, Erwin; Kuttruff, Heinrich: Progress in Architectural Acoustics. In: E. G. Richardson and E[rwin] Meyer (Eds.): Technical Aspects 
of Sound. Vol. III: Recent Developments in Acoustics. Elsevier Publishing Co., Amsterdam and New York 1962, Chapter 5, pp. 221-337.

[165] Meyer, Erwin; Eisfeld, Dietmar: Versuche zur Ausbreitung elektromagnetischer Wellen über einer absorbierenden Fläche. Zeitschrift für angewandte Physik 15(1) (Januar 1963) 31-39.

[166] Meyer, E[rwin]; Kuttruff, H[einrich]: Reflexionseigenschaften durchbrochener Decken (Modelluntersuchungen an der Reflektoranordnung der neuen Philharmonic Hall in New York). Acustica 13(3) (1963) 183-186.

[167] Meyer, E[rwin]; Kuttruff, H[einrich]; Gruschka, H[einz]-D[ieter]: Modellversuche zur Schallrichtungsdiffusität und Nachhallvorgang. Acustica 13(AB 1) (1963) 187-193.

[168] Meyer, Erwin; Brendel, Klaus Diether: Breitbandige reflexionsarme schalldämpfende Schicht. Patentschrift DE 1197 242. Anmelder: Grünzweig \& Hartmann AG, Ludwigshafen. Anmeldung: 7. Feb. 1964. Veröffentlichung: 22. Juli 1965. Erteilung: 7. April 1966. Kl. 42g-1/10. Int. Cl.: G10K.

[169] Meyer, E[rwin]; Kunstmann, D[irk]; Kuttruff, H[einrich]: Über einige Messungen zur Schallabsorption von Publikum. Acustica 14(2) (1964) 119-124.

[170] Meyer, E[rwin]; Kuttruff, H[einrich]: Zur Raumakustik einer großen Festhalle (Erfahrungen mit einer elektroakustischen Nachhallanlage). [„Jahrhunderthalle“ der Farbwerke Hoechst]. Acustica 14(3) (1964) 138-147.

[171] Meyer, Erwin; Brendel, Klaus Diether: Breitbandiger, reflexionsarmer Schallabsorber für Flüssigkeits- und Festkörperschall und Verfahren für dessen Herstellung. Patentschrift DE 1207 651. Anmelder: Grünzweig \& Hartmann AG, Ludwigshafen. Anmeldung: 10. Sept. 1964. Veröffentlichung: 23. Dez. 1965. Erteilung: 30. Juni 1966. Kl. 42g-1/10. Int. Cl.: G10K. Folgepatente: FR 1423 473, 23. Juni 1965; GB 1089 251, 1. Feb. 1965; IT 749807 (881 769 ?), 2. Feb. 1965; JP 558 370, 8. Feb. 1965; NL 6500 637, 19. Jan. 1965; NO 115 685, 6. Feb. 1965; SE 327 094, 5. Feb. 1965; US 3,615,961, 8. Feb. 1965.

[172] Meyer, E[rwin]; Helberg, H[ans]-W[ilhelm]; Macrander, Ch[rista]: Keilabsorber mit magnetischen Verlusten. Zeitschrift für angewandte Physik 20(1) (1965) 51-56. 
[173] Meyer, E[rwin]; Kuttruff, H[einrich]; Schulte, F[ritz]: Versuche zur Schallausbreitung über Publikum. Acustica 15(3) (1965) 175-182.

[174] Meyer, Erwin: Interactions between Electroacoustics and Room Acoustics. [Title only]. Journal of the Acoustical Society of America 37(6) (June 1965) 1102. Invited Paper M2, presented at the 69th Meeting of the Acoustical Society of America, Washington, DC, USA, June 2-5, 1965.

[175] Meyer, E[rwin]; Eisenmenger, W[olfgang]; Güsewell, D[ietrich]: Akustische Steuerung der Emission eines Rubinlasers durch longitudinale Schwingungen des Rubinstabes. Acustica 15(5) (1965) 249-255.

[176] Meyer, E[rwin]; Kuttruff, H[einrich]; Matthaei, H[artwig]: Experimentelle Untersuchung der Schalldurchlässigkeit von schallharten, gitterartig durchbrochenen Strukturen. Acustica 15(5) (1965) 285-294.

[177] Meyer, E[rwin]; Kuttruff, H[einrich]: Über einige raumakustische Beobachtungen in der neuerbauten Stadthalle zu Göttingen. Acustica 15(5) (1965) 301-303.

[178] Meyer, E[rwin]; Burgtorf, W[olfgang]; Damaske, P[eter]: Eine Apparatur zur elektroakustischen Nachbildung von Schallfeldern. Subjektive Hörwirkungen beim Übergang Kohärenz - Inkohärenz. Acustica 15(AB 1) (1965) 339-344.

[179] Meyer, Erwin: Zur Akustik von Konzert- und Theaterräumen. Abendvortrag mit Demonstrationen in der Hoechster Festhalle anlässlich der Deutschen Physiker-Tagung im Oktober 1965. Plenarvorträge, S. $368-414$.

[180] Meyer, E[rwin]: Hyperschalluntersuchungen. Arbeitsberichte der wissenschaftlichen Unternehmungen im Berichtsjahr, S. 180-183 (Akademie der Wissenschaften, Göttingen 1965).

[181] Meyer, E[rwin]; Reipka, R[ichard]: Das Reflexions- und Durchlaßverhalten von Stoßwellen an porösen Absorbern (Rayleigh-Modelle). Acustica 16(3) (1965/66) 149-158.

[182] Meyer, Erwin: Some Recent Advances in Electroacoustics. Electronics \& Power, March 1966, pp. 66-69. Lecture given to the Electronics Division of IEE, London, November 17, 1965. 
[183] Meyer, Erwin; Neumann, Ernst-Georg: Physikalische und Technische Akustik. Eine Einführung mit zahlreichen Versuchsbeschreibungen. Friedr. Vieweg \& Sohn Verlag, Braunschweig, 1. Aufl. 1967; 2. Aufl. 1974, ISBN 3-528-18255-5; 3. Aufl. 1979, ISBN 3-528-28255-X.

[184] Meyer, E[rwin]; Kuttruff, H[einrich]; Lauterborn, W[erner]: Modellversuche zur Bestimmung des Schallabsorptionsgrades im Hallraum. Acustica 18(1) (1967) 21-32.

[185] Meyer, E[rwin]; Brendel, K[laus]; Richter, J[oachim]: Absorption von Wasserschall durch erzwungene Wechselströmung von Flüssigkeiten. Acustica 19(1) $(1967 / 68)$ 8-20.

[186] Meyer, Erwin (Buchbesprechung). Josef und Herbert Krautkrämer: Werkstoffprüfung mit Ultraschall, Springer-Verlag 1966. Die Naturwissenschaften 54(1) (1967) 28.

[187] Meyer, E[rwin]; Kuttruff, H[einrich]; Roy, N[orbert]: Raumakustische Untersuchungen an einem Modell der Stadthalle in Göttingen. Acustica 19(3) (1967/68) 132-142.

[188] Meyer, Erwin; Brendel, Klaus-Dieter; Blau, Hans; Stoof, Gerhard: Reflexionsarmer Wasserschallabsorber. Patentschrift DE 1622064 B2. Anmelder: Fried. Krupp GmbH, Essen. Anmeldung: 24. Jan. 1968. Veröffentlichung: 10. Dez. 1970. Erteilung: 16. Juni 1976. Int. Cl.: G10K 11/00.

[189] Meyer, Erwin; Brendel, Klaus: Reflexionsarme Dünnschichtabsorber für Wasserschall. 6th International Congress on Acoustics (ICA), Tokyo, JP, August 21-28, 1968. Proceedings: Paper L-3-1, pp. L-65 L-68.

[190] Meyer, Erwin; Brendel, Klaus-Dieter; Blau, Hans; Stoof, Gerhard: Absorptionsschicht für die Schallwellen in Flüssigkeiten. Deutsches Patentamt, Offenlegungsschrift DE 18 11998. Anmelder: Grünzweig \& Hartmann AG, Ludwigshafen. Anmeldung: 30. Nov. 1968. Veröffentlichung: 11. Juni 1970. Kl. 42g, 1/10. Int. Cl.: G10K. Folgeanmeldungen: Eléments à faible réflexion pour l'absorption du son dans l'eau et couche formée de tels éléments pour l'absorption des ondes sonores dans des liquides, FR 2.024.969, Anmeldung: 1. Dez. 1969, Appl. No. 69.41356, Veröffentlichung: 4. Sept. 1970, Int. Cl.: G10K 11/00; An acoustic layer for absorbing sound waves propagated in liquids, GB 
1296 695, Anmeldung: 28. Nov. 1969, Appl. No. 58234/69, Veröffentlichung: 15. Nov. 1972, Int. Cl.: F16L 59/02; IT 881 769, Anmeldung: 29. Nov., 1969; Sound Absorber Construction, US 3,647,022, Anmeldung: 28. Nov. 1969, Appl. No. 880,550, Erteilung: 7. März 1972, Int. Cl.: E04B 1/86, US Cl.: 181/33 G.

[191] Meyer, E[rwin]: Small-Scale Models in Room Acoustics and the Simulation of Sound Fields in an Anechoic Chamber. European Broadcasting Union (EBU), Technical Centre, Brussels, BE, Meeting on "Use of Acoustical Scale-Models for the Study of Studios and Concert Halls", Hamburg, April 15-16, 1969 (published Oct. 1969). EBUReport Tech. 3089-E, Group 2, Paper 2.1, pp. 5-10.

[192] Meyer, E[rwin]: Modèles reduits pour études acoustiques et simulation des champs sonores en chambre sourde. European Broadcasting Union (EBU), Meeting, Hamburg, April 15-16, 1969 [französische Übersetzung des englischen Vortragstextes], pp. 5-10.

[193] Meyer, Erwin: Kleine raumakustische Modelle und die Simulierung von Schallfeldern im reflexionsarmen Raum. Rundfunktechnische Mitteilungen 13(5) (1969) 194-196. Vortrag beim „Symposium über die Planung von Konzertsälen und Studios mit Hilfe raumakustischer Modelle“, Hamburg, 15.-16. April 1969, Gruppe 2: Modelluntersuchungen, Vortrag 2.1 [deutsche Übersetzung des englischen Vortragstextes].

[194] Meyer, Erwin; Pottel, Reinhard: Physikalische Grundlagen der Hochfrequenztechnik. Eine Darstellung mit zahlreichen Versuchsbeschreibungen. Lehrbuch für Physiker und Elektrotechniker. Friedr. Vieweg \& Sohn Verlag, Braunschweig 1969. VIII + 335 S.

[195] Anon.: First Rayleigh Medal presented to Professor Doktor Erwin Meyer. Citation and Erwin Meyer's Dinner address. Applied Acoustics $3(3)$ (1970) 167-168.

[196] Meyer, Erwin: Wave Absorbers - A Historical Survey. Applied Acoustics 3(3) (1970) 169-180.

[197] Meyer, Erwin; Kurtze, Günther; Leuschner, Hanns-Wilhelm: Flüssigkeitsschallabsorber. Deutsches Patentamt, Offenlegungsschrift DE 2152 872. Anmelder: Grünzweig \& Hartmann AG, Ludwigshafen. Anmeldung: 23. Okt. 1971. Veröffentlichung: 3. Mai 1973. Kl. 42g, 1/10. Int. Cl.: G10K 11/02. 
[198] Meyer, Erwin; Neumann, Ernst-Georg: Physical and Applied Acoustics. An Introduction. Academic Press, New York and London 1972. English translation of „Physikalische und Technische Akustik. Eine Einführung mit zahlreichen Versuchsbeschreibungen“, translated by John M. Taylor, Jr., xvii + 412 pp.

[199] Meyer, Erwin; Guicking, Dieter: Schwingungslehre. Friedr. Vieweg \& Sohn Verlag, Braunschweig 1974. ISBN 3-528-08254-2. XI + 472 S. 


\section{Publikationen über Erwin Meyer (chronologisch)}

[200] Anon.: Auszeichnung. Elektrische Nachrichtentechnik (ENT) 5(12) (Dezember 1928) 555, rechte Spalte.

[201] [Notiz über Erwin Meyers Habilitation]. Elektrische Nachrichtentechnik (ENT) 5(12) (Dezember 1928) 555, rechte Spalte.

[202] Anon.: Ein Institut für Schwingungsforschung. [Bericht über das neue Heinrich-Hertz-Institut für Schwingungsforschung, insbesondere die Abteilung Akustik mit Erwin Meyer als Leiter]. Die Schalltechnik 2(2) (März 1929) 31.

[203] Adrian: Tagung für mechanische Schwingungen. [Bericht über eine Tagung des Schwingungsausschusses des VDI in Göttingen, Ende Mai 1929, Vortrag von Erwin Meyer über „Raumakustische Messungen“]. Die Schalltechnik 2(5) (September 1929) 80-81.

[204] Anon.: Die Eröffnung des Heinrich-Hertz-Institutes für Schwingungsforschung in Berlin. Die Schalltechnik 3(2) (März 1930) 21 [mit Hinweis auf Erwin Meyer als Leiter der Abteilung Akustik].

[205] Anon.: Eine Unterredung mit Präsident Wagner. Die Schalltechnik 3(2) (März 1930) 22-23 [mit Hinweis auf Erwin Meyer als Gesprächspartner].

[206] Membership List of the Acoustical Society of America. Journal of the Acoustical Society of America 2(4) (1931) 412 [Erwin Meyer listed as Fellow].

[207] [Notiz über Erwin Meyers Ernennung zum nichtbeamteten außerordentlichen Professor an der TH Berlin]. Elektrische Nachrichtentechnik (ENT) 11(3) (März 1934) 118.

[208] Wolf, S. K.: Luncheon of the Acoustical Society of America in honor of Professor Erwin Meyer of Berlin. [Title only]. Journal of the Acoustical Society of America 8(3) (January 1937) 209. Toastmaster's Address; A word of welcome by P. E. Sabine; A word of response by Erwin Meyer.

[209] [Notiz über Erwin Meyers Ernennung zum persönlichen ordentlichen Professor an der TH Berlin]. Elektrische Nachrichtentechnik (ENT) 15 (1938) 162. 
[210] Anon.: Meyer, Erwin Walter. J. C. Poggendorffs biographischliterarisches Handwörterbuch für Mathematik, Astronomie, Physik mit Geophysik, Chemie, Kristallographie und verwandte Wissensgebiete. Band VI: 1923 bis 1931, III. Teil: L-R, S. 1713-1714; Verlag Chemie, Berlin 1938 [mit Daten und ausgewählten Veröffentlichungen].

[211] Firestone, F. A.: [Briefwechsel mit Erwin Meyer 1939 und 1940]. Journal of the Acoustical Society of America 12(1) (1940) 205.

[212] Firestone, F. A.: News of Dr. Erwin Meyer and Akustische Zeitschrift. [Abdruck eines Briefes von E. Meyer vom 2.2.1946]. Journal of the Acoustical Society of America 18(1) (1946) 221.

[213] Anon.: Der größte „schalltote“ Raum der Welt. Göttinger Tageblatt vom 9. und 10. Juni 1953, jeweils die Seite „Göttingen“.

[214] Anon.: New Look at Old School. Göttingen's famous university is recapturing much of its past greatness. LIFE International Edition, Vol. 16, No. 11 (May 31, 1954). Special Issue "Germany - A Giant Awakened", p. 37.

[215] Universitätsarchiv Göttingen, Akte Kur.2675: „III. Physikalisches Institut, Bausachen, 3. 6. 1947 - 15.11.1957“.

[216] Universitätsarchiv Göttingen, Akte Kur.0141: „Grundstück Bürgerstr. 44 (Erbengemeinschaft Rott)“.

[217] Kniehahn, Werner: (Ansprache des Rektors der TU Berlin anlässlich der Verleihung der Ehrendoktorwürde an Erwin Meyer). Druckschrift der Technischen Universität Berlin, 18. November 1958, S. 5-7.

[218] Strigel, Robert: (Ansprache des Dekans der Fakultät für Elektrotechnik der TU Berlin anlässlich der Verleihung der Ehrendoktorwürde an Erwin Meyer). Druckschrift der Technischen Universität Berlin, 18. November 1958, S. 8-11.

[219] Anon.: Ein Richtfest mit Experimenten. Erweiterungsbau des III. Physikalischen Instituts an der Bürgerstraße. Göttinger Tageblatt vom 28. Mai 1959, Seite „Göttingen“.

[220] Anon.: Die Richtkrone über 3. Physikalischen Institut. Göttinger Presse vom 28. Mai 1958, Seite „Stadt Göttingen“. 
[221] Anon.: Meyer, Erwin Walter. J. C. Poggendorffs biographischliterarisches Handwörterbuch der exakten Naturwissenschaften. Band VIIa, Teil 3: L-R, Berichtsjahre 1932 bis 1953 (1959), S. 278-279, Akademie-Verlag, Berlin 1959 [mit Daten und ausgewählten Veröffentlichungen].

[222] Acustica 9(AB 1) (1959) 185-288 mit Beiträgen von [Ludwig] Bergmann; L[othar] Bohn und H[ermann] Oberst; L[othar] Cremer und M[anfred] Heckl; R[olf] Esche; F[riedrich] A[lexander] Fischer; M[artin] Grützmacher und E. Wesselhöft; H. O. Kneser und H. Roesler; Winston E. Kock; G[ünther] Kurtze und R[ichard] H[enry] Bolt; E[rnst] Lübcke; W. Meyer-Eppler; W[alter] Reichardt und A[rno] Lenk; M[anfred] R[obert] Schroeder; K. Schuster und H. Vosahlo; H[ans] Severin; K[onrad] Tamm und O[laf] Weis.

[223] Anon.: Neue Möglichkeiten für Physiker. Erweiterungsbau des dritten Physikalischen Instituts der Göttinger Universität übergeben Verteidigungsministerium half bei der Einrichtung. Göttinger Tageblatt vom 31. Mai 1960, Seite "Göttingen“.

[224] Anon.: Mehr Raum auch für Physiker. Erweiterungsbau zum III. Physikalischen Institut wurde seiner Bestimmung übergeben. Mit Wasserschall- und Windkanal-Labor. Göttinger Presse vom 31. Mai 1960, Seite „Stadt Göttingen“.

[225] Anon.: Besuch in Göttingen - Schlüssel zum Tor der Freundschaft. Die Delegation aus der Vereinigten Arabischen Republik in der Universitätsstadt - Besuche in Instituten und bei der Phywe - Die Landesregierung gab einen Empfang. Göttinger Tageblatt vom 6. Dezember 1960, Seite „Göttingen“.

[226] Anon.: Gestern beim Staatsbesuch in der Universitätstadt. Glaube an die Wissenschaft. Göttinger Presse vom 6. Dezember 1960, Seite „Stadt Göttingen“ [u.a. Foto vom Besuch im III. Physikalischen Institut mit Erwin Meyer].

[227] Anon.: Göttinger Professor gab entscheidendes Gutachten. Plenarsaal des Landtages wird völlig umgebaut / Ein Jahr Ärger mit der Akustik. Göttinger Tageblatt, 5. September 1963, Seite „Göttingen“.

[228] Anon.: Neue Löcher für 150000 Mark. Lehners: Landtag kann im Oktober wieder tagen. Hannoversche Presse und Göttinger Presse, 5. September 1963, Seite „Bericht und Kommentar“. 
[229] Anon.: Jetzt stimmt die Akustik. Soldaten und Polizei als Probepublikum im Landtag. Göttinger Presse, 4. Oktober 1963, Seite "Bericht und Kommentar".

[230] Seufert, Rolf: 250000 Löcher für die Akustik. Parlamentarier ohne Plenarsaal. Die WELT, 29. August 1963, S. 20.

[231] Knudsen, Vern O[liver]: Tribute to Professor Erwin Walter Meyer. On the Occasion of His 65th Birthday. Journal of the Acoustical Society of America 36(7) (July 1964) 1402.

[232] Anon.: Fackelzug für Professor Meyer. Göttinger Tageblatt, 21. Juli 1964, Seite "Göttingen".

[233] Schroeder, Manfred R[obert]: Wallace Clement Sabine Award of the Acoustical Society of America, Citation to Erwin Meyer, Austin, TX, USA, 22 October 1964. [Broschüre der Acoustical Society, 11 S.]

[234] Schroeder, Manfred R[obert]: Erwin Meyer Receives Wallace Clement Sabine Award. Journal of the Acoustical Society of America 37(1) (January 1965) 178-180.

[235] (Ohne Autor und Titel), Göttinger Tageblatt, 15. Juli 1965, Frontseite [Bild: Besuch des Botschafters der USA, George C. McGhee, in Göttingen, u.a. mit Erwin Meyer].

[236] Anon.: Auch Glück gehört dazu. Gute Akustik oder nicht? Prof. Dr. Meyer beim Physikerkongreß: Drei Schüsse zur Illustration. Göttinger Presse, 12. Oktober 1965, Seite „Stadt Göttingen“.

[237] Anon.: Personalnachrichten der Universität. [u.a. Einladungen an Erwin Meyer zu Vorträgen in Warschau, Kopenhagen und Birmingham]. Göttinger Tageblatt, 28. Juni 1966.

[238] Anon.: [Notiz über die Verleihung der Sabine-Medaille an Professor Meyer]. Gravesaner Blätter, Nr. 27/28 (1966), 1. Seite.

[239] Anon.: Professor Meyer tritt zurück. 20 Jahre Leiter des III. Physikalischen Instituts. Göttinger Tageblatt, 17. Oktober 1968, Seite "Göttingen".

[240] (Ohne Autor und Titel, nur Bild mit Unterschrift) Foto von einem Fackelzug am 18. Oktober 1968 zum Dienstende von Erwin Meyer. Göttinger Tageblatt, 21. Oktober 1968, Seite „Göttingen“. 
[241] Kuttruff, H[einrich]: Erwin Meyer zum 70. Geburtstag. Physikalische Blätter 25(7) (Juli 1969) 324.

[242] Anon.: Professor Meyer 70 Jahre alt. Göttinger Tageblatt, 21. Juli 1969, Seite „Göttingen“.

[243] Grützmacher, M[artin]: (Nachruf:) Erwin Meyer † / 1899 - 1972. Acustica 26(5) (1972) 240a-240b.

[244] Schroeder, M[anfred] R[obert]: (Nachruf:) Erwin Meyer • 1899 1972. Journal of the Acoustical Society of America 51(5,1) (May 1972) 1489 .

[245] Cremer, Lothar: (Nachruf:) Erwin Meyer / 21. Juli 1899 - 6. März 1972. Jahrbuch der Akademie der Wissenschaften in Göttingen 1972, S. $179-185$.

[246] Kurtze, G[ünther]: Acoustical activities in Western Germany. [Abstract]. Journal of the Acoustical Society of America, 69, Suppl. 1 (Spring 1981) S46. Invited Paper, presented at the 101st Meeting of the Acoustical Society of America, Ottawa, Ontario, Canada, May $18-22,1981$.

[247] Guicking, Dieter: Meyer, Erwin Walter. In: Sigfrid von Weiher (Hrsg.): Männer der Funktechnik. Eine Sammlung von 70 Lebenswerken deutscher Pioniere der Funktechnik (drahtlose Telegrafie, Radar, Rundfunk und Fernsehen), VDE-Verlag, Berlin und Offenbach 1983, ISBN 3-80007-1314-4, S. 120-123.

[248] Ardenne, Manfred von: Ich bin ihnen begegnet - Wegweiser der Wissenschaft, Pioniere der Technik, Köpfe der Politik. Droste Verlag, Düsseldorf 1997, ISBN 3-7700-1072-8, S. 70-72: „12.08.1929. ... so schallt es heraus. Begegnung mit Erwin Meyer".

[249] Schroeder, Manfred [Robert]: Erwin Meyer - Professor für Physik an der Universität Göttingen. Rede anläßlich der Enthüllung einer Gedenktafel am 03.12.1999, Otfried-Müller-Weg 6. Göttinger Jahrbuch, Band 48 (2000), Verlag Erich Goltze, Göttingen 2000, S. 181183 („Göttinger Laudationes“).

[250] Schroeder, Manfred R[obert]: Erwin Meyer, 1899-1972, Angewandte Physik, Ordentliches Mitglied seit 1950. In: Karl Arndt, Gerhard Gottschalk und Rudolf Smend (Hrsg.): Göttinger Gelehrte. Die 
Akademie der Wissenschaften zu Göttingen in Bildnissen und Würdigungen 1751-2001, Wallstein Verlag, Göttingen 2001, ISBN 3-89244485-4, Zweiter Band, S. 552-553.

[251] Anon.: Meyer, Erwin Walter - Physiker - 1960-1972 - OtfriedMüller-Weg 6. In: Walter Nissen, Christina Prauss und Siegfried Schütz: Göttinger Gedenktafeln. Ein biografischer Wegweiser. Vandenhoeck \& Ruprecht, Göttingen 2002, ISBN 3-525-39161-7, S. 150.

[252] Kohlrausch, Armin: Erwin Meyers frühe Beiträge zur Psychoakustik. Fortschritte der Akustik - DAGA 2007 (Stuttgart), 411-412.

[253] Guicking, Dieter: Erwin Meyer - ein bedeutender deutscher Akustiker. Fortschritte der Akustik - DAGA 2007 (Stuttgart), 413-414. 


\section{Ausgewählte Veröffentlichungen aus dem Dritten Physikali- schen Institut}

[254] Haas, H[elmut]: The Influence of a Single Echo on the Audibility of Speech. Translated from the German by K. P. R. Ehrenberg. Department of Scientific and Industrial Research, Building Research Station, Garston, Watford, Herts., UK, Library Communication No. 363, December 1949 (25 pp.) Reprint: Journal of the Audio Engineering Society 20(2) (March 1972) 146-159.

[255] Haas, Helmut: Über den Einfluß eines Einfachechos auf die Hörsamkeit von Sprache. Dissertation TH Braunschweig 1949/1950 (55 S.)

[256] Haas, Helmut: Über den Einfluß eines Einfachechos auf die Hörsamkeit von Sprache. Acustica 1(2) (1951) 49-58.

[257] Schodder, G[eorg] R[enatus]; Schröder, F[riedrich]-K[arl]; Thiele, R[olf]: Die Verbesserung der Hörsamkeit durch eine schallverzögernde Leisesprecheranlage. Bühnentechnische Rundschau 41(6) (1951) 2122 .

[258] Schodder, G[eorg] R[enatus]; Schröder, F[riedrich]-K[arl]; Thiele, R[olf]: Verbesserung der Hörsamkeit eines Theaters durch eine schallverzögernde Leisesprecheranlage. Acustica 2(AB 2) (1952) AB 115 $\mathrm{AB} 116$.

[259] Kuhl, Walter: Über Messungen in einem schallschluckend ausgekleideten Wasserschall-Meßbecken. Acustica 2(AB 3) (1952) AB 140 AB 144 .

[260] Kösters, Angelika: Über Schallschnellemessungen in Flüssigkeiten mit der Rayleighschen Scheibe. Acustica 2(AB 2) (1952) AB 171 AB 174.

[261] Kuhl, W[alter]; Tamm, K[onrad]: Messung der Schallausbreitung in flüssigkeitsgefüllten Rohren mit schallweichen Wänden. Acustica 3(AB 2) (1953) 303-316.

[262] Kurtze, Günther: Untersuchungen zur Verbesserung der Auskleidung schallgedämpfter Räume. Acustica 2(AB 2) (1952) AB 104 AB 107. 
[263] Epprecht, G. W.; Kurtze, G[ünther]; Lauber, A.: Bau eines reflexionsfreien Raumes für Schallwellen und elektrische Dezimeterwellen. Acustica 4(AB 2) (1954) 567-577.

[264] Schmitt, Hans Jürgen: Breitbandiger Resonanzabsorber für elektromagnetische Zentimeterwellen. Zeitschrift für angewandte Physik 8(8) (1956) 372-382.

[265] Walther, Klaus: Polarisations- und Winkelabhängigkeit des Reflexionsfaktors von Absorbern für elektromagnetische Zentimeterwellen. Zeitschrift für angewandte Physik 10(6) (1958) 285-295.

[266] Pottel, Reinhard: Über die Erhöhung der Frequenzbandbreite dünner „, $\lambda / 4$-Schicht"-Absorber für elektromagnetische Zentimeterwellen. Zeitschrift für angewandte Physik 11(2) (1959) 46-51.

[267] Schmidt, H[elmut]: Über einige Messungen an Bariumtitanat. Acustica 2(AB 2) (1952) AB 83 - AB 86.

[268] Esche, R[olf]: Über das Verhalten von Bariumtitanat-Rohrschwingern, die in Radialresonanz nach außen abstrahlen. Acustica 9(AB 1) (1959) 211-214.

[269] Schmitt, H[ans] J[ürgen]; Futtermenger, W[erner]: Mehrkreisige Resonanzabsorber für elektromagnetische Zentimeterwellen. Zeitschrift für angewandte Physik 10(1) (1958) 1-7.

[270] Pottel, Reinhard: Absorption elektromagnetischer Zentimeterwellen in künstlich anisotropen Medien. Zeitschrift für angewandte Physik 10(1) (1958) 8-16.

[271] Wiekhorst, Friedrich: Absorption elektromagnetischer Wellen mit Hilfe verlustbehafteter Resonanzschlitze. Zeitschrift für angewandte Physik 10(4) (1958) 173-178.

[272] Kurtze, Günther; Neumann, Ernst-Georg: Ein Dipolabsorber für elektromagnetische Zentimeterwellen mit verminderter Reflexion bei schräger Inzidenz. Zeitschrift für angewandte Physik 12(9) (1960) 385393.

[273] Helberg, Hans-Wilhelm: Die Absorption elektromagnetischer Wellen in einem großen Frequenzbereich durch eine dünne homogene Schicht mit Verlusten. Zeitschrift für angewandte Physik 13(5) (1961) $237-245$. 
[274] Luhmann, Siegfried: Schlitzabsorber für elektromagnetische Zentimeterwellen. Zeitschrift für angewandte Physik 15(6) (1963) 534-541.

[275] Helberg, Hans-Wilhelm; Wünsche, Claus: Ein Mehrschichtabsorber für elektromagnetische Zentimeterwellen. Zeitschrift für angewandte Physik 16(3) (1963) 157-162.

[276] Helberg, Hans-Wilhelm: Die Absorption elektromagnetischer Wellen durch eine dünne Materialschicht in kleinem Abstand vor einer Metallfläche. Zeitschrift für angewandte Physik 16(4) (1963) 214-220.

[277] Schunk, Erich: Keil-Ferrit-Absorberkombinationen für elektromagnetische Wellen. Zeitschrift für angewandte Physik 19(5) (1965) 420427.

[278] Helberg, Hans-Wilhelm: Ferritmaterialien zur Absorption elektromagnetischer Wellen. Zeitschrift für angewandte Physik 26(3) (1969) 228-231.

[279] Helberg, Hans-Wilhelm; Kose, Volkmar: Die breitbandige Absorption elektromagnetischer Wellen durch dünne Ferritschichten. Zeitschrift für angewandte Physik 19(6) (1965) 509-514.

[280] Wartenberg, B[ernd]: Messung der elektromagnetischen Stoffkonstanten $\mu$ und $\varepsilon$ von Ferriten im mm-Wellengebiet. Zeitschrift für angewandte Physik 24(4) (1968) 211-217.

[281] Helberg, H[ans] W[ilhelm]; Wartenberg, B[ernd]: Die elektrische Leitfähigkeit von pyrolisiertem Polyacrylnitril im Temperaturbereich 1,7 bis $700{ }^{\circ} \mathrm{K}$. Physica Status Solidi (A) 3(2) (1970) 401-405.

[282] Haddenhorst, Hans-Günter: Durchgang von elektromagnetischen Wellen durch inhomogene Schichten. Zeitschrift für angewandte Physik 7(10) (1955) 487-496.

[283] Haddenhorst, Hans-Günter: Durchgang von elektromagnetischen Wellen durch inhomogene Schichten (Teil II: Absorption von elektromagnetischen Wellen). Zeitschrift für angewandte Physik 8(6) (1956) 264-267.

[284] Müller, Volkmar: Inhomogene Wellen im Beugungsnahfeld von verlustlosen dielektrischen Kreiszylindern. Zeitschrift für angewandte Physik 12(5) (1960) 206-212. 
[285] Müller, Volkmar: Streuung elektromagnetischer Wellen an absorbierend verkleideten Metallzylindern. Zeitschrift für angewandte Physik 14(10) (1962) 612-620.

[286] Schmitt, Hans Jürgen: Dielektrizitätskonstante von Bariumtitanat bei $10 \mathrm{GHz}$. Zeitschrift für angewandte Physik 9(3) (1957) 107-111.

[287] Jäckle, Wilfried: Messung der komplexen Dielektrizitätskonstante von Seignettesalz bei der Frequenz $10 \mathrm{GHz}$ in Abhängigkeit von der Temperatur und einer elektrischen Vorspannung. Zeitschrift für angewandte Physik 12(4) (1960) 148-155.

[288] Helberg, H[ans]-W[ilhelm]; Wartenberg, B[ernd]: Zur Messung der Stoffkonstanten $\varepsilon$ und $\mu$ im GHz-Bereich mit Resonatoren. Zeitschrift für angewandte Physik 20(6) (1966) 505-510.

[289] Kose, Volkmar: Feldabhängigkeit der komplexen Dielektrizitätskonstante von Bariumtitanat bei 58,2 GHz. Zeitschrift für angewandte Physik 23(6) (1967) 425-432.

[290] Kaatze, U[do]: Messungen der komplexen Dielektrizitätszahl von Bariumtitanat-Einkristallen bei Mikrowellenfrequenzen. Physica Status Solidi B 50(2) (1972) 537-544.

[291] Pottel, Reinhard; Wülfing, Arnd: Messungen der komplexen Dielektrizitätskonstante von wasserhaltigem Glycerin und GlycerinGelatine-Gelen bei Frequenzen zwischen $100 \mathrm{MHz}$ und $15 \mathrm{GHz}$. Zeitschrift für angewandte Physik 15(6) (1963) 501-505.

[292] Pottel, Reinhard: Die komplexe Dielektrizitätskonstante wäßriger Lösungen einiger 2-2-wertiger Elektrolyte im Frequenzbereich 0,1 bis $38 \mathrm{GHz}$. Berichte der Bunsengesellschaft für physikalische Chemie 69(5) (1965) 363-378.

[293] Pottel, Reinhard; Lossen, Ortwin: Die komplexe Dielektrizitätskonstante wäßriger Lösungen einiger 1-1-wertiger Elektrolyte (Salze) im Frequenzbereich 0,5 bis $38 \mathrm{GHz}$. Berichte der Bunsengesellschaft für physikalische Chemie 71(2) (1967) 135-146.

[294] Pottel, R[einhard]; Kaatze, U[do]: Permittivity and Dielectric Relaxation of Aqueous Solutions of Hydrocarbons. Berichte der Bunsengesellschaft für physikalische Chemie 73(5) (1969) 437-446. 
[295] Pottel, R[einhard]: Permittivity and Dielectric Relaxation Time of Aqueous Alkali Halide Solutions. Journal de Chimie Physique 66, Numéro Spécial (Octobre 1969) 115-117.

[296] Giese, K[arl]; Kaatze, U[do]; Pottel, R[einhard]: Permittivity and Dielectric and Proton Magnetic Relaxation of Aqueous Solutions of the Alkali Halides. Journal of Physical Chemistry 74(21) (1970) 37183725 .

[297] Pottel, R[einhard]: Dielectric Relaxation and Molecular Motions in Liquids. Berichte der Bunsengesellschaft für physikalische Chemie 75(3/4) (1971) 286-294.

[298] Giese, K[arl]: Dielectric Relaxation in Aqueous Alkali Halide Solutions Due to Hydration Water Exchange. Berichte der Bunsengesellschaft für physikalische Chemie 76(6) (1972) 495-500.

[299] Neumann, Ernst-Georg: Ausbreitung von elektromagnetischen Zentimeterwellen in einem absorbierenden Paralleldrahtmedium. Zeitschrift für angewandte Physik 13(11) (1961) 509-517.

[300] Neumann, Ernst-Georg: Über das elektromagnetische Feld der schwach geführten Dipolwelle. Zeitschrift für angewandte Physik 16(6) (1964) 452-460.

[301] Neumann, Ernst-Georg: Ein neues Prinzip zur Umlenkung elektromagnetischer Wellen. Zeitschrift für angewandte Physik 18(2) (1964) $71-76$.

[302] Neumann, Ernst-Georg: Experimentelle Untersuchung der Oberflächenwelle an einer Yagi-Struktur. Zeitschrift für angewandte Physik 19(2) (1965) 121-128.

[303] Neumann, E[rnst]-G[eorg]; Stumper, U[lrich]: Durchgang einer dielektrischen Leitung durch eine Irisblende. Zeitschrift für angewandte Physik 20(1) (1965) 56-64.

[304] Neumann, E[rnst]-G[eorg]; Güsewell, D[ietrich]: Tafeln zur Dipolwellenausbreitung an runden dielektrischen Leitungen. Nachrichtentechnische Zeitschrift 19(9) (1966) 545-551.

[305] Neumann, Ernst-Georg: Über das elektromagnetische Feld am freien Ende einer dielektrischen Leitung. I. Abstrahlung. Zeitschrift für angewandte Physik 24(1) (1967) 1-11. 
[306] Neumann, Ernst-Georg: Über das elektromagnetische Feld am freien Ende einer dielektrischen Leitung. II. Empfang. Zeitschrift für angewandte Physik 24(1) (1967) 12-18.

[307] Neumann, E[rnst]-G[eorg]: Das akustische Analogon der YagiAntenne. Acustica 15(5) (1965) 295-300.

[308] Schröder, M[anfred R.]: Eigenfrequenzstatistik und Anregungsstatistik in Räumen. Modellversuche mit elektrischen Wellen. Acustica 4(AB 1) (1954) 456-468. English translation: M. R. Schroeder: Normal Frequency and Excitation Statistics in Rooms: Model Experiments with Electric Waves. Journal of the Audio Engineering Society 35(5) (May 1987) 307-316.

[309] Schröder, M[anfred R.]: Die statistischen Parameter der Frequenzkurven von großen Räumen. Acustica 4(AB 2) (1954) 594-600. English translation: M. R. Schroeder: Statistical Parameters of the Frequency Response Curves of Large Rooms. Journal of the Audio Engineering Society 35(5) (May 1987) 299-306.

[310] Kuttruff, H[einrich]; Thiele, R[olf]: Über die Frequenzabhängigkeit des Schalldrucks in Räumen. Acustica 4(AB 2) (1954) 614-617.

[311] Schroeder, M[anfred] R[obert]; Kuttruff, K.H[einrich]: On Frequency Response Curves in Rooms. Comparison of Experimental, Theoretical, and Monte Carlo Results for the Average Frequency Spacing between Maxima. The Journal of the Acoustical Society of America $34(1)$ (1962) $76-80$.

[312] Schodder, G[eorg] R[enatus]: Über die Verteilung der energiereicheren Schallrückwürfe in Sälen. Acustica 6(AB 2) (1956) 445-465.

[313] Thiele, R[olf]: Richtungsverteilung und Zeitfolge der Schallrückwürfe in Räumen. Acustica 3(AB 2) (1953) 291-302.

[314] Schroeder, M[anfred] R[obert]; Gottlob, D[ieter]; Siebrasse, K[arl] F[riedrich]: Comparative study of European concert halls: correlation of subjective preference with geometric and acoustic parameters. The Journal of the Acoustical Society of America 56(4) (1974) 1195-1201.

[315] Junius, W[alther]: Raumakustische Untersuchungen mit neueren Meßverfahren in der Liederhalle Stuttgart. Acustica 9(4) (1959) 289 303. 
[316] Kunstmann, D[irk]: Modelluntersuchungen zur Schallausbreitung über Publikum (Schallstreuung an Kugelzeilen). Acustica 18(5) (1967) 259-273.

[317] Dämmig, P[eter]: Zur Messung der Diffusität von Schallfeldern durch Korrelation. Acustica 7(6) (1957) 387-398.

[318] Kuttruff, H[einrich]: Raumakustische Korrelationsmessungen mit einfachen Mitteln. Acustica 13(2) (1963) 120-122.

[319] Kuttruff, $\mathrm{H}[\mathrm{einrich}]$ : Über Autokorrelationsmessungen in der Raumakustik. Acustica 16(3) (1965/66) 166-174.

[320] Burgtorf, W[olfgang]; Seraphim, H[ans]-P[eter]: Eine Apparatur zur elektroakustischen Herstellung einfacher Schallfelder in einem reflexionsfreien Raum. Acustica 11(2) (1961) 92-96.

[321] Schodder, G[eorg] R[enatus]: Vortäuschungen eines akustischen Raumeindrucks. Acustica 6(AB 2) (1956) 482-488.

[322] Seraphim, H[ans]-P[eter]: Untersuchungen über die Unterschiedsschwelle exponentiellen Abklingens von Rauschbandimpulsen. Acustica 8(AB 1) (1959) 280-284.

[323] Seraphim, H[ans]-P[eter]: Über die Wahrnehmbarkeit mehrerer Rückwürfe von Sprachschall. Acustica 11(2) (1961) 80-91.

[324] Burgtorf, W[olfgang]: Untersuchungen zur Wahrnehmbarkeit verzögerter Schallsignale. Acustica 11(2) (1961) 97-111.

[325] Burgtorf, W[olfgang]: Zur subjektiven Wirkung von Schallfeldern in Räumen (Rückverdeckung, Phantomschallquellen). Acustica 13(2) (1963) 86-91.

[326] Burgtorf, W[olfgang]; Oehlschlägel, H. K[onrad]: Untersuchungen über die richtungsabhängige Wahrnehmbarkeit verzögerter Schallsignale. Acustica 14(5) (1964) 254-266.

[327] Burgtorf, W[olfgang]; Wagener, B[ernd]: Verdeckung durch subjektiv diffuse Schallfelder. Acustica 19(2) (1967/68) 72-79.

[328] Junius, W[alther]: Apparatur zur automatischen Auswertung von Schallrückwurffolgen. Acustica 8(AB 1) (1958) 266-272. 
[329] Zimmermann, K[arl] H[einz]: Eine neue Richtungsanalyse und ihre Anwendung bei akustischen Messungen. Acustica 12(AB 1) (1962) 206-221.

[330] Burgtorf, W[olfgang]: Raumakustische Modellversuche im Ultraschallbereich. Acustica 18(6) (1967) 323-333.

[331] Kuttruff, H[einrich]; Jusofie, M. J[unos]: Nachhallmessungen nach dem Verfahren der integrierten Impulsantwort. Acustica 19(1) (1967/68) 56-58.

[332] Damaske, P[eter]: Subjektive Untersuchung von Schallfeldern. Acustica 19(4) (1967/68) 199-213.

[333] Damaske, P[eter]; Wagener, B[ernd]: Richtungshörversuche über einen nachgebildeten Kopf. Acustica 21(1) (1969) 30-35.

[334] Damaske, P[eter]: Richtungsabhängigkeit von Spektrum und Korrelationsfunktionen der an den Ohren empfangenen Signale. Acustica 22(4) $(1969 / 70)$ 191-204.

[335] Wagener, B[ernd]: Räumliche Verteilungen der Hörrichtungen in synthetischen Schallfeldern. Acustica 25(4) (1971) 203-219.

[336] Damaske, P[eter]; Mellert, V[olker]: Ein Verfahren zur richtungstreuen Schallabbildung des oberen Halbraumes über zwei Lautsprecher. Acustica 22(3) (1969/70) 153-162.

[337] Damaske, P[eter]: Head-Related Two-Channel Stereophony with Loudspeaker Reproduction. The Journal of the Acoustical Society of America 50(4,2) (1971) 1109-1115.

[338] Damaske, P[eter]; Mellert, V[olker]: Zur richtungstreuen stereophonen Zweikanalübertragung. Acustica 24(4) (1971) 222-225.

[339] Exner, Marie-Luise: Schalldämmung durch Gummi- und Stahlfedern. Acustica 2(5) (1952) 213-221.

[340] Lange, Thomas: Die Messung der Trittschalldämmung von Decken mit sinusförmiger Erregung. Acustica 3(3) (1953) 161-168.

[341] Exner, Marie-Luise; Böhme, Werner: Messung der Körperschalldämmung bei Biegewellen. Acustica 3(AB 1) (1953) 105-110. 
[342] Kurtze, G[ünther]; Tamm, K[onrad]; Vogel, S[iegfried]: Modellversuche zur Biegewellendämmung an Ecken. Acustica 5(4) (1955) 223233.

[343] Kuhl, W[alther]; Kaiser, H[elmut]: Absorption of Structure-Borne Sound in Building Materials Without and With Sand-Filled Cavities. Acustica 2(4) (1952) 179-188.

[344] Exner, M[arie]-L[uise]; Güth, W[ernfried]; Immer, F[riedrich]: Untersuchung des akustischen Verhaltens körniger Substanzen bei Anregung zu Schubschwingungen. Acustica 4(2) (1954) 350-358.

[345] Schmidt, H[elmut]: Die Schallausbreitung in körnigen Substanzen. Acustica 4(6) (1954) 639-952.

[346] Kurtze, G[ünther]: Körperschalldämpfung durch körnige Medien. VDI-Berichte 8 (1956) 110-115.

[347] Westphal, Wolfgang: Körperschallmessungen in einem Hochhaus. VDI-Berichte 8 (1956) 41-43.

[348] Westphal, Wolfgang: Ausbreitung von Körperschall in Gebäuden. Acustica 7(AB 1) (1957) 335-348.

[349] Rupprecht, J[oachim]: Körperschallausbreitung in Baukörpern aus homogenen und zusammengesetzten Baustoffen. Acustica 8(1) (1958) $19-26$.

[350] Schoch, A[rnold]; Fehér, K[arl]: The Mechanism of Sound Transmission Through Single Leaf Partitions, Investigated Using Small Scale Models. Acustica 2(5) (1952) 189-204.

[351] Schoch, Arnold: Der Schalldurchgang durch Platten. Acustica 2(1) (1952) 1-17.

[352] Westphal, Wolfgang: Zur Schallabstrahlung einer zu Biegeschwingungen angeregten Wand. Acustica 4(AB 2) (1954) 603-610.

[353] Schoch, A[rnold]: Der Durchgang von Ultraschall durch Platten. Il Nuovo Cimento, Serie IX, Supplemento al Vol. VII, No. II (1950) 1-5.

[354] Schoch, Arnold: Seitliche Versetzung eines total reflektierten Strahls bei Ultraschallwellen. Acustica 2(1) (1952) 18-19. 
[355] Tamm, K[onrad]; Aha, E[rich]: Ein kapazitiver Schnelleempfänger für Körperschall. Acustica 3(AB 2) (1953) 270-273.

[356] Elling, W[ilhelm]: Die Bestimmung großer mechanischer Eingangsimpedanzen fester Körper im Frequenzband $50 \cdots 3000 \mathrm{~Hz}$. Acustica 4(3) (1954) 396-402.

[357] Tamm, K[onrad]: Meßgeräte und Meßverfahren für Körperschall. VDI-Berichte 8 (1956) 145-151.

[358] Vogel, S[iegfried]: Meßleitungen für Biegewellen. Acustica 6(AB 2) (1956) 511-520.

[359] Hinsch, Hermann: Verkettete mechanische Impedanzen zur Messung der Körperschalldämmung an ecken- und kreuzförmigen Stoßstellen (Modellversuche). Acustica 10(AB 1) (1960) 287-294.

[360] Eisenmenger, W[olfgang]: Erzeugung und Nachweis von höchstfrequentem Schall durch Quantenprozesse in Supraleitern. Kurznachrichten der Akademie der Wissenschaften in Göttingen, Jg. 1966, Nr. 24, S. $115-120$.

[361] Eisenmenger, W[olfgang]; Kinder, H[elmut]; Laßmann, K[urt]: Messung der Hyperschalldämpfung in Quarz. Acustica 16(1) $(1965 / 66) 1-13$.

[362] Eisenmenger, W[olfgang]; Dayem, A. H.: Quantum Generation and Detection of Incoherent Phonons in Superconductors. Physical Review Letters 18(4) (1967) 125-127.

[363] Koppelmann, Jan: Beiträge zur Ultraschallmeßtechnik in Flüssigkeiten. Acustica 2(2) (1952) 92-95.

[364] Tamm, K[onrad]; Lange, Th[omas]; Malzfeldt, J[oachim]: Absolute Calibration of Hydrophones by Various Methods in the Frequency Range $0.1 \cdots 15 \mathrm{kc} / \mathrm{s}$. First International Congress on Acoustics (ICA), Delft, NL, June 16-24, 1953. Proceedings: Section III, pp. 128131.

[365] Schodder, G[eorg] R[enatus]; Wiekhorst, F[riedrich]: Electrostatic Transducers with Solid Dielectric for Waterborne Sound. Acustica 7(1) (1957) 38-45. 
[366] Hund, M[artin]; Kuttruff, H[einrich]: Druckkammerverfahren zur Messung von akustischen Impedanzen kleiner Körper (Mikrophone) in Flüssigkeiten. Acustica 12(6) (1962) 404-410.

[367] Kuttruff, H[einrich]; Wille, P[eter]: Absoluteichung verschiedenartiger Wasserschallwandler im Bereich von 5 bis $250 \mathrm{kHz}$. Acustica $12(6)$ (1962) 410-421.

[368] Richter, J[oachim]: Mechanische Impedanzen dünner Flüssigkeitsschichten. Acustica 22(2) (1969/70) 95-106.

[369] Richter, J[oachim]: Viskosimeter für sehr geringe Flüssigkeitsmengen. Rheologica Acta 9(4) (1970) 550-553.

[370] Richter, J[oachim]; Leuschner, H[ans]-W[ilhelm]; Ahlswede, Th[omas]: Druckkammerverfahren zur Messung von akustischen Impedanzen in Wasser. Acustica 28(2) (1973) 90-97.

[371] Brendel, K[laus]; Hinsch, K[laus]: Wasserschall-Resonanzabsorber mit Relaxationsverlusten in Hochpolymeren. Acustica 21(4) (1969) 189-198.

[372] Brendel, K[laus]; Leuschner, H[ans]-W[ilhelm]: Wasserschall-Resonanzabsorber mit Reibungsverlusten in Flüssigkeitsschichten. Acustica 21(5) (1969) 260-268.

[373] Siebrasse, K[arl]-F[riedrich]: Untersuchungen an Wasserschall-Resonanzabsorbern mit Reibungsverlusten in Flüssigkeitsschichten. Acustica 23(5) (1970) 251-260.

[374] Leuschner, H[ans]-W[ilhelm]: Ölgedämpfter Resonanzabsorber für Wasserschall. Acustica 25(5) (1971) 280-288.

[375] Naake, H[ans] J[oachim]; Tamm, K[onrad]: Sound Propagation in Plates and Rods of Rubber-Elastic Materials. Acustica 8(2) (1958) $65-76$.

[376] Heydemann, P[eter]: The Dynamic Compressibility of Highpolymers in the Frequency Range from $0.1 \mathrm{c} / \mathrm{s}$ to $60 \mathrm{kc} / \mathrm{s}$. Acustica 9(6) (1959) 446-452.

[377] Heydemann, P[eter]; Zosel, A[lbrecht]: Determination of the Complex Young's Modulus of Polymers at Audiofrequencies in a Wide Temperature Range. Acustica 12(5) (1962) 360-365. 
[378] Heydemann, P[eter]; Guicking, H[einz]-D[ieter]: Specific Volume of Polymers as a Function of Temperature and Pressure. KolloidZeitschrift und Zeitschrift für Polymere 193(1) (1963) 16-25.

[379] Heydemann, P[eter]; Nägerl, H[ans]: Determination of the Complex Shear Modulus of Polymers at Audiofrequencies in a Wide Temperature Range. Acustica 14(2) (1964) 70-75.

[380] Nägerl, Hans: Dynamischer Schub- und Elastizitätsmodul amorpher Hochpolymere als Funktion von statischer Vorspannung und Temperatur. Kolloid-Zeitschrift und Zeitschrift für Polymere 204(1/2) (1965) 29-38.

[381] Guicking, D[ieter]: Dynamisch-mechanische Eigenschaften von plastischen Massen und vernetzten Polyurethanen. Acustica 18(2) (1967) 93-104.

[382] Helberg, H[ans] W[ilhelm]: Zur Schallausbreitung in flüssigkeitsgefüllten engen Rohren. Acustica 5(5) (1955) 267-268.

[383] Wille, Peter: Experimentelle Untersuchungen zur Schallstreuung an schallweichen Objekten. Acustica 15(1) (1965) 11-25.

[384] Buddruß, C[laus Peter]; Wille, P[eter]: Experimentelle Untersuchungen zur Wasserschallstreuung an absorbierend verkleideten Zylindern. Acustica 18(3) (1967) 159-168.

[385] Buddruß, C[laus] P[eter]: Modelluntersuchungen zur Wasserschallstreuung an Meeresoberflächen mit Wellengang und Luftblasenschleiern in den oberen Wasserschichten. Acustica 22(1) (1969/70) 1-22.

[386] Hund, M[artin]: Streuung von Wasserschall an zu Biegeschwingungen angeregten Hohlzylindern in einem Flachtank. Acustica 15(2) (1965) 88-97.

[387] Hund, M[artin]: Streuung von Wasserschall an Hohlzylindern, die vom einfallenden Schall zu Schwingungen angeregt werden. Acustica 16(4) $(1965 / 66) 233-237$.

[388] Heusinger, Peter-Paul: Messung der Temperaturabhängigkeit der Schallgeschwindigkeit für leichtes und schweres Wasser sowie für Wasser-Äthylalkohol-Mischungen. Acustica 1(AB 1) (1951) AB 3 AB 6 . 
[389] Mukhopadhyay, S[anat] K[umar]: Ultraschallabsorption in Wasser und ihre Abhängigkeit von Temperatur und Luftgehalt des Wassers. Acustica 6(1) (1956) 25-34.

[390] Böcher, E[rwin]: Untersuchungen zur Absorption von Wasserschall im Frequenzbereich von $1 \mathrm{kHz}$ bis $6 \mathrm{kHz}$. Acustica 15(6) (1965) 418426.

[391] Kurtze, G[ünther]: Untersuchung der Schallabsorption in wäßrigen Elektrolytlösungen im Frequenzbereich 3 bis 100 MHz. Nachrichten der Akademie der Wissenschaften in Göttingen, MathematischPhysikalische Klasse, IIa: Mathematisch-Physikalisch-Chemische Abteilung, Jahrgang 1952, Nr. 9, S. 57-79.

[392] Tamm, K[onrad]: Schallabsorptionsmessungen in Wasser und in wässerigen Elektrolytlösungen im Frequenzbereich $5 \mathrm{kHz}$ bis $1 \mathrm{MHz}$. Nachrichten der Akademie der Wissenschaften in Göttingen, Mathematisch-Physikalische Klasse, IIa: Mathematisch-PhysikalischChemische Abteilung, Jahrgang 1952, Nr. 10, S. 81-110.

[393] Tamm, K[onrad]; Kurtze, G[ünther]: Absorption of Sound in Aqueous Solutions of Electrolytes. Nature 168, No. 4269 (Aug. 25, 1951) 346-348.

[394] Kurtze, G[ünther]; Tamm, K[onrad]: Measurements of Sound Absorption in Water and in Aqueous Solutions of Electrolytes. Acustica 3(1) (1953) 33-48.

[395] Tamm, K[onrad]; Kurtze, G[ünther]; Kaiser, R[einhold]: Measurements of Sound Absorption in Aqueous Solutions of Electrolytes. Acustica 4(3) (1954) 380-386.

[396] Tamm, K[onrad]; Haddenhorst, H[ans] G[ünther]: Measurements by Optical Methods of the Sound Velocity in Aqueous Solutions of Electrolytes in Dependence on Concentration and Temperature. Acustica 4(6) (1954) 653-657.

[397] Plaß, K[laus] G[ottfried]; Kehl, A[lbin]: Schallabsorption in Lösungen 2-2-wertiger Elektrolyte im Frequenzbereich $0,3 \mathrm{GHz}$ bis 2,8 GHz. Acustica 20(6) (1968) 360-365.

[398] Plaß, K[laus] G[ottfried]: Ultraschalldämpfung in Flüssigkeiten bei $1 \mathrm{GHz}$. Acustica 15(6) (1965) 446. 
[399] Plaß, K[laus] G[ottfried]: Relaxationen in organischen Flüssigkeiten bei $1 \mathrm{GHz}$. Acustica 19(4) (1967/68) 236-242.

[400] Plaß, K[laus] G[ottfried]: Vibrational Relaxation in Liquids. Berichte der Bunsengesellschaft für physikalische Chemie 74(4) (1970) $343-347$.

[401] Bader, F[riedrich]; Plaß, K[laus] G[ottfried]: Sound Absorption in Liquid Acetic Acid in the Frequency Range Between 0.3 to 1.5 GHz. Berichte der Bunsengesellschaft für physikalische Chemie 75(6) (1971) $553-555$.

[402] Eigen, M[anfred]; Kurtze, G[ünther]; Tamm, K[onrad]: Zum Reaktionsmechanismus der Ultraschallabsorption in wäßrigen Elektrolytlösungen. Zeitschrift für Elektrochemie - Berichte der Bunsengesellschaft für physikalische Chemie 57(2) (1953) 103-118.

[403] Exner, Marie Luise: Messung der Dämpfung pulsierender Gasblasen in Wasser. Acustica 1(AB 1) (1951) AB 25 - AB 33.

[404] Exner, M[arie] L[uise]; Hampe, W[ilfried]: Experimental Determination of the Damping of Pulsating Air Bubbles in Water.

Acustica 3(2) (1953) 67-72.

[405] Haeske, Horst: Neue Dämpfungsmessungen an pulsierenden Luftblasen in Wasser. Nachrichten der Akademie der Wissenschaften in Göttingen, Mathematisch-Physikalische Klasse, IIa: MathematischPhysikalisch-Chemische Abteilung, Jahrgang 1955, Nr. 10, S. 239-256.

[406] Haeske, H[orst]: Experimental Determination of the Damping of Pulsating Air Bubbles in Water in the Frequency Range 100 to $300 \mathrm{kc} / \mathrm{s}$. Acustica 6(2) (1956) 266-275.

[407] Naake, H[ans]-J[oachim]; Tamm, K[onrad]; Dämmig, P[eter]; Helberg, H[ans] W[ilhelm]: Formation of Air Bubbles in Air-Saturated Water at Reduced Pressure and Their Indication by an Acoustical Measuring Procedure. Acustica 8(3) (1958) 142-152.

[408] Naake, H[ans]-J[oachim]; Tamm, K[onrad]; Dämmig, P[eter]; Helberg, $\mathrm{H}$ [ans] W[ilhelm]: Observation of the Formation and Growth of Bubbles in Water Containing Air, by Optical Methods. Acustica 8(4) (1958) 193-196. 
[409] Lauterborn, W[erner]: Fotografische Aufnahmen vom Aufreißen einer rotierenden Wassersäule und Zerreißfestigkeitsmessungen an Wasser nach der Zentrifugenmethode: Apparatur und erste Ergebnisse. Acustica 22(1) (1969/70) 35-47.

[410] Strube, H[ans] W[erner]; Lauterborn, W[erner]: Untersuchung der Kavitationskeime an der Grenzfläche Quarzglas-Wasser nach der Zentrifugenmethode. Zeitschrift für angewandte Physik 29(6) (1970) 349357.

[411] Güth, W[ernfried]: Nichtlineare Schwingungen von Luftblasen in Wasser. Acustica 6(6) (1956) 532-538.

[412] Lauterborn, W[erner]: Eigenfrequenzen von Gasblasen in Flüssigkeiten. Acustica 20(1) (1968) 14-20.

[413] Hund, M[artin]: Zur näherungsweisen Berechnung der Eigenfrequenzen von Gasblasen in Flüssigkeiten. Acustica 21(1) (1969) 54-56.

[414] Lauterborn, W[erner]: Subharmonische Schwingungen von Gasblasen in Wasser. Acustica 22(4) (1969/70) 238-239

[415] Lauterborn, W[erner]: Resonanzkurven von Gasblasen in Flüssigkeiten. Acustica 23(2) (1970) 73-81.

[416] Strube, H[ans] W[erner]: Numerische Untersuchungen zur Stabilität nichtsphärisch schwingender Blasen. Acustica 25(5) (1971) 289303.

[417] Lange, Th[omas]: Methoden zur Untersuchung der Schwingungskavitation in Flüssigkeiten mit Ultraschall. Acustica 2(AB 2) (1952) AB $75-\mathrm{AB} 82$.

[418] Esche, R[olf]: Untersuchung der Schwingungskavitation in Flüssigkeiten. Acustica 2(AB 4) (1952) AB 208 - AB 218.

[419] Güth, W[ernfried]: Ein Experiment zur Demonstration von Kavitationsblasen und Kavitationskeimen. Acustica 5(3) (1955) 192-195.

[420] Güth, W[ernfried]: Zur Entstehung der Stoßwellen bei der Kavitation. Acustica 6(6) (1956) 526-531.

[421] Bohn, L[othar]: Schalldruckverlauf und Spektrum bei der Schwingungskavitation. Acustica 7(4) (1957) 201-216. 
[422] Mundry, E[berhard]; Güth, W[ernfried]: Kinematographische Untersuchungen der Schwingungskavitation. Acustica 7(4) (1957) 241250 .

[423] Kurtze, Günther: Über die Bedingungen für das Auftreten von Kavitation in Flüssigkeiten. Nachrichten der Akademie der Wissenschaften in Göttingen, Mathematisch-Physikalische Klasse, IIa: Mathematisch-Physikalisch-Chemische Abteilung, Jahrgang 1958, Nr. 1, S. 1-47.

[424] Schmid, J[örg]: Kinematographische Untersuchung der Einzelblasen-Kavitation. Acustica 9(4) (1959) 321-326.

[425] Lauterborn, W[erner]: Theoretische Untersuchungen zur Kavitation. Acustica 20(6) (1968) 370-371.

[426] Kuttruff, H[einrich]; Radek, U[lrich]: Messungen des Druckverlaufs in kavitationserzeugten Druckimpulsen. Acustica 21(5) (1969) 253259 .

[427] Hund, M[artin]: Untersuchungen zur Einzelblasenkavitation bei $10 \mathrm{~Hz}$ in einer wassergefüllten Druckkammer. Acustica 21(5) (1969) $269-282$.

[428] Lauterborn, W[erner]: Zu einer Theorie der Kavitationsschwellen. Acustica 22(1) (1969/70) 48-54.

[429] Wagner, Wolf-Udo: Phasenkorrelation von Schalldruck und Sonolumineszenz. Zeitschrift für angewandte Physik 10(10) (1958) 445452 .

[430] Kuttruff, H[einrich]; Plaß, K[laus Gottfried]: Sonolumineszenz und Blasenschwingung bei Ultraschallkavitation (30 kHz). Acustica 11(4) (1961) 224-229.

[431] Schmid, Jörg: Gasgehalt und Lumineszenz einer Kavitationsblase (Modellversuche an Glaskugeln). Acustica 12(2) (1962) 70-83.

[432] Kuttruff, H[einrich]: Über den Zusammenhang zwischen der Sonolumineszenz und der Schwingungskavitation in Flüssigkeiten. Acustica 12(AB 1) (1962) 230-254.

[433] Müller, H[erbert] M.: Untersuchungen über das Leuchten implodierender Blasen in Flüssigkeiten (Modellversuche zur Sonolumineszenz). Acustica 16(1) (1965/66) 22-33. 
[434] Lauterborn, W[erner]: Zur Frage der Abhängigkeit der Erosion und Lumineszenz von der Schallwechseldruckamplitude bei Kavitation. Acustica 20(2) (1968) 105-108.

[435] Olaf, J[örn]: Oberflächenreinigung mit Ultraschall. Acustica 7(5) (1957) 253-263.

[436] Kuhl, W[alther]; Schodder, G[eorg] R[enatus]; Schröder, F[riedrich]-K[arl]; Condenser Transmitters and Microphones with Solid Dielectric for Airborne Ultrasonics. Acustica 4(5) (1954) $519-532$.

[437] Geide, K[arl]: Schwingungseigenschaften von elektrostatischen Wandlern nach dem Sell-Prinzip. Acustica 10(AB 1) (1960) 295-304.

[438] Sessler, G[erhard]: Schallabsorption und Schalldispersion in gasförmigem Stickstoff und Sauerstoff bei hohen Frequenz/Druck-Werten. Acustica 8(6) (1958) 395-397.

[439] Sessler, G[erhard]: Schallausbreitung in gasförmigem Wasserstoff. Acustica 10(3) (1960) 176-180.

[440] Sessler, G[erhard]: Schallabsorption und Schalldispersion in gasförmigem Distickstofftetroxyd (Stickstoffdioxyd). Acustica 9(2) (1959) 119-120.

[441] Sessler, G[erhard]: Schallausbreitung in teilweise dissoziiertem, gasförmigem Distickstofftetroxyd. Acustica 10(1) (1960) 44-59.

[442] Hinsch, H[ermann]: Ultraschallabsorption und -dispersion in den dampfförmigen Chloriden der Elemente der vierten Hauptgruppe. Acustica 11(4) (1961) 230-238.

[443] Hinsch, H[ermann]: Die Temperaturabhängigkeit der Schwingungsrelaxation im dampfförmigen $\mathrm{CCL}_{4}$. Acustica 11(6) (1961) 426.

[444] Geide, K[laus]: Rotationsrelaxation in gasförmigem Schwefelwasserstoff und Parawasserstoff. Acustica 13(1) (1963) 31-41.

[445] Haebel, E[rnst]-U[lrich]: Ultraschallabsorption und -dispersion in dampfförmigem $\mathrm{CHCl}_{3}, \mathrm{CHCl}_{2} \mathrm{Br}$ und und $\mathrm{CHClBr}_{2}$. Acustica 15(6) (1965) 426-436. 
[446] Haebel, E[rnst]-U[lrich]: Messungen zur Temperaturabhängigkeit der Schwingungsrelaxation in Schwefelhexafluorid zwischen $10^{\circ} \mathrm{C}$ und $215^{\circ} \mathrm{C}$. Acustica 20(2) (1968) 65-75.

[447] Beste, K[arl]-W[ilhelm]: Messungen zur Temperaturabhängigkeit der Schwingungsrelaxation in Schwefelhexafluorid zwischen $-20^{\circ} \mathrm{C}$ und $+20^{\circ} \mathrm{C}$. Acustica 23(3) (1970) 121-130.

[448] Mechel, F[ridolin]: Schalldämpfung in absorbierend ausgekleideten Kanälen mit überlagerter Luftströmung. 3rd International Congress on Acoustics (ICA), Stuttgart, Sept. 1-8, 1959. Proceedings: Vol. 2, pp. 1136-1139.

[449] Mechel, Fr[idolin]: Schalldämpfung und Schallverstärkung in Luftströmungen durch absorbierend ausgekleidete Kanäle. Acustica 10(3) (1960) 133-148.

[450] Schilz, W[olfram]: Untersuchungen zur Wechselwirkung zwischen Schallfeld und Strömung im Windkanal, der mit porösen Absorbern und Helmholtzresonatoren ausgekleidet ist. Acustica 11(3) (1961) $137-151$.

[451] Schilz, W[olfram]: Die Anwendung des Plattenabsorbers zur Bedämpfung von luftdurchströmten Kanälen. Acustica 12(AB 1) (1962) 202-205.

[452] Mechel, Fr[idolin]; Mertens, P[eter]: Schallausbreitung in absorbierend ausgekleideten Strömungskanälen bei hohen Windgeschwindigkeiten. Acustica 13(3) (1963) 154-165.

[453] Mechel, F[ridolin]; Mertens, P[eter]; Schilz, W[olfram]: Research on Sound Propagation in Sound-Absorbent Ducts with Superimposed Air Streams. Biomedical Laboratory, Aerospace Medical Research Laboratories, Aerospace Medical Division, Air Force Systems Command, Wright-Patterson Air Force Base, Ohio, USA: Technical Documentary Report No. AMRL-TDR-62-140, Vol. I, December 1962 (vi + 90 pp.); Vol. II, December 1962 (ix + 72 pp.); Vol. III, December 1962 (vii + 106 pp); Vol. IV, December 1963 (xi +51 pp).

[454] Mechel, F[ridolin]; Schilz, W[olfram]: Untersuchungen zur akustischen Beeinflussung der Strömungsgrenzschicht in Luft. Acustica 14(6) (1964) 325-331. 
[455] Schilz, W[olfram]: Experimentelle Untersuchungen zur akustischen Beeinflussung der Strömungsgrenzschicht in Luft. Acustica 16(4) (1965/66) 208-223.

[456] Schilz, W[olfram]: Untersuchungen über den Einfluß biegeförmiger Wandschwingungen auf die Entwicklung der Strömungsgrenzschicht. Acustica 15(1) (1965) 6-10.

[457] Mechel, F[ridolin]; Schilz, W[olfram]; Dietz, K[arl]-J[ürgen]: Akustische Impedanz einer luftdurchströmten Öffnung. Acustica 15(4) (1965) 199-206.

[458] Schilz, W[olfram]: Richtcharakteristik der Schallabstrahlung einer durchströmten Öffnung. Acustica 17(6) (1966) 364-366.

[459] Mertens, P[eter]: Schlierenoptische Untersuchungen zur Schallausbreitung in der Strömungsgrenzschicht eines luftdurchströmten Kanals. Acustica 15(6) (1965) 410-417.

[460] Dinkelacker, A[lbrecht]: Measurements and Observations on Flow Noise in Water-Filled Plastic Tubes. Acustica 12(5) (1962) 341-350.

[461] Gruschka, H[einz] D[ieter]: Periodisch angeregte Grenzschichtstörungen über einer ebenen Platte in einer Wasserströmung. Acustica 16(1) $(1965 / 66)$ 46-60.

[462] Mechel, F[ridolin]; Wille, P[eter]: Ein Ähnlichkeitsgesetz bei der Streuung ebener Wellen an Zylindern komplexer Wandimpedanz. Acustica 16(2) (1965/66) 101-107.

[463] Mechel, F[ridolin]: Axial geführte Oberflächenwellen an Zylindern mit komplexer Impedanz. Acustica 16(6) (1965/66) 343-355.

[464] Mechel, Fr[idolin]: Calculation of the Modified Bessel Functions of the Second Kind with Complex Argument. Mathematics of Computation 20(95) (July 1966) 407-412.

[465] Mechel, Fridolin: Die Streuung ebener Wellen an Zylindern und Kugeln komplexer Impedanz. Abhandlungen der Akademie der Wissenschaften in Göttingen, Mathematisch-Physikalische Klasse, Dritte Folge, Nr. 28, Vandenhoek \& Ruprecht, Göttingen 1966. VII + 249 S.

[466] Ronneberger, D[irk]; Schilz, W[olfram]: Schallausbreitung in luftdurchströmten Rohren mit Querschnittsveränderungen und Strömungsverlusten. Acustica 17(3) (1966) 168-175. 
[467] Ronneberger, D[irk]: Experimentelle Untersuchungen zum akustischen Reflexionsfaktor von unstetigen Querschnittsänderungen in einem luftdurchströmten Rohr. Acustica 19(4) (1967/68) 222-235.

[468] Ahrens, C[arsten]; Ronneberger, D[irk]: Luftschalldämpfung in turbulent durchströmten, schallharten Rohren bei verschiedenen Wandrauhigkeiten. Acustica 25(3) (1971) 150-157.

[469] Ronneberger, D[irk]: The Acoustical Impedance of Holes in the Wall of Flow Ducts. Journal of Sound and Vibration 24(1) (1972) $133-150$.

[470] Esche, R[olf]: Untersuchungen zur Ultraschallabsorption in tierischen Geweben und Kunststoffen. Acustica 2(AB 2) (1952) AB 71 AB 74 .

[471] Schröder, F[riedrich]-K[arl]: Der Schallschluckgrad als Funktion des Schalleinfallswinkels. Acustica 3(2) (1953) 54-66.

[472] Exner, M[arie]-L[uise]: Untersuchung unperiodischer Zeitvorgänge mit der Autokorrelations- und der Fourieranalyse. Acustica 4(3) (1954) 365-379.

[473] Naake, Hans-Joachim: Experimentelle Schwingungsuntersuchungen an Eisenbahnschienen. Acustica 3(AB 1) (1953) 139-147.

[474] Haeske, H[orst]: Schwingungsuntersuchungen an Eisenbahnschienen im Ultraschall-Bereich. Acustica 7(3) (1957) 146-150.

[475] Tamm, K[onrad]; Kurtze, G[ünther]: Ein neuartiges Mikrophon großer Richtungsselektivität. Acustica 4(AB 1) (1954) 469-470.

[476] Diestel, H[orst]-G[unther]: Akustische Messungen an einem mechanischen Modell des Innenohres. Ein Beitrag zur Hydrodynamik der Cochlea. Acustica 4(4) (1954) 489-499 (im Druck irrtümlich 421431).

[477] Güth, W[ernfried]: Die Leitung von Schallimpulsen in Metallstäben. Acustica 5(1) (1955) 35-43.

[478] Kaiser, R[einhold]: Die mechanischen Eingangsimpedanzen von Tonabnehmern. Acustica 5(AB 1) (1955) 81-92.

[479] Quietzsch, G[erhard]: Objektive und subjektive Lautstärkemessungen. Acustica 5(AB 1) (1955) 49-66. 
[480] Rademacher, H[ans]-J[oachim]: Subjektive Bewertung der Schalldämmung, untersucht an elektrisch nachgebildeten Schalldämmkurven. Acustica 5(1) (1955) 19-27.

[481] Schröder, Manfred [Robert]: Messung von Dielektrizitätskonstanten durch Aufspaltung entarteter Eigenfrequenzen. Zeitschrift für angewandte Physik 7(4) (1955) 169-174.

[482] Dörr, W[olfgang]: Anziehende und abstoßende Kräfte zwischen Kugeln im Schallfeld. Acustica 5(3) (1955) 163-166.

[483] Balachandran, Muthuswami: Messungen der Dielektrizitätskonstanten und des Verlustwinkels von Baumaterialien. Zeitschrift für angewandte Physik 7(12) (1955) 588-593.

[484] Walther, K[laus]: Elektrische Modellversuche zu akustischen Relaxationsvorgängen. Acustica 6(2) (1956) 245-251.

[485] Eggers, F[rieder]: Messung der Amplituden- und Phasenverteilung auf Konuslautsprecher-Membranen. Acustica 7(1) (1957) 21-28.

[486] Eggers, F[rieder]: Untersuchung von Corpus-Schwingungen am Violoncello. Acustica 9(6) (1959) 453-465.

[487] Weis, O[laf]: Spannungsoptische Untersuchungen an Biegewellen mit exponentiellen Nahfeldern. Acustica 7(6) (1957) 402-408.

[488] Tamm, K[onrad]; Weis, O[laf]: Untersuchungen über periodische Wellen, exponentielle und komplexe Nahfelder im begrenzten Festkörper. Acustica 9(AB 1) (1959) 275-288.

[489] Weis, O[laf]: Über die Schallausbreitung in verlustbehafteten Medien mit komplexem Schub- und Kompressionsmodul. Acustica 9(5) (1959) 387-398.

[490] Tamm, K[onrad]; Weis, O[laf]: Wellenausbreitung in unbegrenzten Scheiben und Scheibenstreifen. Acustica 11(1) (1961) 8-17.

[491] Kinder, H[elmut]: Demonstrationsversuche zur Wanderwellenverstärkung. Acustica 13(2) (1963) 118-120.

[492] Eisenmenger, W[olfgang]: Ein Demonstrationsversuch zur Pulskompression. Acustica 15(1) (1965) 54-56. 
[493] Eisenmenger, W[olfgang]: Demonstration des „Strahlungsdruckes“ von Saitenschwingungen. Acustica 16(1) (1965/66) 64.

[494] Karstens, D[etleff]: Ein einfaches Demonstrationsmodell für Stoßwellen. Acustica 21(1) (1969) 57-58.

[495] Helberg, H[ans]-W[ilhelm]: Schallstreuung durch Luftballons. Acustica 9(2) (1959) 118.

[496] Eisenmenger, W[olfgang]: Theoretische und experimentelle Untersuchung der Frequenzabhängigkeit des elektrokinetischen Effektes (Strömungsstromes) an porösen Glasfilterplatten bei Ultraschall. Acustica 7(1) (1957) 45-56.

[497] Kuttruff, H[einrich]: Optische Modellversuche zur stationären Diffusität in Hallräumen. Acustica 8(5) (1958) 330-336.

[498] Kuttruff, H[einrich]: Eigenschaften und Auswertung von Nachhallkurven. Acustica 8(AB 1) (1958) 273-280.

[499] Eisenmenger, W[olfgang]: Dynamic Properties of the Surface Tension of Water and Aqueous Solutions of Surface Active Agents with Standing Capillary Waves in the Frequency Range from $10 \mathrm{kc} / \mathrm{s}$ to $1.5 \mathrm{Mc} / \mathrm{s}$. Acustica 9(4) (1959) 327-340.

[500] Eisenmenger, W[olfgang]: Elektromagnetische Erzeugung von ebenen Druckstößen in Flüssigkeiten. Acustica 12(AB 1) (1962) 185-202.

[501] Eisenmenger, W[olfgang]: Experimentelle Bestimmung der Stoßfrontdicke aus dem akustischen Frequenzspektrum elektromagnetisch erzeugter Stoßwellen in Flüssigkeiten bei einem Stoßdruckbereich von $10 \mathrm{~atm}$ bis $100 \mathrm{~atm}$. Acustica 14(4) (1964) 187-204.

[502] Mechel, F[ridolin]; Wille, P[eter]: Experimentelle Untersuchungen aspektunabhängiger Sonarreflektoren nach dem Prinzip inhomogener Linsen. Acustica 16(5) (1965/66) 305-311.

[503] Wille, P[eter]: Ein strömungsgünstiges Richtmikrofon für Wasserschall als Analogon des dielektrischen Stielstrahlers. Acustica 17(3) (1966) 148-152. 


\section{Sonstige Publikationen (chronologisch)}

[504] Göttinger Vereinigung zur Förderung der Angewandten Physik und Mathematik: Die Physikalischen Institute der Universität Göttingen. Festschrift im Anschluß an die Einweihung der Neubauten am 9. Dezember 1905. Verlag: B. G. Teubner, Leipzig und Berlin 1906.

[505] Sabine, Wallace Clement: Reverberation. The American Architect and The Engineering Record, 1900. Reprinted in: Collected Papers on Acoustics / Wallace Clement Sabine, Harvard University Press 1922, pp. 8-68.

[506] Grützmacher, Martin: Eine neue Methode der Klanganalyse. Zeitschrift für technische Physik 8(11) (November 1927) 506-509.

[507] Grützmacher, Martin: Eine neue Methode der Klanganalyse. Elektrische Nachrichtentechnik (ENT) 4(12) (Dezember 1927) 533-545. Vorgetragen auf der Physikertagung in Kissingen im Herbst 1927.

[508] Petzold, Ernst: Elementare Raumakustik. Bauwelt-Verlag, Berlin 1927, XII + 129 S.

[509] Wente, E. C.: The Charateristics of Sound Transmission in Rooms. Journal of the Acoustical Society of America 7(2,1) (1935) 123-126.

[510] Cremer, Lothar: Die wissenschaftlichen Grundlagen der Raumakustik, Band 1: Geometrische Raumakustik, S. Hirzel Verlag, Stuttgart 1948, VII + $170 \mathrm{~S}$.

[511] Wallach, H.; Newman, E. B.; Rosenzweig, M. R.: The Precedence Effect in Sound Localization. American Journal of Psychology 52 (1949) 315-336.

[512] Bolt, R[ichard] H[enry] Roop, R. W.: Frequency Response Fluctuations in Rooms. Journal of the Acoustical Society of America 22(2) (March 1950) 280-289.

[513] Richardson, E[dward] G[ick] (editor): Technical Aspects of Sound. Vol. I: Sonic Range and Airborne Sound. Elsevier Publ. Co., Amsterdam/New York 1953, xviii + 544 pp.

[514] Richardson, E[dward] G[ick] (editor): Technical Aspects of Sound. Vol. II: Ultrasonic Range, Underwater Acoustics and Aircraft Noise. Elsevier Publ. Co., Amsterdam/New York 1957, xiv + 412 pp. 
[515] Redlich, Horst; Klemp, Hans-Joachim: Messung der Lichtbandbreite auf Stereo-Schallplatten. Radio Mentor, Jg. 1958, Heft 10, 679682 .

[516] Schroeder, M[anfred] R[obert]: Methoden zur Messung der Diffusität in Hallräumen. Acustica 9(AB 1) (1959) 256-264.

[517] Sessler, Gerhard M.; West, James E.: Foil-Electret Microphones. Journal of the Acoustical Society of America 40(6) (1966) 1433-1440.

[518] Gardner, Mark B.: Historical Background of the Haas and/or Precedence Effect. Journal of the Acoustical Society of America 43(6) (1968) 1243-1248.

[519] Barron, M[ichael]: The subjective effects of first reflections in concert halls - The need for lateral reflections. Journal of Sound and Vibration 15(4) (1971) 475-494.

[520] Schroeder, M[anfred] R[obert]: Number Theory in Science and Communication. Springer-Verlag, Berlin/Heidelberg 1984 (1st ed.), 1986 (2nd), 1997 (3rd), 2006 (4th), 2009 (5th), Section: "Toward Better Concert Hall Acoustics".

[521] International Standard ISO 354-1985 (E): Acoustics - Measurement of sound absorption in a reverberation room. First edition 1985-02-01.

[522] Litovsky, Ruth Y.; Colburn, H. Steven; Yost, William A.; Guzman, Sandra J.: The precedence effect. Journal of the Acoustical Society of America 106(4,1) (Oct. 1999) 1633-1654.

[523] Eisenmenger, W[olfgang] et al.: The first clinical results of "widefocus and low-pressure" ESWL [extracorporal shock-wave lithotripsy]. Ultrasound in Medicine and Biology 28(6) (2002) 769-774.

[524] Fernsehfilm „Vom Jäger zum Gejagten. Das erste Stealth-U-Boot der Welt", ausgestrahlt von arte am 18. Februar 2008, 21:00-21:50 Uhr. Info: http://de.wikipedia.org/wiki/U_480. 


\section{Personen- und Sachregister}

Absorber

für elektromagnetische

Wellen, 21, 29, 43

für Luftschall, 10, 11, 40

für Wasserschall, 12, 14, 36

Acoustical Society, 9, 51

Acustica, 20

Akustische Beihefte, 20

Akustische Zeitschrift, 10

Alberich, 12, 13

Amerikavertrag, 29, 39

Analogien, 8, 16, 29, 43, 53

Ardenne, Manfred von, 8

Audiologie, 8

Barron, Michael, 31

Bauakustik, 11, 36, 37

Erschütterungen, 10

Schallschutz, 9

Baustoffe, 41

Becker, Richard, 49

Beethovenhalle Bonn, 31

Berlin, 7

Berufungen, 15, 24

Biegewellen, 41

Bjerkneskräfte, 3, 41

Blasenentstehung, 37

Bolt, Richard Henry, 19, 30

Breslau, 3

Buchmann, Gerhard, 8

Burgtorf, Wolfgang, 30

clearness, 31
Cochlea, 40

Cremer, Lothar, 18

DAGA, 51, 54

definition, 31

Demonstrationsexperimente, 4 , 29,43

Deutlichkeit, 31

Deutsche Forschungsgemeinschaft, $20,23,29$

Dielektrika, 29, 38, 41

Diestel, Horst-Gunther, 40

Diffusität, 23, 31-34, 41, 42

directional diffusivity, 31

Dissoziation, 38

III. Physikalisches Institut, DPI, 15

Druckkammer, 40

Echos, 18, 32

Eggers, Frieder, 22, 41

Ehrungen, 52, 53

Eigen, Manfred, 37

Einweihung, 20

Eisenbahnschienen, 40

Eisenmenger, Wolfgang, 13, 36,

42,49

elastische Moduln, 12, 36

Elektretmikrofon, 38

Elektroakustik, 7, 11, 33

elektrokinetischer Effekt, 42

Elektrolyte, 27, 37

Elektronik-Praktikum, 16

Emeritierung, 49 
Englandvertrag, 18, 37, 38, 42

Erschütterungsmesser, 10

Erweiterungsbau, 25

Exkursionen, 51

Exner, Marie-Luise, 40

Fackelzug, 53

Fafnir, 12

Fellow, 9

Fernmeldetechnik, 5

Festkörper-Wellentypen, 41

Festkörperphysik, 43

Firestone, Floyd A., 51

Flachglas, 9

Flachraum, 40

Flachspule, 42

Flachtank, 37

Flachwasser, 12

Flammersfeld, Arnold, 52

Flüssigkeiten, 12, 29, 37, 42

Forschungsvertrag

DSIR, DNPR, 18, 37, 38, 42

US Air Force, 29, 38

Fortgeschrittenen-

Praktikum, 16, 36

frequency irregularity, 30

Frequenzkurvenschwankung, 30, 42

Funktechnik, 8

Gartenhaus, 15

Gasblasen, 12, 37

Gase

Schallausbreitung, 38

Schalldämpfung, 38

Gedenktafel, 54, 55
Gehör, 7, 10

Gesetz der ersten Wellenfront, 18

Gesundheit, 54

Glocken, 9

Göttingen, 15

Grammophon, 7

Grenzschicht, 39, 40

Grützmacher, Martin, 9

Güth, Wernfried, 40

Haas, Helmut, 18

Haas-Effekt, 19

Habilitation (E. Meyer), 7

Habilitationen (Mitarbeiter), 17, $27,29,39,42$

Hallraum, 8, 11, 23, 24, 34, 42 Absorptionsgradmessung, 8, 53

elektromagnetischer, 23

Leistungsmessung, 8, 10

Handbuchartikel, 7, 33, 36, 37

Hauskolloquium, 47

Heinrich-Hertz-Institut, HHI, $8,15,36,43$

Heirat, 9

Helberg, Hans-Wilhelm, 42

Helmholtz, Hermann von, 3

Helmholtzresonator, 21

Henze, Heinrich, 16, 28, 44

Herausgeberschaft, 10, 20, 33

Hitzdraht, 39

Holzverkleidung, 9, 32

Hörakustik, 34

Hörprüfung, 7

Hörsamkeit, 18, 30, 31 
Hort, Wilhelm, 8

Hörtheorie, 17

Hörverlust, 9

Hydroakustik, 14, 36

Hyperschall, 36

ICA-Kongresse, 51, 53

Impedanz, 10, 19, 39, 40

Impulsschallquelle, 42

Institutserweiterungen, 20

Intermittenz, 39

Jahrhunderthalle Hoechst, 31, 33

Kapillarwellen, 42

Kathodophon, 7

Kavitation, 37, 42

Keilabsorber, 11, 21

Kinofilm, Schallaufnahmetechnik, 7, 11

Klanganalyse, 7

Klein, Felix, 15

Knudsen, Vern Oliver, 53

Kohärenz, 35

Kohlewiderstände, 10

Kolleg, 43

Konzertsaalakustik, 33

Konzertsäle, 10

körnige Materialien, 36

Körperschall

Ausbreitung, 36

Dämmung, 36, 37

Dämpfung, 36, 37

Messungen, 10

Korrelation, 34, 40

Kraftfahrzeug, 9
Kramers-Kronig-Relationen, 36

Kreml, 19

Kuhfuß, Edith, 28

Kunstkopf, 35

Kurtze, Günther, 40

Kuttruff, Heinrich, 22, 30-33, $42,49,50,54$

Landtag Hannover, 32

Landtag Stuttgart, 31

Laser, 41

Lauterborn, Werner, 34, 37

Lautsprecher, 7, 18, 19, 32,

$34,35,40,41$

Lautstärkemessung, 40

Lehrbücher, 45

Leistungsmessung, 8, 10

Leithäuser, Gustav, 8

Leitungen, dielektrische, 29

Lichtbandbreite, 8

Liederhalle Stuttgart, 31

LIFE International, 21

Lummer, Otto, 4

Mechel, Fridolin P., 39

Medianebene, 35

Meerwasser

Schallabsorption, 12

Schallausbreitung, 12

Mehrfachwände, 10

Messtechnik

akustische, 7, 10, 11, 34

elektroakustische, 7, 9

Körperschall, 36

Schallabsorption, 8

Schallfelder, 7

Schallisolation, 8 
Ultraschall, 36

Wasserschall, 36

Meyerbreite, 8

Mikrofon, 7, 23, 29, 31, 38, 40

Mikrowellen, 16, 29

Absorber, 29, 43

Ausbreitung, 29

Beugung, 29

Führung, 29

Messleitungen, 29

Streuung, 29

Modellversuche, 23, 33, 34,

41,42

mit Ultraschall, 36

Moduln, elastische, 36

Molekularakustik, 10, 38

musikalische Akustik, 10

Musikinstrumente, 7, 9, 41

Nachhall, 10, 18, 30

Aufzeichnung, 7, 10

künstlicher, 31

nicht-exponentieller, 42

Nachhallzeit, 10, 30, 32, 33

Messung, 7, 8, 34

Nachrufe, 54

Nahfeld, 41

Nationaltheater Bukarest, 54

Navy-Report, 13, 14

Neumann, Ernst-Georg, 29, 45

nichtlineare Verzerrungen, 7, 40

Oberflächenspannung, 42

Ohrmodell, 40

Ortskurvenschreiber, 19

Petzold, Ernst, 18
Phasengitter, 41

Philharmonic Hall, 33

Phononen, 36

Platten, 10

Schallabstrahlung, 36

Schalldurchgang, 10, 36

Polymere, 36

Pottel, Reinhard, 29

Praktikum, 16, 36

precedence effect, 19

Privatdozent, 7

Psychoakustik, 34

Publikum, 10, 34

Schallabsorption, 33

Quarz, 36

Randdämpfung, 11

Raumakustik, 9, 11, 30, 33,

34, 49

geometrische, 30

statistische, 30

Raumeindruck, 34

Rauschen, 10

Rayleigh-Absorber, 42

Rayleigh-Medaille, 53

Reaktionskinetik, 37

Redewendungen, 50

Reflexionsfreier Raum, 11, 20,

$22,34,35,41$

Reichardt, Walter, 51

Reichspostzentralamt, 5

Relaxationen, 37, 38, 41

Resonanzabsorber, 12, 21, 40

Richardson, Edward Gick, 33

Richthydrofon, 47

Richtmikrofon, 23, 29, 31, 40 
Richtungsdiffusität, 31

Richtungseindruck, 18

Richtungshören, 35

Riffelbildung, 40

Rippenabsorber, 12, 26

Röhrenpraktikum, 16

Rohrleitungen, 39

Rohrmündung, Abstrahlung, 39

Ronneberger, Dirk, 39

Roop, R. W., 30

„Rotes Haus“, 15, 16, 25

Rundfunktechnik, 4, 5, 7

Sabine, Wallace Clement, 8, 30, 54

Salinger, Hans, 4, 8

Schallabsorption, 8 körnige Materialien, 36

Meerwasser, 12

poröse Stoffe, 9, 42

Schallabstrahlung, 36, 39

Schallaufzeichnung, 9, 10

Schallausbreitung

im Strömungskanal, 39

in Rohren, 37

in Wasser, 12

Schalldämmung, 11, 41

Schalldämpfer, 39

Schalldämpfung, 39

Schallfeld, 7, 23, 30-32, 42

diffuses, 23, 31, 42

Nachbildung, 34

Simulation, 31

synthetisches, 35

Wasserschall, 37

Schalligel, 31, 32
Schallintensität, 8

Schallisolation, 8

Schallplatten, 8, 9

Schallspektroskopie, 10

Schallspiegel, 30

schalltoter Raum, siehe Reflexionsfreier Raum schallverzögernde Leise-

sprecheranlage, 19, 32

Scheitelebene, 35

Schlierenoptik, 39, 40

Schluckgradvergleichsmessungen,

12

Schluckstoffkeile, 11, 20

schnelle Reaktionen, 37

Schodder, Georg Renatus, 30

Schroeder, Manfred Robert, 16, $30,31,41,49,54$

Schwingungen

akustische, 8, 43

elektrische, 8, 43

nichtlineare, 37

parametrische, 42, 44

Sell-Wandler, 38

Sessler, Gerhard, 38

Severin, Hans, 16, 29

Soldat, 3, 4

Sonar, 12, 47

Sonolumineszenz, 37, 42

Spannungsoptik, 41

Sprachforschung, 18, 49

Staatsexamen, 3

Stadthalle Göttingen, 32

Stealth-U-Boot, 13

Stereophonie, kopfbezogene, 35

Stoßfront, 42 
Streukörper, 23

Streuung

an Kugeln, 26, 39

an Zylindern, 39

Mikrowellen, 29, 41

Wasserschall, 26, 37

Strömungsabsorber, 36

Strömungsakustik, 38

Suchtonanalyse, 9

Suchtonverfahren, 7

Tamm, Konrad, 12, 27, 40, 41

Telefon, 7

Telegraphentechnisches

Reichsamt, 5

Testat, 45, 46

Thiele, Rolf, 30, 31

Thiele-Igel, 32

Tieftank, 25, 26, 37

Tonabnehmer, 7, 40

Turbulenz, 39

U-Boot, 12, 13

Überblicke

Artikel, 7, 10, 11, 29, 33, 36,37

Vorträge, 9, 11, 33, 53

Übersprechkompensation, 35

Ultraschall, 36

Absorption, 38, 40

Dispersion, 38

Kongress, 19

Mikrofon, 42

Modellversuche, 36

Oberflächenreinigung, 37

Spektroskopie, 10
Werkstoffprüfung, 11

Verbeamtung, 11

Verwischungsschwelle, 18

Violoncello, 41

Viskoelastizität, 36

Vorlesung, 7, 16, 17, 43-46

Waetzmann, Erich, 3, 7, 10

Wagener, Bernd, 46

Wagner, Karl Willy, 5, 8

Wasser

Schallabsorption, 27, 37

Schallgeschwindigkeit, 37

Wasserschall, 12, 20, 26, 36

Absorber, 12, 36

Gasblasen, 37

Messtechnik, 36

Streuung, 37

wässrige Lösungen, 42

Weis, Olaf, 41

„Weißes Haus“, 15, 17

Werkstoffprüfung mit Ultraschall, 11

West, James E., 38

Westphal, Wolfgang, 22

Wille, Peter, 47

Windkanal, 39

Wissenschaftlicher Hilfsarbeiter, 5

Wolfston, 41

Zentimeterwellen, 29

Zweikreisabsorber, 12 


\section{Bildnachweis}

Abb. 1: Photo-Schubert, Göttingen, jetzt im Familienbesitz; Abb. 2 und 5: im Familienbesitz; Abb. 3: aus Festschrift 1906, Zitat [504]; Abb. 4, 7, 8, 9, 11: Drittes Physikalisches Institut; Abb. 6: Reproduktion aus LIFE International 1954, Zitat [214]; Abb. 10 und 15: D. Guicking; Titelbild und Abb. 12, 13, 14: K. Brendel, jetzt im Besitz des Dritten Physikalischen Instituts. 
Erwin Meyer (1899-1972) war der führende deutsche Akustiker seiner Zeit. Diese Biographie lässt seine beeindruckende Persönlichkeit, seine breit gefächerten Interessen an vielen Aspekten der Schwingungsphysik und die wichtigen Forschungsergebnisse seiner „Schule“ lebendig werden. 